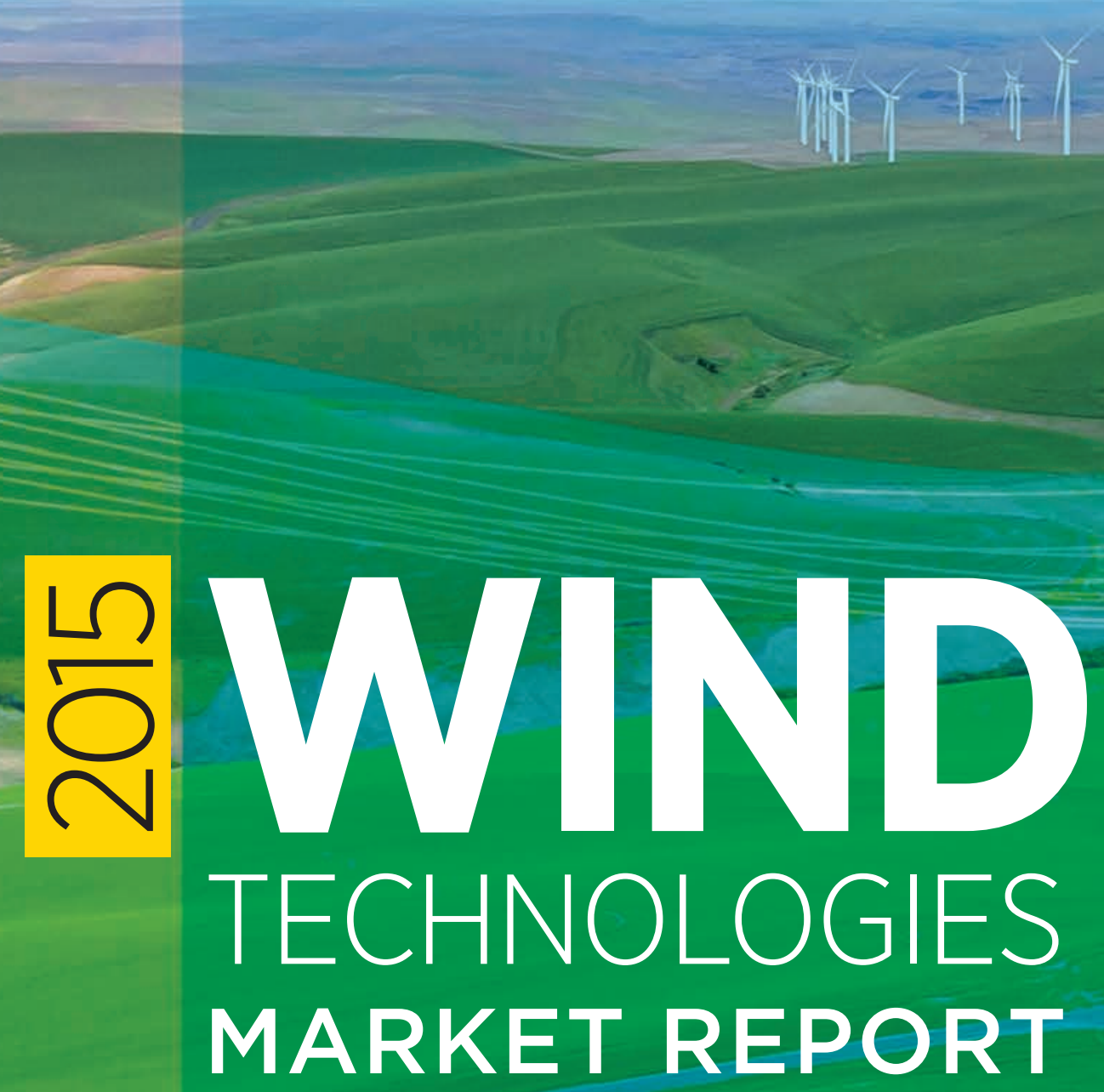
3in 
This report is being disseminated by the U.S. Department of Energy (DOE). As such, this document was prepared in compliance with Section 515 of the Treasury and General Government Appropriations Act for fiscal year 2001 (public law 106-554) and information quality guidelines issued by DOE. Though this report does not constitute "influential" information, as that term is defined in DOE's information quality guidelines or the Office of Management and Budget's Information Quality Bulletin for Peer Review, the study was reviewed both internally and externally prior to publication. For purposes of external review, the study benefited from the advice and comments of six wind industry and trade association representatives, two utility-sector representatives, three federal laboratory staff, and four U.S. government employees and contractors.

\section{NOTICE}

This report was prepared as an account of work sponsored by an agency of the United States government. Neither the United States government nor any agency thereof, nor any of their employees, makes any warranty, express or implied, or assumes any legal liability or responsibility for the accuracy, completeness, or usefulness of any information, apparatus, product, or process disclosed, or represents that its use would not infringe privately owned rights. Reference herein to any specific commercial product, process, or service by trade name, trademark, manufacturer, or otherwise does not necessarily constitute or imply its endorsement, recommendation, or favoring by the United States government or any agency thereof. The views and opinions of authors expressed herein do not necessarily state or reflect those of the United States government or any agency thereof.

Available electronically at osti.gov/bridge

Available for a processing fee to U.S. Department of Energy and its contractors, in paper, from:

U.S. Department of Energy

Office of Scientific and Technical Information

P.O. Box 62

Oak Ridge, TN 37831-0062

phone: 865.576 .8401

fax: 865.576.5728

email: reports@adonis.osti.gov

Available for sale to the public, in paper, from:

U.S. Department of Commerce

National Technical Information Service

5285 Port Royal Road

Springfield, VA 22161

phone: 800.553 .6847

fax: 703.605.6900

email: orders@ntis.fedworld.gov

online ordering: ntis.gov 


\title{
2015 Wind Technologies Market Report
}

\author{
Primary Authors \\ Ryan Wiser, Lawrence Berkeley National Laboratory \\ Mark Bolinger, Lawrence Berkeley National Laboratory \\ With Contributions From \\ Galen Barbose, Naïm Darghouth, Ben Hoen, Andrew Mills, Joe Rand, \\ Dev Millstein (Lawrence Berkeley National Laboratory) \\ Kevin Porter, Rebecca Widiss (Exeter Associates) \\ Frank Oteri, Suzanne Tegen, Tian Tian (National Renewable Energy Laboratory)
}

\section{Table of Contents}

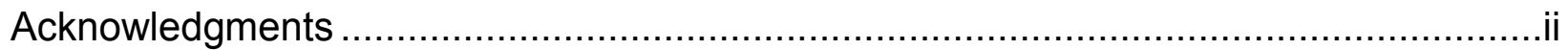

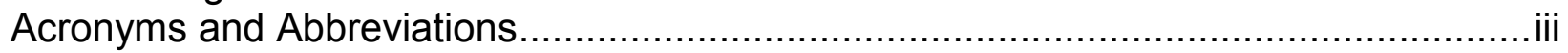

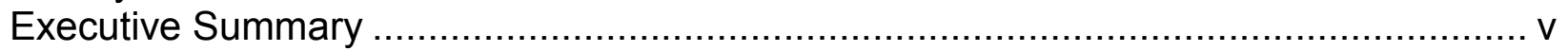

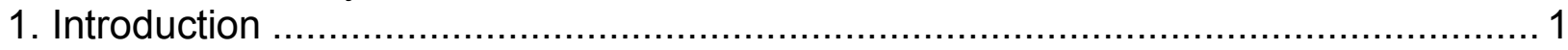

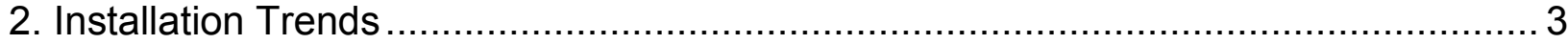

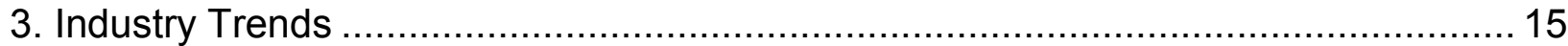

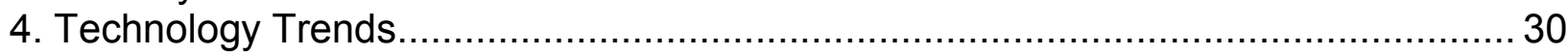

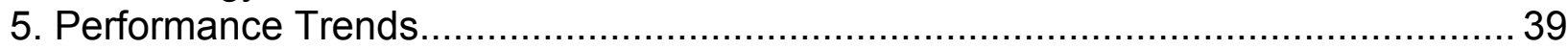

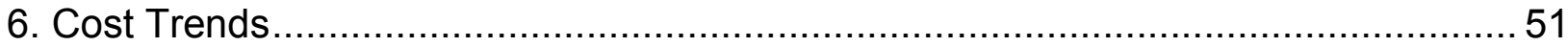

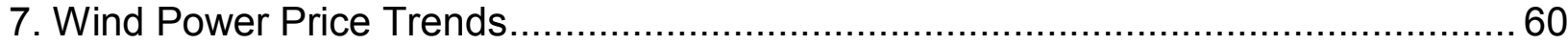

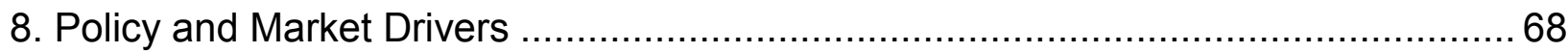

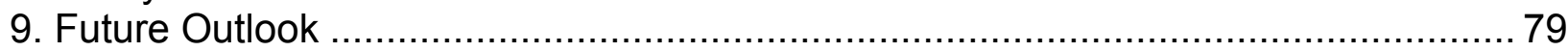

Appendix: Sources of Data Presented in this Report ........................................ 81

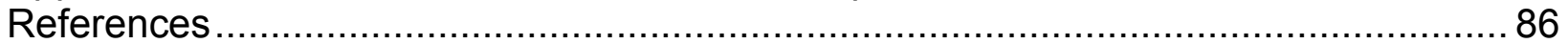

\section{Acknowledgments}

For their support of this ongoing report series, the authors thank the entire U.S. Department of Energy (DOE) Wind Power Technologies Office team. In particular, we wish to acknowledge Patrick Gilman, Mark Higgins, Rich Tusing, and Jose Zayas. For reviewing elements of this report or providing key input, we acknowledge: Andrew David (U.S. International Trade Commission); Patrick Gilman, Charlton Clark, Rich Tusing, John Coggin, Daniel Beals, Devan Willemsen (DOE staff and contractors); Michael Goggin, John Hensley, Hannah Hunt (American Wind Energy Association, AWEA); Eric Lantz, Walt Musial, Christopher Moné (National Renewable Energy Laboratory, NREL); Erik Ela (Electric Power Research Institute); Charlie Smith (Utility Variable-Generation Integration Group); Liz Salerno (Siemens); Ed Weston (GLWN); Chris Namovicz, Cara Marcy, Manussawee Sukunta (Energy Informational Administration, EIA); and Matt McCabe (Clear Wind). We greatly appreciate AWEA for the use of their comprehensive database of wind power projects. We also thank Amy Grace (Bloomberg New Energy Finance) for the use of Bloomberg NEF data; Donna Heimiller and Billy Roberts (NREL) for assistance with the wind project and wind manufacturing maps as well as for assistance in mapping wind resource quality; and Carol Laurie and Alex Lemke (NREL) for assistance with layout, formatting, production, and communications. Lawrence Berkeley National Laboratory's contributions to this report were funded by the Wind Power Technologies Office, Office of Energy Efficiency and Renewable Energy of the DOE under Contract No. DE-AC02-05CH1 1231. The authors are solely responsible for any omissions or errors contained herein. 


\section{Acronyms and Abbreviations}

\begin{tabular}{|c|c|}
\hline AWEA & American Wind Energy Association \\
\hline Bloomberg NEF & Bloomberg New Energy Finance \\
\hline BPA & Bonneville Power Administration \\
\hline BOEM & Bureau of Ocean Energy Management \\
\hline CAISO & California Independent System Operator \\
\hline DOE & U.S. Department of Energy \\
\hline EDPR & EDP Renováveis \\
\hline EEI & Edison Electric Institute \\
\hline EIA & U.S. Energy Information Administration \\
\hline ERCOT & Electric Reliability Council of Texas \\
\hline FERC & Federal Energy Regulatory Commission \\
\hline GE & General Electric Corporation \\
\hline GW & gigawatt \\
\hline HTS & Harmonized Tariff Schedule \\
\hline ICE & Intercontinental Exchange \\
\hline IOU & investor-owned utility \\
\hline IPP & independent power producer \\
\hline ISO & independent system operator \\
\hline ISO-NE & New England Independent System Operator \\
\hline ITC & investment tax credit \\
\hline $\mathrm{kV}$ & kilovolt \\
\hline $\mathrm{kW}$ & kilowatt \\
\hline $\mathrm{kWh}$ & kilowatt-hour \\
\hline $\mathrm{m}^{2}$ & square meter \\
\hline MISO & Midcontinent Independent System Operator \\
\hline MW & megawatt \\
\hline MWh & megawatt-hour \\
\hline NERC & North American Electric Reliability Corporation \\
\hline NREL & National Renewable Energy Laboratory \\
\hline NYISO & New York Independent System Operator \\
\hline O\&M & operations and maintenance \\
\hline OEM & original equipment manufacturer \\
\hline PJM & PJM Interconnection \\
\hline POU & publicly owned utility \\
\hline PPA & power purchase agreement \\
\hline PTC & production tax credit \\
\hline REC & renewable energy certificate \\
\hline RGGI & Regional Greenhouse Gas Initiative \\
\hline RPS & renewables portfolio standard \\
\hline
\end{tabular}


RTO

SPP

USITC

W

WAPA

regional transmission organization

Southwest Power Pool

U.S. International Trade Commission

watt

Western Area Power Administration 


\section{Executive Summary}

Annual wind power capacity additions in the United States surged in 2015 and are projected to continue at a rapid clip in the coming five years. Recent and projected near-term growth is supported by the industry's primary federal incentive - the production tax credit (PTC) - as well as a myriad of state-level policies. Wind additions are also being driven by improvements in the cost and performance of wind power technologies, yielding low power sales prices for utility, corporate, and other purchasers. At the same time, the prospects for growth beyond the current PTC cycle remain uncertain: growth could be blunted by declining federal tax support, expectations for low natural gas prices, and modest electricity demand growth.

Key findings from this year's Wind Technologies Market Report include:

\section{Installation Trends}

- Wind power additions surged in 2015, with 8,598 MW of new capacity added in the United States and $\mathbf{\$ 1 4 . 5}$ billion invested. Supported by favorable tax policy and other drivers, cumulative wind power capacity grew by $12 \%$, bringing the total to $73,992 \mathrm{MW}$.

- Wind power represented the largest source of U.S. electric-generating capacity additions in 2015. Wind power constituted $41 \%$ of all U.S. generation capacity additions in 2015, up sharply from its 24\% market share the year before and close to its all-time high. Over the last decade, wind power represented $31 \%$ of all U.S. capacity additions, and an even larger fraction of new generation capacity in the Interior (54\%) and Great Lakes (48\%) regions. Its contribution to generation capacity growth over the last decade is somewhat smaller in the West (22\%) and Northeast (21\%), and considerably less in the Southeast (2\%).

- The United States ranked second in annual wind additions in 2015, but was well behind the market leaders in wind energy penetration. A record high amount of new wind capacity, roughly 63,000 MW, was added globally in 2015, yielding a cumulative total of 434,000 MW. The United States remained the second-leading market in terms of cumulative capacity, but was the leading country in terms of wind power production. A number of countries have achieved high levels of wind penetration; end-of-2015 wind power capacity is estimated to supply the equivalent of roughly $40 \%$ of Denmark's electricity demand, and between $20 \%$ to $30 \%$ of Portugal, Ireland, and Spain's demand. In the United States, the wind power capacity installed by the end of 2015 is estimated, in an average year, to equate to $5.6 \%$ of electricity demand.

- Texas installed the most capacity in 2015 with 3,615 MW, while twelve states meet or exceed $10 \%$ wind energy penetration. New utility-scale wind turbines were installed in 20 states in 2015. On a cumulative basis, Texas remained the clear leader, with 17,711 MW. Notably, the wind power capacity installed in Iowa and South Dakota supplied more than $31 \%$ and $25 \%$, respectively, of all in-state electricity generation in 2015 , with Kansas close behind at nearly $24 \%$. A total of twelve states have achieved wind penetration levels of $10 \%$ or higher.

- The first commercial offshore turbines are expected to be commissioned in the United States in 2016 amid mixed market signals. At the end of 2015, global offshore wind capacity stood at roughly $12 \mathrm{GW}$. In the United States, the $30 \mathrm{MW}$ Block Island project off 
the coast of Rhode Island will be the first plant to be commissioned, anticipated by the end of 2016. Projects in Massachusetts, New Jersey, Virginia, and Oregon, meanwhile, all experienced setbacks. Strides continued to be made in the federal arena in 2015, both through the U.S. Department of the Interior's responsibilities in issuing offshore leases, and the U.S. Department of Energy's (DOE's) funding for demonstration projects. A total of 23 offshore wind projects totaling more than $16 \mathrm{GW}$ are in various stages of development in the United States.

- Data from interconnection queues demonstrate that a substantial amount of wind power capacity is under consideration. At the end of 2015, there were $110 \mathrm{GW}$ of wind power capacity within the transmission interconnection queues reviewed for this report, representing $31 \%$ of all generating capacity within these queues - higher than all other generating sources except natural gas. In 2015, $45 \mathrm{GW}$ of wind power capacity entered interconnection queues (the largest annual sum since 2010), compared to $58 \mathrm{GW}$ of natural gas and $24 \mathrm{GW}$ of solar.

\section{Industry Trends}

- GE and Vestas captured $73 \%$ of the U.S. wind power market in 2015. Continuing their recent dominance as the three largest turbine suppliers to the U.S., in 2015 GE captured 40\% of the market, followed by Vestas (33\%) and Siemens (14\%). Globally, Goldwind and Vestas were the top two suppliers, followed by GE, Siemens, and Gamesa. Chinese manufacturers continued to occupy positions of prominence in the global ratings, with five of the top 10 spots; to date, however, their growth has been based almost entirely on sales in China.

- The manufacturing supply chain continued to adjust to swings in domestic demand for wind equipment. With growth in the U.S. market, wind sector employment reached a new high of 88,000 full-time workers at the end of 2015. Moreover, the profitability of turbine suppliers has rebounded over the last three years. Although there have been a number of recent plant closures, each of the three major turbine manufacturers serving the U.S. market has one or more domestic manufacturing facilities. Domestic nacelle assembly capability stood at roughly $10 \mathrm{GW}$ in 2015 , and the United States also had the capability to produce approximately $7 \mathrm{GW}$ of blades and $6 \mathrm{GW}$ of towers annually. Despite the significant growth in the domestic supply chain over the last decade, conflicting pressures remain, such as: an upswing in near- to medium-term expected growth, but also strong international competitive pressures and possible reduced demand over time as the PTC is phased down. As a result, though many manufacturers increased the size of their U.S. workforce in 2015, expectations for significant supply-chain expansion have become more pessimistic.

- Domestic manufacturing content is strong for some wind turbine components, but the U.S. wind industry remains reliant on imports. The U.S. is reliant on imports of wind equipment from a wide array of countries, with the level of dependence varying by component. Domestic content is highest for nacelle assembly $(>85 \%)$, towers $(80-85 \%)$, and blades and hubs $(50-70 \%)$, but is much lower $(<20 \%)$ for most components internal to the nacelle. Exports of wind-powered generating sets from the United States rose from $\$ 16$ million in 2007 to \$544 million in 2014, but fell to \$149 million in 2015.

- The project finance environment remained strong in 2015. Spurred on by the December 2014 and March 2015 single-year extensions of the PTC's construction start deadline and 
IRS safe harbor guidance, respectively, the U.S. wind market raised $\sim \$ 6$ billion of new tax equity in 2015 - the largest single-year amount on record. Debt finance increased slightly to \$2.9 billion, with plenty of additional availability. Tax equity yields drifted slightly lower to just below $8 \%$ (in unlevered, after-tax terms), while the cost of term debt fell to just $4 \%$ by the end of the year-perhaps the lowest it has ever been. Looking ahead, 2016 should be another busy year, given the recent 5-year PTC extension and phase down.

- IPPs own the vast majority of wind assets built in 2015. Independent power producers (IPPs) own $85 \%$ of the new wind capacity installed in the United States in 2015, with the remaining assets owned by investor-owned utilities (12\%) and other entities (3\%). On a cumulative basis through 2015 , IPPs own $83 \%$ and utilities own $15 \%$ of U.S. wind capacity, with the remaining $2 \%$ owned by entities that are neither IPPs nor utilities (e.g., towns, schools, businesses, farmers).

- Long-term contracted sales to utilities remained the most common off-take arrangement, but direct retail sales gained ground. Electric utilities continued to be the dominant off-takers of wind power in 2015 , either owning (12\%) or buying $(48 \%)$ power from $60 \%$ of the new capacity installed last year. Merchant/quasi-merchant projects accounted for another $29 \%$, while direct retail purchasers - including corporate off-takers are buying the remaining $10 \%$ (a share that should increase next year). On a cumulative basis, utilities own (15\%) or buy (53\%) power from $68 \%$ of all wind capacity in the United States, with merchant/quasi-merchant projects accounting for $24 \%$, power marketers $6 \%$, and direct retail buyers just $2 \%$ (though likely to increase in the coming years).

\section{Technology Trends}

- Turbine nameplate capacity, hub height, and rotor diameter have all increased significantly over the long term. The average nameplate capacity of newly installed wind turbines in the United States in 2015 was 2.0 MW, up 180\% since 1998-1999. The average hub height in 2015 was 82.0 meters, up 47\% since 1998-1999, while the average rotor diameter was 102 meters, up 113\% since 1998-1999.

- Growth in rotor diameter has outpaced growth in nameplate capacity and hub height in recent years. Rotor scaling has been especially significant in recent years, and more so than increases in nameplate capacity and hub heights, both of which have seen a stabilization of the long-term trend since at least 2011. In 2008, no turbines employed rotors that were 100 meters in diameter or larger; by $2015,86 \%$ of new installed wind capacity featured rotor diameters of at least 100 meters.

- Turbines originally designed for lower wind speed sites have rapidly gained market share. With growth in average swept rotor area outpacing growth in average nameplate capacity, there has been a decline in the average "specific power" ${ }^{\mathrm{i}}$ (in $\mathrm{W} / \mathrm{m}^{2}$ ) over time, from $394 \mathrm{~W} / \mathrm{m}^{2}$ among projects installed in $1998-1999$ to $246 \mathrm{~W} / \mathrm{m}^{2}$ among projects installed in 2015. In general, turbines with low specific power were originally designed for lower wind speed sites. Another indication of the increasing prevalence of lower wind speed turbines is that, in 2015, the vast majority of new installations used IEC Class 3 and Class 2/3 turbines.

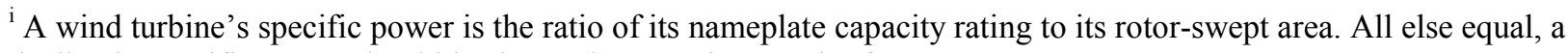
decline in specific power should lead to an increase in capacity factor.
} 
- Turbines originally designed for lower wind speeds are now regularly employed in both lower and higher wind speed sites; taller towers predominate in the Great Lakes and Northeast. Low specific power and IEC Class 3 and 2/3 turbines are now regularly employed in all regions of the United States, and in both lower and higher wind speed sites. In parts of the Interior region, in particular, relatively low wind turbulence has allowed turbines designed for lower wind speeds to be deployed across a wide range of site-specific resource conditions. The tallest towers, meanwhile, have principally been deployed in the Great Lakes and Northeastern regions, in lower wind speed sites, with specific location decisions likely driven by the wind shear of the site.

\section{Performance Trends}

- Sample-wide capacity factors have gradually increased, but have been impacted by curtailment and inter-year wind resource variability. Wind project capacity factors have generally increased over time. For a large sample of projects built from 1998 through 2014, capacity factors averaged $32.8 \%$ between 2011 and 2015 versus $31.8 \%$ between 2006 and 2010 versus $30.3 \%$ between 2000 and 2005 . That being said, time-varying influences - such as inter-year variations in the strength of the wind resource or changes in the amount of wind energy curtailment - have partially masked the positive influence of turbine scaling on capacity factors. For example, wind speeds throughout the interior and western U.S. were significantly below normal for much of 2015, which negatively impacted fleet-wide capacity factors. Positively, the degree of wind curtailment has declined recently in what historically have been the most problematic areas. For example, only $1.0 \%$ of all wind generation within ERCOT was curtailed in 2015, down sharply from the peak of 17\% in 2009.

- The impact of technology trends on capacity factor becomes more apparent when parsed by project vintage. Focusing only on performance in 2015 (to partially control for time-varying influences) and parsing capacity factors by project vintage tells a more interesting story, wherein rotor scaling over the past few years has clearly begun to drive capacity factors higher. The average 2015 capacity factor among projects built in 2014 reached $41.2 \%$, compared to an average of 31.2\% among projects built from 2004-2011 and just $25.8 \%$ among projects built from 1998-2003. The ongoing decline in specific power has been offset to some degree by a trend - especially from 2009 to 2012 - towards building projects at lower-quality wind sites. Controlling for these two competing influences confirms this offsetting effect and shows that turbine design changes are driving capacity factors significantly higher over time among projects located within given wind resource regimes. Performance degradation over time is a final driver examined in this section: though many caveats are in order, older wind projects appear to suffer from performance degradation, particularly as they approach and enter their second decade of operations.

- Regional variations in capacity factors reflect the strength of the wind resource and adoption of new turbine technology. Based on a sub-sample of wind projects built in 2014, average capacity factors in 2015 were the highest in the Interior region (42.7\%). Not surprisingly, the regional rankings are roughly consistent with the relative quality of the wind resource in each region, and they reflect the degree to which each region has adopted turbines with lower specific power or taller towers. For example, the Great Lakes has thus far adopted these new designs to a much larger extent than has the West, with corresponding implications for average capacity factors in each region. 


\section{Cost Trends}

- Wind turbine prices remained well below levels seen several years ago. After hitting a low of roughly $\$ 750 / \mathrm{kW}$ from 2000 to 2002 , average turbine prices increased to more than $\$ 1,500 / \mathrm{kW}$ by the end of 2008 . Wind turbine prices have since dropped substantially, despite increases in hub heights and especially rotor diameters. Recently announced transactions feature pricing in the $\$ 850-\$ 1,250 / \mathrm{kW}$ range. These price reductions, coupled with improved turbine technology, have exerted downward pressure on project costs and wind power prices.

- Lower turbine prices have driven reductions in reported installed project costs. The capacity-weighted average installed project cost within our 2015 sample stood at roughly $\$ 1,690 / \mathrm{kW}$ - down $\$ 640 / \mathrm{kW}$ from the apparent peak in average reported costs in 2009 and 2010. Early indications from a preliminary sample of projects currently under construction and anticipating completion in 2016 suggest no material change in installed costs in 2016.

- Installed costs differed by project size, turbine size, and region. Installed project costs exhibit some economies of scale, at least at the lower end of the project and turbine size range. Additionally, among projects built in 2015, the windy Interior region of the country was the lowest-cost region, with a capacity-weighted average cost of $\$ 1,640 / \mathrm{kW}$.

- Operations and maintenance costs varied by project age and commercial operations date. Despite limited data availability, it appears that projects installed over the past decade have, on average, incurred lower operations and maintenance (O\&M) costs than older projects in their first several years of operation, and that O\&M costs increase as projects age.

\section{Wind Power Price Trends}

- Wind PPA prices remain very low. After topping out at nearly $\$ 70 / \mathrm{MWh}$ for PPAs executed in 2009, the national average level-through price of wind PPAs within the Berkeley Lab sample has dropped to around the \$20/MWh level, inclusive of the federal production tax credit (PTC), though this latest nationwide average is admittedly focused on a sample of projects that largely hail from the lowest-priced Interior region of the country, where most of the new capacity built in recent years is located. Focusing only on the Interior region, the PPA price decline has been more modest, from $\sim \$ 55 / \mathrm{MWh}$ among contracts executed in 2009 to $\sim$ \$20/MWh today. Today's low PPA prices have been enabled by the combination of higher capacity factors, declining costs, and record-low interest rates documented elsewhere in this report.

- The relative economic competitiveness of wind power declined in 2015 with the drop in wholesale power prices. A sharp drop in wholesale power prices in 2015 made it somewhat harder for wind power to compete, notwithstanding the low wind energy PPA prices available to purchasers. This is particularly true in light of the continued expansion of wind development in the Interior region of the U.S., where wholesale power prices are among the lowest in the nation. That said, the price stream of wind PPAs executed in 2014-2016 compares very favorably to the EIA's latest projection of the fuel costs of gas-fired generation extending out through 2040. 


\section{Policy and Market Drivers}

- A long-term extension and phase down of federal incentives for wind projects is leading to a resurgent domestic market. In December 2015, Congress passed a 5-year phased-down extension of the PTC. To qualify, projects must begin construction before January 1, 2020. In May 2016, the IRS issued favorable guidance allowing four years for project completion after the start of construction, without the burden of having to prove continuous construction. In extending the PTC, Congress also included a progressive reduction in the value of the credit for projects starting construction after 2016. Specifically, the PTC will phase down in increments of 20 percentage points per year for projects starting construction in 2017 (80\% PTC), 2018 (60\%), and 2019 (40\%).

- State policies help direct the location and amount of wind power development, but current policies cannot support continued growth at recent levels. As of July 2016, RPS policies existed in 29 states and Washington D.C. Of all wind capacity built in the United States from 2000 through 2015, roughly 51\% is delivered to load-serving entities with RPS obligations. Among just those wind projects built in 2015, however, this proportion fell to $24 \%$. Existing RPS programs are projected to require average annual renewable energy additions of roughly $3.7 \mathrm{GW} /$ year through 2030, only a portion of which will come from wind. These additions are well below the average growth rate in wind power capacity in recent years.

- System operators are implementing methods to accommodate increased penetrations of wind energy, but transmission and other barriers remain. Studies show that wind energy integration costs are almost always below $\$ 12 / \mathrm{MWh}$ - and often below $\$ 5 / \mathrm{MWh}$ - for wind power capacity penetrations of up to or even exceeding $40 \%$ of the peak load of the system in which the wind power is delivered. System operators and others continue to implement a range of methods to accommodate increased wind energy penetrations and reduce barriers to deployment: treating wind as dispatchable, increasing wind's capability to provide grid services, revising ancillary service market design, balancing area coordination, and new transmission investment. About 1,500 miles of transmission lines came on-line in 2015-less than in previous years. The wind industry, however, has identified 15 near-term transmission projects that - if all were completed — could carry $52 \mathrm{GW}$ of additional wind capacity.

\section{Future Outlook}

With the five-year phased-down extension of the PTC, annual wind power capacity additions are projected to continue at a rapid clip for several years. Near-term additions will also be driven by improvements in the cost and performance of wind power technologies, which continue to yield very low power sales prices. Growing corporate demand for wind energy and state-level policies are expected to play important roles as well, as might utility action to proactively stay ahead of possible future environmental compliance obligations. As a result, various forecasts for the domestic market show expected capacity additions averaging more than 8,000 MW/year from 2016 to 2020. Projections for 2021 to 2023, however, show a downturn in additions as the PTC progressively delivers less value to the sector. Expectations for continued low natural gas prices, modest electricity demand growth, and lower near-term demand from state RPS policies also put a damper on growth expectations, as do inadequate transmission infrastructure and competition from solar energy in certain regions of the country. At the same time, the potential for continued 
technological advancements and cost reductions enhance the prospects for longer-term growth, as does burgeoning corporate demand for wind energy and longer-term state RPS requirements. EPA's Clean Power Plan, depending on its ultimate fate, may also create new markets for wind. Moreover, new transmission in some regions is expected to open up high-quality wind resources to development. Given these diverse underlying potential trends, wind capacity additionsespecially after 2020 - remain uncertain. 


\section{Introduction}

Annual wind power capacity additions in the United States surged in 2015 and are projected to continue at a rapid clip in the coming five years. Recent and projected near-term growth is supported by the industry's primary federal incentive - the production tax credit (PTC) - having been extended for several years (though with a phase-down schedule, described further on pages 68-69), as well as a myriad of state-level policies. Wind additions are also being driven by improvements in the cost and performance of wind power technologies, yielding low power sales prices for utility, corporate, and other purchasers. At the same time, the prospects for growth beyond the current PTC cycle remain uncertain: growth could be blunted by declining federal tax support, expectations for low natural gas prices, and modest electricity demand growth.

This annual report — now in its tenth year - provides a detailed overview of developments and trends in the U.S. wind power market, with a particular focus on 2015. The report begins with an overview of key installation-related trends: trends in U.S. wind power capacity growth; how that growth compares to other countries and generation sources; the amount and percentage of wind energy in individual states; the status of offshore wind power development; and the quantity of proposed wind power capacity in various interconnection queues in the United States. Next, the report covers an array of wind power industry trends: developments in turbine manufacturer market share; manufacturing and supply-chain developments; wind turbine and component imports into and exports from the United States; project financing developments; and trends among wind power project owners and power purchasers. The report then turns to a summary of wind turbine technology trends: turbine size, hub height, rotor diameter, specific power, and IEC Class. After that, the report discusses wind power performance, cost, and pricing trends. In so doing, it describes trends in project performance, wind turbine transaction prices, installed project costs, and operations and maintenance $(\mathrm{O} \& \mathrm{M})$ expenses. It also reviews the prices paid for wind power in the United States and how those prices compare to short-term wholesale electricity prices and forecasts of future natural gas prices. Next, the report examines policy and market factors impacting the domestic wind power market, including federal and state policy drivers as well as transmission and grid integration issues. The report concludes with a preview of possible near-term market developments.

This edition of the annual report updates data presented in previous editions while highlighting key trends and important new developments from 2015. The report concentrates on larger, utility-scale wind turbines, defined here as individual turbines that exceed $100 \mathrm{~kW}$ in size. ${ }^{1}$ The U.S. wind power sector is multifaceted, however, and also includes smaller, customer-sited wind turbines used to power residences, farms, and businesses. Further information on distributed wind power, which includes smaller wind turbines as well as the use of larger turbines in distributed applications, is available through a separate annual report funded by the U.S. Department of Energy (DOE). ${ }^{2}$ Additionally, because this report has an historical focus, and all

\footnotetext{
${ }^{1}$ This $100-\mathrm{kW}$ threshold between "smaller" and "larger" wind turbines is applied starting with 2011 projects to better match AWEA's historical methodology, and is also justified by the fact that the U.S. tax code makes a similar distinction. In years prior to 2011, different cut-offs are used to better match AWEA's reported capacity numbers and to ensure that older utility-scale wind power projects in California are not excluded from the sample.

${ }^{2}$ As used by the DOE, distributed wind is defined in terms of technology application based on a wind project's location relative to end use and power distribution infrastructure, rather than on technology size or project size. Distributed wind systems are connected either on the customer side of the meter (to meet the onsite load) or directly
} 
U.S. wind power projects have been land-based, its treatment of trends in the offshore wind power sector is limited to a brief summary of recent developments.

Much of the data included in this report were compiled by Lawrence Berkeley National Laboratory (Berkeley Lab) from a variety of sources, including the American Wind Energy Association (AWEA), the U.S. Energy Information Administration (EIA), and the Federal Energy Regulatory Commission (FERC). The Appendix provides a summary of the many data sources used in the report, and a list of specific references follows the Appendix. Data on wind power capacity additions in the United States (as well as wind power projects) are based largely on information provided by AWEA, although minor methodological differences may yield slightly different numbers from AWEA (2016a) in some cases. In other cases, the data shown here represent only a sample of actual wind power projects installed in the United States; furthermore, the data vary in quality. As such, emphasis should be placed on overall trends, rather than on individual data points. Finally, each section of this document primarily focuses on historical market information, with an emphasis on 2015. With some limited exceptionsincluding the final section of the report— the report does not seek to forecast trends.

to the local grid (to support grid operations or offset large loads nearby). For the DOE distributed wind report, see: Orrell and Foster (2016). 


\section{Installation Trends}

\section{Wind power additions surged in 2015 , with $8,598 \mathrm{MW}$ of new capacity added in the United States and \$14.5 billion invested}

The U.S. wind power market surged in 2015, with 8,598 MW of new capacity added, bringing the cumulative total to $73,992 \mathrm{MW}$ (Figure 1). ${ }^{3}$ This growth required $\$ 14.5$ billion of investment in wind power project installations in 2015, for a cumulative investment total of more than $\$ 150$ billion since the beginning of the $1980 \mathrm{~s} .{ }^{45}$ With a record $484 \mathrm{MW}$ of wind power capacity decommissioned in 2015, growth in cumulative "net" capacity in 2015 was $12 \%$.

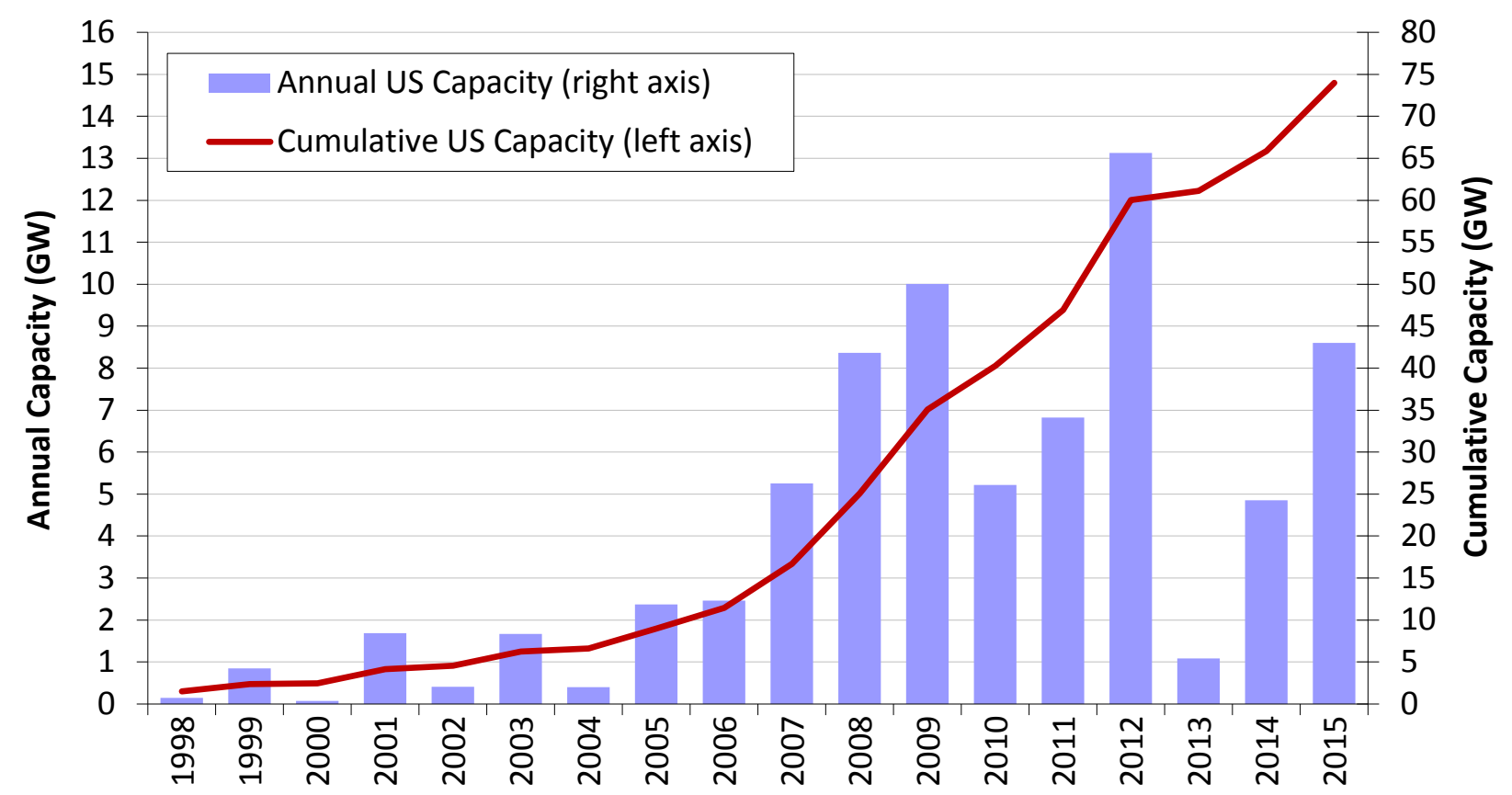

Source: AWEA project database

Figure 1. Annual and cumulative growth in U.S. wind power capacity

In 2015, growth was driven by recent improvements in the cost and performance of wind power technologies. State renewables portfolio standards (RPS) and corporate demand for wind power also played a role. Another key factor was the PTC, which, in December 2015, was extended for an additional 5 years - applying now to projects that begin construction before January 1, 2020, but with a progressive reduction in the value of the credit for projects starting construction after 2016. Substantial additional capacity additions are anticipated in the near term-in part due to the PTC extension.

\footnotetext{
${ }^{3}$ When reporting annual wind power capacity additions, this report focuses on gross capacity additions of large wind turbines. The net increase in capacity each year can be somewhat lower, reflecting turbine decommissioning. ${ }^{4}$ All cost and price data are reported in real $2015 \$$.

${ }^{5}$ These investment figures are based on an extrapolation of the average project-level capital costs reported later in this report and do not include investments in manufacturing facilities, research and development expenditures, or O\&M costs.
} 


\section{Wind power represented the largest source of U.S. electric-generating capacity additions in 2015}

Wind power has comprised a sizable share of generation capacity additions in recent years. In 2015 , wind power constituted $41 \%$ of all U.S. generation capacity additions, up sharply from its $24 \%$ market share the year before and close to its all-time high (Figure 2). ${ }^{6}$ For the second time, wind power was the largest source of annual new generating capacity, well ahead of the next two leading sources, solar power and natural gas.
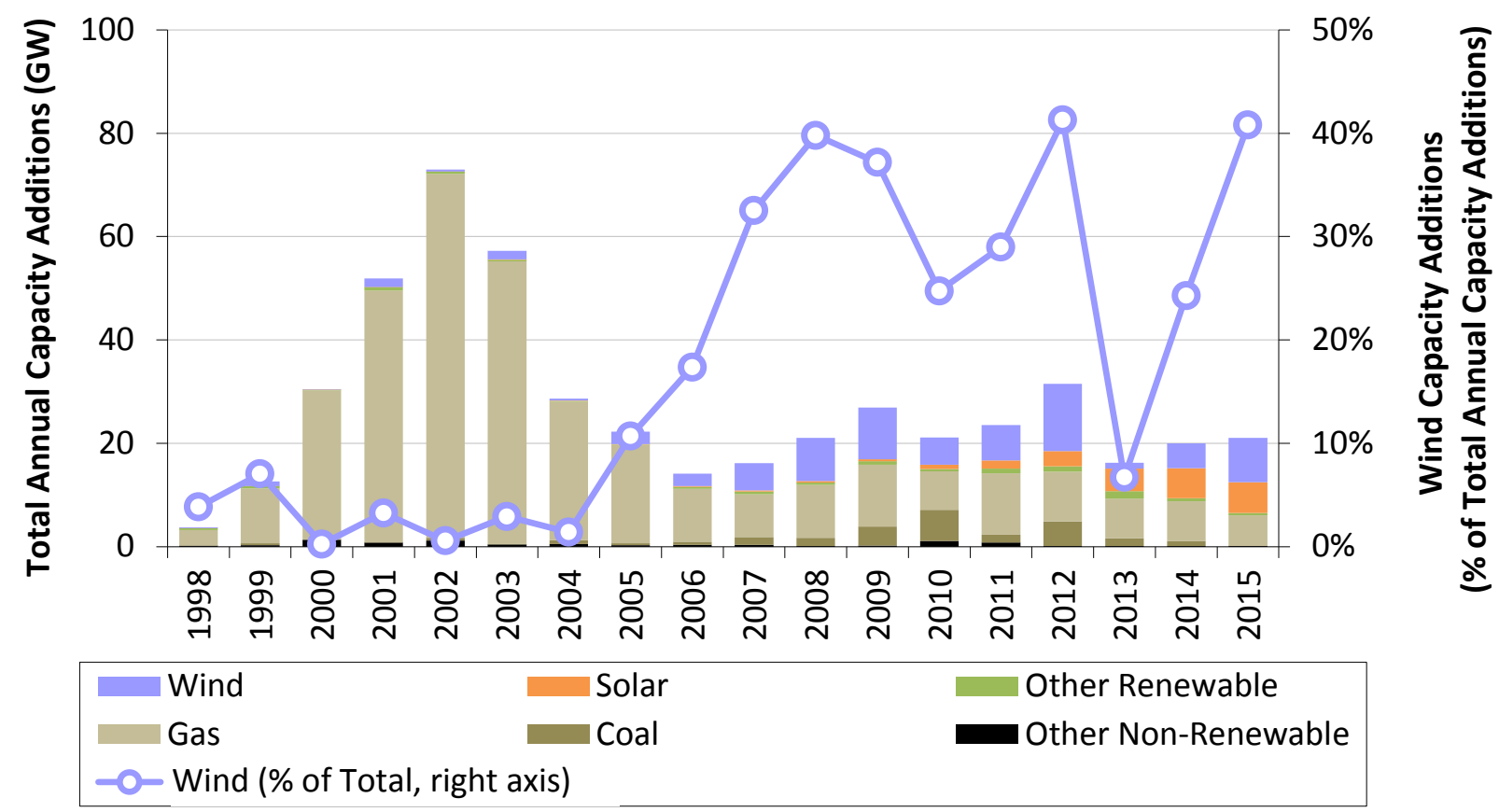

Source: ABB, AWEA, GTM Research, Berkeley Lab

Figure 2. Relative contribution of generation types in annual capacity additions

Over the last decade, wind power represented $31 \%$ of total U.S. capacity additions, and an even larger fraction of new generation capacity in the Interior (54\%) and Great Lakes (48\%) regions (Figure 3; see Figure 29, later, for regional definitions). Its contribution to generation capacity growth over the last decade is somewhat smaller - but still significant - in the West (22\%) and Northeast (21\%), and considerably less in the Southeast (2\%).

\footnotetext{
${ }^{6}$ Data presented here are based on gross capacity additions, not considering retirements. Furthermore, they include only the 50 U.S. states, not U.S. territories.
} 


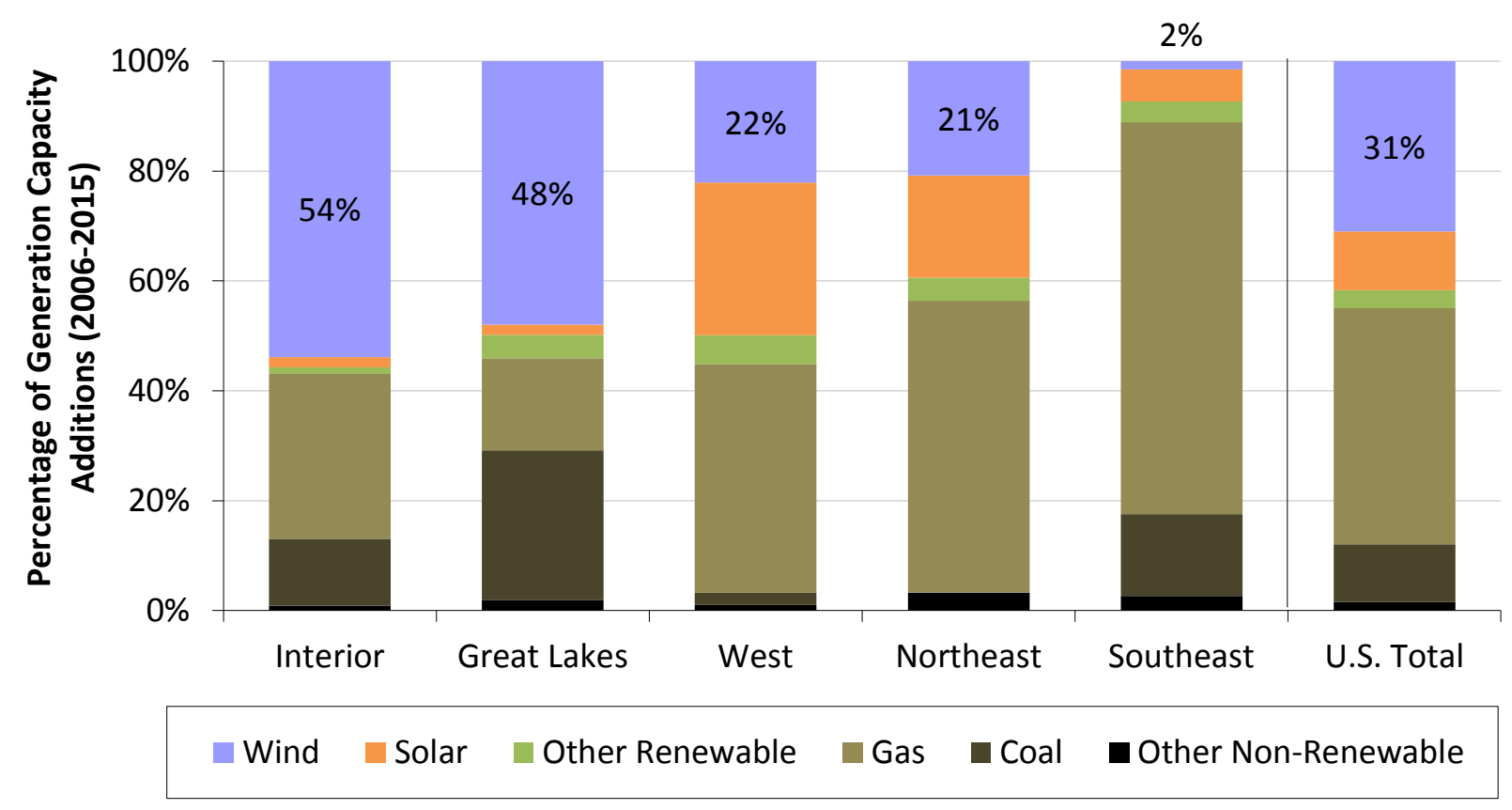

Source: ABB, AWEA, GTM Research, Berkeley Lab

Figure 3. Generation capacity additions by region (2006-2015)

\section{The United States ranked second in annual wind additions in 2015 , but was well behind the market leaders in wind energy penetration}

Global wind additions yet again reached a new high in 2015, with roughly 63,000 MW of new capacity, 23\% above the previous record of 51,000 MW added in 2014. Cumulative global capacity stood at approximately 434,000 MW at the end of the year (Navigant 2016a; Table 1). The United States ended 2015 with $17 \%$ of total global wind power capacity, a distant second to China by this metric (Table 1). ${ }^{8}$ On the basis of wind power production, however, the United States remained the leading country globally in 2015 (AWEA 2016a). Annual growth in cumulative capacity in 2015 was $23 \%$ for the United States and $17 \%$ globally.

After leading the world in annual wind power capacity additions from 2005 through 2008, and then losing the mantle to China from 2009 through 2011, the United States narrowly regained the global lead in 2012. In 2013, the United States dropped precipitously to $6^{\text {th }}$ place in annual additions, but then regained ground, rising to $3^{\text {rd }}$ place in 2014 and $2^{\text {nd }}$ place in 2015 (Table 1). The U.S. wind power market represented 14\% of global installed capacity in 2015 .

\footnotetext{
${ }^{7}$ Yearly and cumulative installed wind power capacity in the United States are from the present report, while global wind power capacity comes from Navigant (2016a) but are updated with the U.S. data presented here. Some disagreement exists among these data sources and others.

${ }^{8}$ Wind power additions and cumulative capacity in China include capacity that was installed but that had not yet begun to deliver electricity by the end of 2015, due to a lack of coordination between wind developers and transmission providers and the lengthier time that it takes to build transmission and interconnection facilities. All of the U.S. capacity reported here, on the other hand, was capable of electricity delivery.
} 
Table 1. International Rankings of Wind Power Capacity

\begin{tabular}{|c|c|c|c|}
\hline \multicolumn{2}{|c|}{$\begin{array}{c}\text { Annual Capacity } \\
(2015, \mathrm{MW})\end{array}$} & \multicolumn{2}{|c|}{$\begin{array}{l}\text { Cumulative Capacity } \\
\text { (end of 2015, MW) }\end{array}$} \\
\hline China & 30,293 & China & 145,053 \\
\hline United States & 8,598 & United States & 73,992 \\
\hline Germany & 6,013 & Germany & 44,986 \\
\hline Brazil & 2,754 & India & 25,352 \\
\hline India & 2,623 & Spain & 22,665 \\
\hline Canada & 1,506 & United Kingdom & 13,388 \\
\hline Poland & 1,266 & Canada & 11,190 \\
\hline France & 1,073 & France & 10,243 \\
\hline United Kingdom & 975 & Brazil & 9,346 \\
\hline Turkey & 956 & Italy & 8,851 \\
\hline Rest of World & 7,078 & Rest of World & 68,464 \\
\hline TOTAL & 63,135 & TOTAL & 433,530 \\
\hline
\end{tabular}

A number of countries have achieved relatively high levels of wind energy penetration in their electricity grids. Figure 4 presents data on end-of-2015 (and end-of-2014) installed wind power capacity, translated into projected annual electricity supply based on assumed country-specific capacity factors and then divided by projected 2016 (and 2015) electricity consumption. Using this approximation for the contribution of wind power to electricity consumption, and focusing only on those countries with the greatest cumulative installed wind power capacity, end-of-2015 installed wind power is estimated to supply the equivalent of roughly $40 \%$ of Denmark's electricity demand, and between $20 \%$ to $30 \%$ of Portugal, Ireland, and Spain's demand. In the United States, the cumulative wind power capacity installed at the end of 2015 is estimated, in an average year, to equate to $5.6 \%$ of the nation's electricity demand. On a global basis, wind energy's contribution is estimated to be approximately $4.3 \%$. 


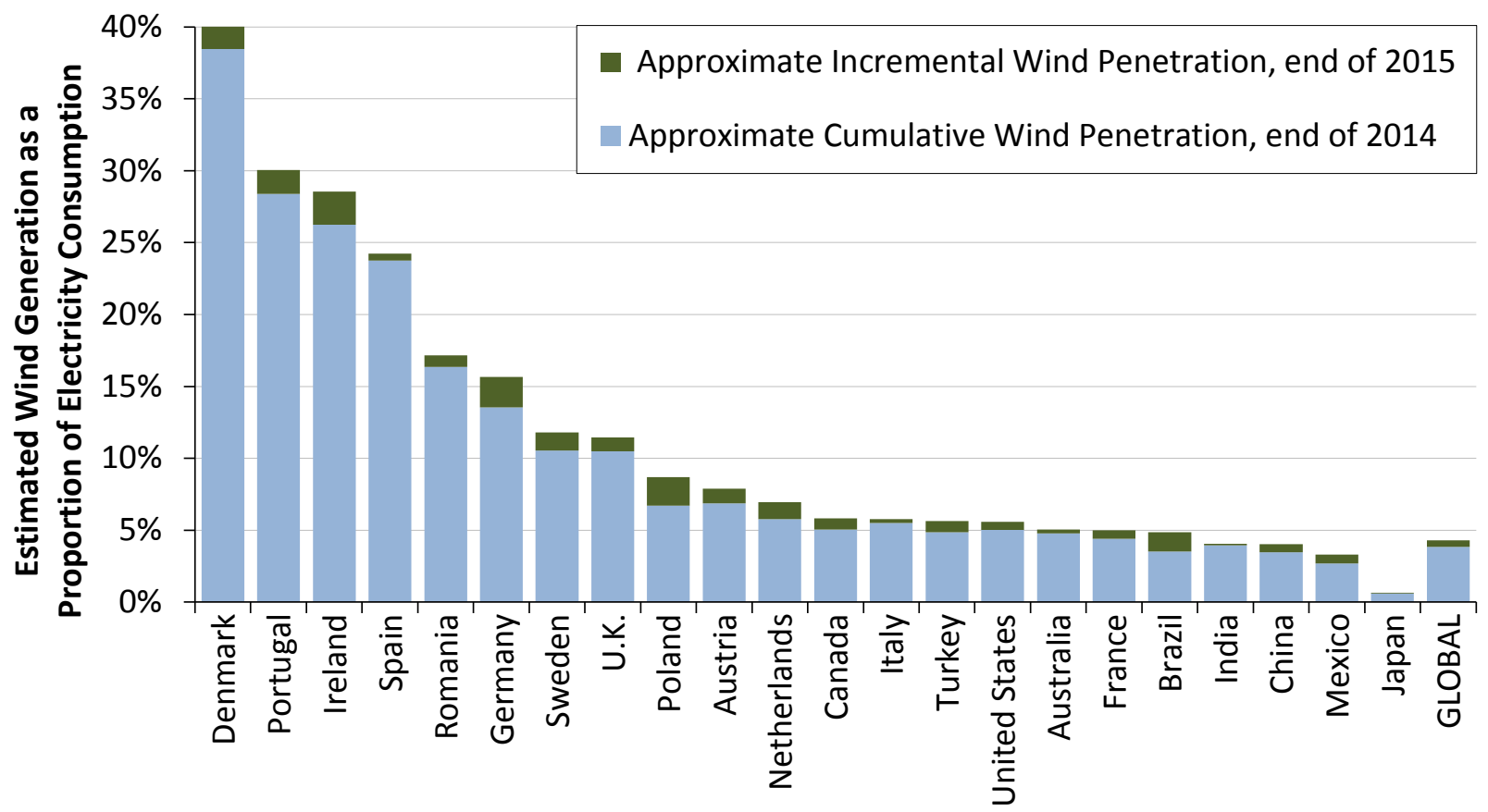

Source: Berkeley Lab estimates based on data from Navigant, EIA, and elsewhere

Figure 4. Approximate wind energy penetration in the countries with the greatest installed wind power capacity

Texas installed the most capacity in 2015 with 3,615 MW, while twelve states meet or exceed $10 \%$ wind energy penetration

New utility-scale wind turbines were installed in 20 states in 2015. Texas installed the most new wind capacity of any state, with 3,615 MW. As shown in Figure 5 and Table 2, other leading states in terms of new capacity included Oklahoma (1,402 MW), Kansas (799 MW), Iowa (524 MW), and Colorado (399 MW).

On a cumulative basis, Texas remained the clear leader among states, with 17,711 MW installed at the end of 2015-nearly three times as much as the next-highest state (Iowa, with 6,209 MW). In fact, Texas has more wind capacity than all but five countries-including the rest of the United States - worldwide. States distantly following Texas in cumulative installed capacity include Iowa, California, Oklahoma, Illinois, Kansas, Minnesota, Oregon, and Washington-all with more than 3,000 MW. Thirty-five states, plus Puerto Rico, had more than $100 \mathrm{MW}$ of wind capacity as of the end of 2015, with 24 of these topping $500 \mathrm{MW}, 17$ topping 1,000 MW, and 11 topping 2,000 MW. Although all commercial wind projects in the United States to date have been installed on land, offshore development activities continued in 2015, as discussed in the next section. 




Note: Numbers within states represent cumulative installed wind capacity and, in brackets, annual additions in 2015.

Figure 5. Location of wind power development in the United States

Some states have realized high levels of wind energy penetration. The right half of Table 2 lists the top 20 states based on actual wind electricity generation in 2015 divided by total in-state electricity generation in $2015 .{ }^{9}$ Iowa leads the list, with $31.3 \%$ wind penetration, followed by South Dakota (25.5\%) and Kansas (23.9\%). A total of twelve states have achieved wind penetration levels of $10 \%$ or higher.

\footnotetext{
${ }^{9}$ Wind energy penetration can either be expressed as a percentage of in-state load or in-state generation. In-state generation is used here, primarily because wind energy (like other energy resources) is often sold across state lines, which tends to distort penetration levels expressed as a percentage of in-state load. Also note that by focusing on generation in 2015, Table 2 does not fully capture the impact of new wind power capacity added during 2015 (particularly if added towards the end of the year).
} 
Table 2. U.S. Wind Power Rankings: the Top 20 States

\begin{tabular}{|c|c|c|c|c|c|}
\hline \multicolumn{4}{|c|}{ Installed Capacity (MW) } & \multirow{2}{*}{\multicolumn{2}{|c|}{$\begin{array}{c}\begin{array}{c}\text { Percentage of } \\
\text { In-State Generation }\end{array} \\
\text { Actual (2015)* }\end{array}$}} \\
\hline \multicolumn{2}{|c|}{ Annual (2015) } & \multicolumn{2}{|c|}{ Cumulative (end of 2015) } & & \\
\hline Texas & 3,615 & Texas & 17,711 & lowa & $31.3 \%$ \\
\hline Oklahoma & 1,402 & lowa & 6,209 & South Dakota & $25.5 \%$ \\
\hline Kansas & 799 & California & 5,662 & Kansas & $23.9 \%$ \\
\hline lowa & 524 & Oklahoma & 5,184 & Oklahoma & $18.4 \%$ \\
\hline Colorado & 399 & Illinois & 3,842 & North Dakota & $17.7 \%$ \\
\hline Illinois & 274 & Kansas & 3,764 & Minnesota & $17.0 \%$ \\
\hline New Mexico & 268 & Minnesota & 3,235 & Idaho & $16.2 \%$ \\
\hline North Dakota & 258 & Oregon & 3,153 & Vermont & $15.4 \%$ \\
\hline Minnesota & 200 & Washington & 3,075 & Colorado & $14.2 \%$ \\
\hline California & 194 & Colorado & 2,965 & Oregon & $11.3 \%$ \\
\hline South Dakota & 175 & North Dakota & 2,143 & Maine & $10.5 \%$ \\
\hline Maine & 173 & Indiana & 1,895 & Texas & $10.0 \%$ \\
\hline Indiana & 150 & New York & 1,749 & Nebraska & $8.0 \%$ \\
\hline Nebraska & 80 & Michigan & 1,531 & Wyoming & $7.7 \%$ \\
\hline Arizona & 30 & Wyoming & 1,410 & Montana & $6.6 \%$ \\
\hline Maryland & 30 & Pennsylvania & 1,340 & Washington & $6.5 \%$ \\
\hline New Hampshire & 14 & New Mexico & 1,080 & New Mexico & $6.3 \%$ \\
\hline Ohio & 8 & South Dakota & 977 & California & $6.2 \%$ \\
\hline Connecticut & 5 & Idaho & 973 & Hawaii & $6.1 \%$ \\
\hline New York & 1 & Nebraska & 890 & Illinois & $5.5 \%$ \\
\hline Rest of U.S. & 0 & Rest of U.S. & 5,203 & Rest of U.S. & $1.0 \%$ \\
\hline TOTAL & 8,598 & TOTAL & 73,992 & TOTAL & $4.7 \%$ \\
\hline
\end{tabular}

* Based on 2015 wind and total generation by state from EIA's Electric Power Monthly.

Source: AWEA project database, EIA

\section{The first commercial offshore turbines are expected to be commissioned in the United States in 2016 amid mixed market signals}

At the end of 2015, global cumulative offshore wind power capacity stood at roughly 12,000 MW (Navigant 2016a), with Europe continuing as the primary center of activity. Navigant (2016a) reports more than 3,500 MW of new offshore wind capacity being commissioned in 2015, with more than 3,000 MW under construction at the end of 2015 . $^{10}$

The $30 \mathrm{MW}$ Block Island project, developed by Deepwater Wind, began construction in 2015. All five jacket foundations were installed in 2015 and cable installation was expected to be complete by June 2016. Once installed, the project will consist of five GE Haliade $6 \mathrm{MW}$ offshore wind turbines. The project is expected to be commissioned by the end of 2016, becoming the first commercial offshore wind power plant to operate in the United States.

\footnotetext{
${ }^{10}$ Various data sources report different figures, in part due to differing perspectives on when to consider a project "completed."
} 
A number of other high-profile projects have run into legal and political headwinds:

- National Grid and NSTAR canceled their power purchase agreements (PPA) with the 468 MW Cape Wind project after it failed to meet contractual deadlines. The Bureau of Ocean Energy Management (BOEM) approved the project's application to suspend the 28-year operations term of its offshore area lease, but denied the project's request to stop its annual lease payments (Hopper 2015). The Massachusetts Energy Facilities Siting Board denied Cape Wind's request for permit extension for its electricity transmission lines in April 2016.

- New Jersey passed the Offshore Wind Economic Development Act in 2010, creating a program for offshore renewable energy credits. However, as of the end of 2015, the New Jersey Board of Public Utilities (BPU) had twice rejected the 25 MW Fishermen's Energy Atlantic City Windfarm's application for the state's Offshore Renewable Energy Credit program. The State Supreme Court subsequently upheld the decision of the BPU.

Fishermen's Energy continues to face roadblocks; legislative efforts to allow the project to reapply for BPU approval were vetoed by the governor. In 2012, DOE selected Fishermen's Energy as one of seven demonstration projects to receive $\$ 4$ million in funding, and chose it as one of three projects eligible for an additional $\$ 46.7$ million in funding in 2014. That eligibility was renewed in 2016 upon evaluation of the project against established milestones.

- Dominion Virginia Power announced that it would delay the $12 \mathrm{MW}$ Virginia Offshore

Wind Technology Advancement Project (VOWTAP) after initial bids for construction came in at $63 \%-74 \%$ above initial estimates. A second round of bidding reduced the cost of the project to $30 \%-65 \%$ above the initial estimate. ${ }^{11}$ BOEM approved a research lease for the project in March 2016. DOE chose VOWTAP as one of seven offshore projects (including Fishermen's Energy) to receive \$4 million in 2012 and, in 2014, up to an additional $\$ 46.7$ million in funding. However, DOE withdrew the offer in May 2016 upon evaluation of the project, determining that VOWTAP could not guarantee commissioning prior to 2020 .

The high cost of offshore wind coupled with the complex regulatory environment serve as key challenges for the U.S. offshore wind industry. The mechanisms for planning, siting, and permitting offshore wind projects are fragmented, requiring developers to engage with multiple local, state, and federal agencies and stakeholders. Furthermore, regulatory processes to secure site control and construction authorization are mostly decoupled from offtake agreements that support the economics of an offshore wind project. U.S. developers with competitive lease auctions must separately negotiate PPAs, which increases uncertainty relative to European markets. Meanwhile, due to the lack of sufficient policy support to cover the high cost of offshore wind in most states, offtake agreements and financing have been hard to obtain. NREL estimates that the levelized cost of fixed-bottom offshore wind energy in 2014 was \$193/MWh in the United States (Moné et al. 2015).

Despite these challenges, the United States remains interested in offshore wind project development. Key drivers include the close proximity of offshore wind resources to population centers, which could address transmission congestion, the potential for local economic development benefits, and superior capacity factors and larger potential project sizes compared to limited developable land-based wind resources in some coastal regions.

\footnotetext{
${ }^{11}$ The initial projection for VOWTAP was $\$ 230$ million, the first round of bidding came in at $\$ 375-400$ million, and the second round of bidding came in at $\$ 300-380$ million.
} 
Policy support for offshore wind originates in state initiatives and policies as well as federal incentives and programs. Of those states with RPS requirements, Maryland, New Jersey, and Maine have offshore-specific carve-out mandates or goals. At the federal level, the recent extension of the PTC and ITC may help support offshore projects that are able to meet the relevant deadlines. In addition, federal support in the form of regulatory approvals and technology investment is boosting commercial interest. BOEM had granted five leases for sites in Rhode Island, Massachusetts, Maryland, and Virginia as of the end of 2015. In 2015, BOEM issued four additional leases from competitive auctions for offshore wind areas in Massachusetts and New Jersey. In January 2015, the Massachusetts auction received bids for two of the four available zones, potentially adding up to $1.4 \mathrm{GW}$ of offshore development. ${ }^{12}$ In November 2015 , the New Jersey auction resulted in two lease areas totaling more than $3 \mathrm{GW}$ of announced potential offshore wind power. ${ }^{13}$ Further competitive leases are planned in New York, North Carolina, and South Carolina.

DOE has also made significant investments in offshore wind energy, including funding for advanced technology demonstration partnerships. In 2012, DOE launched the Offshore Wind Advanced Technology Demonstration program by selecting seven offshore demonstration projects to receive up to $\$ 4$ million to complete engineering, design, and permitting phases of development. In 2014, DOE selected three innovative projects from the seven demonstration projects for additional federal funding of $\$ 6.7$ million each to finalize the initial development phase. These three projects, Dominion Power's VOWTAP (12 MW, Virginia), Principle Power's WindFloat Pacific (up to $30 \mathrm{MW}$, Oregon), and Fishermen's Energy Atlantic City Windfarm (at least $24 \mathrm{MW}$, New Jersey), also received eligibility to receive up to $\$ 40$ million in funding for future phases. In addition, DOE selected two alternate projects, University of Maine's 12 MW Aqua Ventus project in Maine and Lake Erie Energy Development Corporation's 18 MW Icebreaker Project in Ohio, to receive \$3 million each to complete the engineering designs of their technology concepts.

In May 2016, DOE decided that Principle Power's WindFloat Pacific project in Oregon and Dominion's VOWTAP in Virginia would no longer be eligible for the funding due to their inability to guarantee project milestones. Instead, DOE selected the two alternate projects in Maine and Ohio to receive the additional funding as part of the demonstration program.

Figure 6 identifies 23 proposed offshore wind projects in the United States in various stages of development. These projects total more than $16 \mathrm{GW}$ of potential capacity, of which approximately $10 \mathrm{GW}$ have obtained site control through leases or determinations of no competitive interest. ${ }^{14}$ The proposed projects are primarily located in the Northeast and MidAtlantic, with one project each in the Great Lakes, Pacific Northwest, and California. Developers have also filed lease requests to BOEM for three areas in Hawaii in 2015 and 2016.

\footnotetext{
${ }^{12}$ The potential capacity for the two lease areas is based on announced estimated capacity by the developers, Offshore MW LLC (400 MW) and DONG Energy (1000 MW).

${ }^{13}$ The potential capacity of $3 \mathrm{GW}$ is based on the announced capacity by DONG Energy (1000 MW) and estimates by NREL for US Wind's lease area (2230 MW).

${ }^{14}$ A project reaches the site control phase when the developer obtains exclusive development rights to a site.
} 


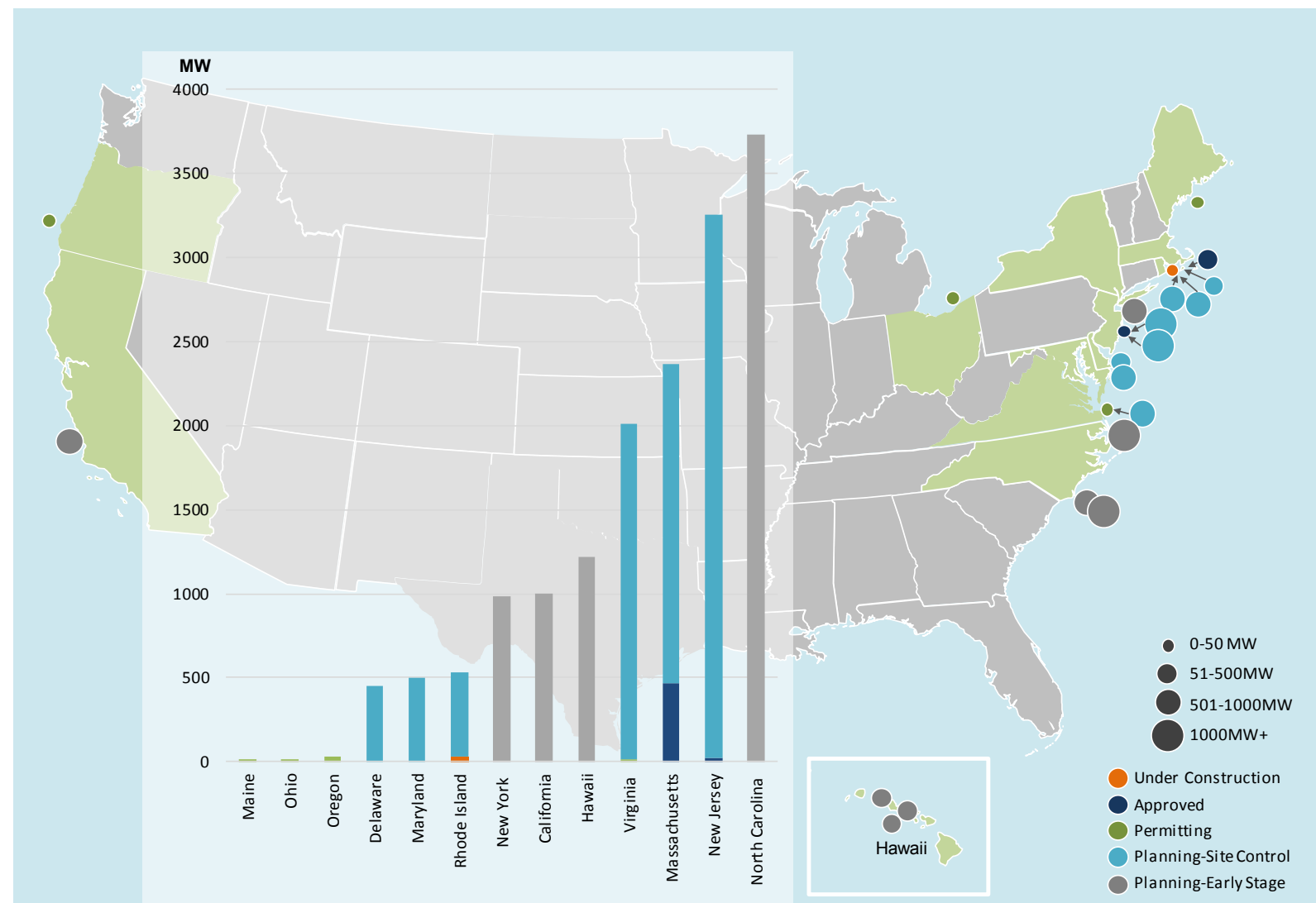

Note: Capacities of projects are based on owner/developer announced capacity. In cases where announced capacity is unavailable, the capacity refers to the estimated maximum potential, which assumes an average capacity density of $3 \mathrm{MW} / \mathrm{km}^{2}$ based on spacing of 9 to 10 rotor diameters developed. For methodology of estimated maximum potential, please refer to Musial et al. (2013a, 2013b). For definitions of the different stages of development, please refer to Smith et al. (2015).

Figure 6. Offshore wind power projects under development in the United States as of June 2016

Of the projects identified in Figure 6, Deepwater Wind's Block Island project off the coast of Rhode Island is the only one that has a PPA. Achievement of this milestone enabled the project to close financing and to begin construction in spring 2015. Other projects are working with regulators to finalize design, secure permits, and/or establish power sales agreements. The recent challenges highlighted above suggest that the schedules for these projects are subject to uncertainty.

\section{Data from interconnection queues demonstrate that a substantial amount of wind power capacity is under consideration}

One testament to the continued interest in land-based wind energy is the amount of wind power capacity currently working its way through the major transmission interconnection queues across the country. Figure 7 provides this information for wind power and other resources aggregated across 34 different interconnection queues administered by independent system operators (ISOs), regional transmission organizations (RTOs), and utilities. ${ }^{15}$ These data should be interpreted with

\footnotetext{
${ }^{15}$ The queues surveyed include PJM Interconnection (PJM), Midcontinent Independent System Operator (MISO), New York ISO (NYISO), ISO-New England (ISO-NE), California ISO (CAISO), Electric Reliability Council of Texas (ERCOT), Southwest Power Pool (SPP), Western Area Power Administration (WAPA), Bonneville Power
} 
caution: placing a project in the interconnection queue is a necessary step in project development, but being in the queue does not guarantee that a project will be built. Efforts have been made by FERC, ISOs, RTOs, and utilities to reduce the number of speculative projects that have clogged these queues in past years. One consequence of those efforts is that the total amount of wind power capacity in the nation's interconnection queues has declined dramatically since 2009.

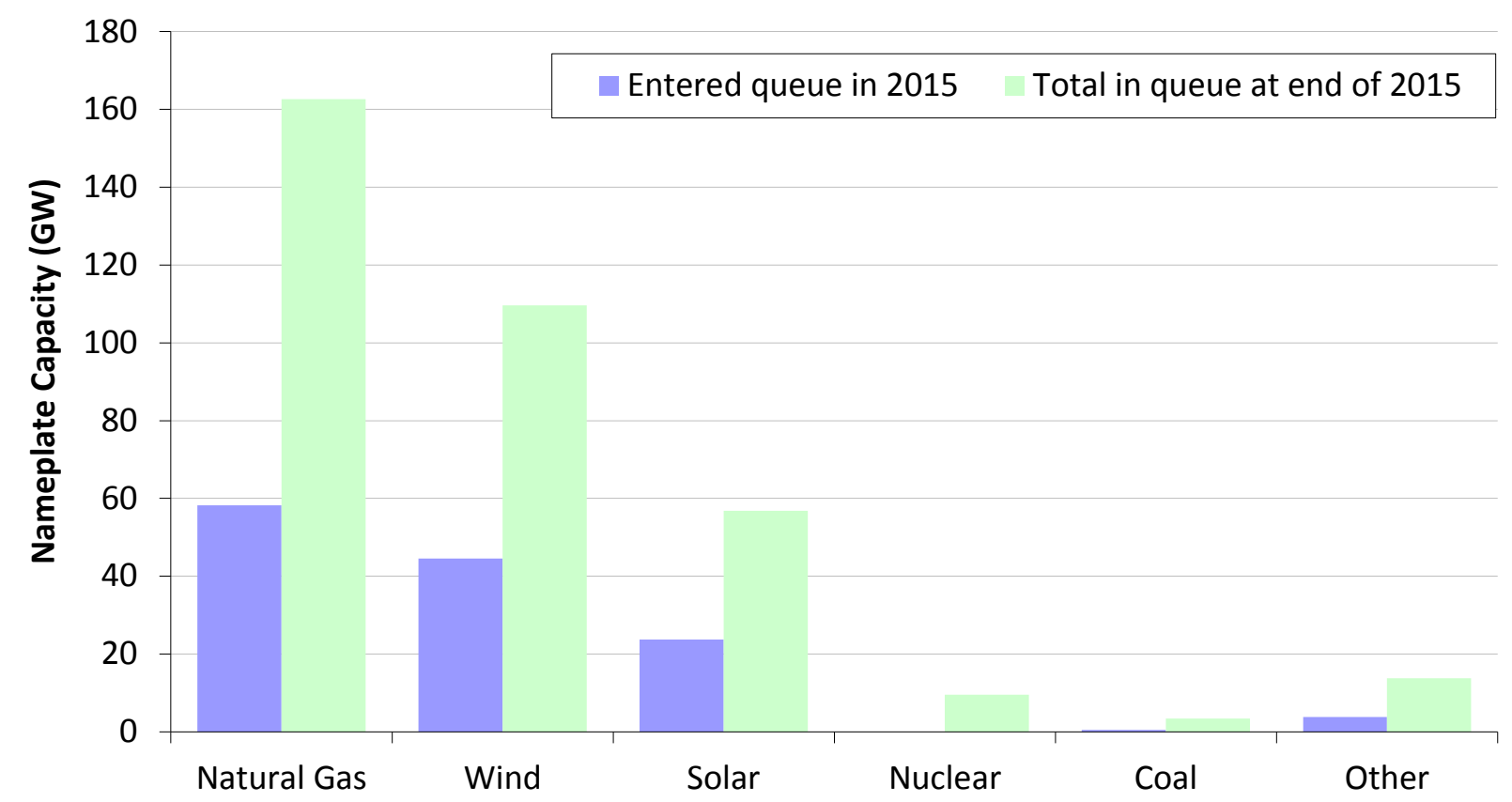

Source: Exeter Associates review of interconnection queues

Figure 7. Generation capacity in 34 selected interconnection queues, by resource type

Even with this important caveat, the amount of wind capacity in the nation's interconnection queues still provides at least some indication of the amount of planned development. At the end of 2015, there were $110 \mathrm{GW}$ of wind power capacity within the interconnection queues reviewed for this report-almost one-and-a-half times the installed wind power capacity in the United States. This $110 \mathrm{GW}$ is an increase from the end of $2014(96 \mathrm{GW})$, and represented $31 \%$ of all generating capacity within these selected queues at that time, higher than all other generating sources except for natural gas. In $2015,45 \mathrm{GW}$ of wind power capacity entered the interconnection queues, compared to $58 \mathrm{GW}$ of natural gas and $24 \mathrm{GW}$ of solar. The $45 \mathrm{GW}$ of new wind capacity entering the queues in 2015 is the largest annual sum since 2010.

Of note, however, is that the total amount of wind, coal, and nuclear power in the sampled interconnection queues (considering gross additions and project drop-outs) has generally declined in recent years, whereas natural gas and solar capacity has increased or held steady.

Administration (BPA), Tennessee Valley Authority (TVA), and 24 other individual utilities. To provide a sense of sample size and coverage, the ISOs, RTOs, and utilities whose queues are included here have an aggregated noncoincident (balancing authority) peak demand of about $88 \%$ of the U.S. total. Figures 7 and 8 only include projects that were active in the queue at the end of 2015 but that had not yet been built; suspended projects are not included. 
Since 2009 , for example, the amount of wind power capacity has dropped by $64 \%$, coal by $89 \%$, and nuclear by $67 \%$, whereas solar capacity has increased by $68 \%$ and natural gas by $47 \%$.

The wind capacity in the interconnection queues is spread across the United States, as shown in Figure 8, with larger amounts in ERCOT (22\%), the Midwest (20\%), Southwest Power Pool (SPP) (18\%), the Northwest (11\%), and the PJM Interconnection (11\%). Somewhat smaller amounts are found in the Mountain region (8\%), ISO-New England (4\%), New York ISO (3\%), California (3\%), and the Southeast $(0.5 \%)$.

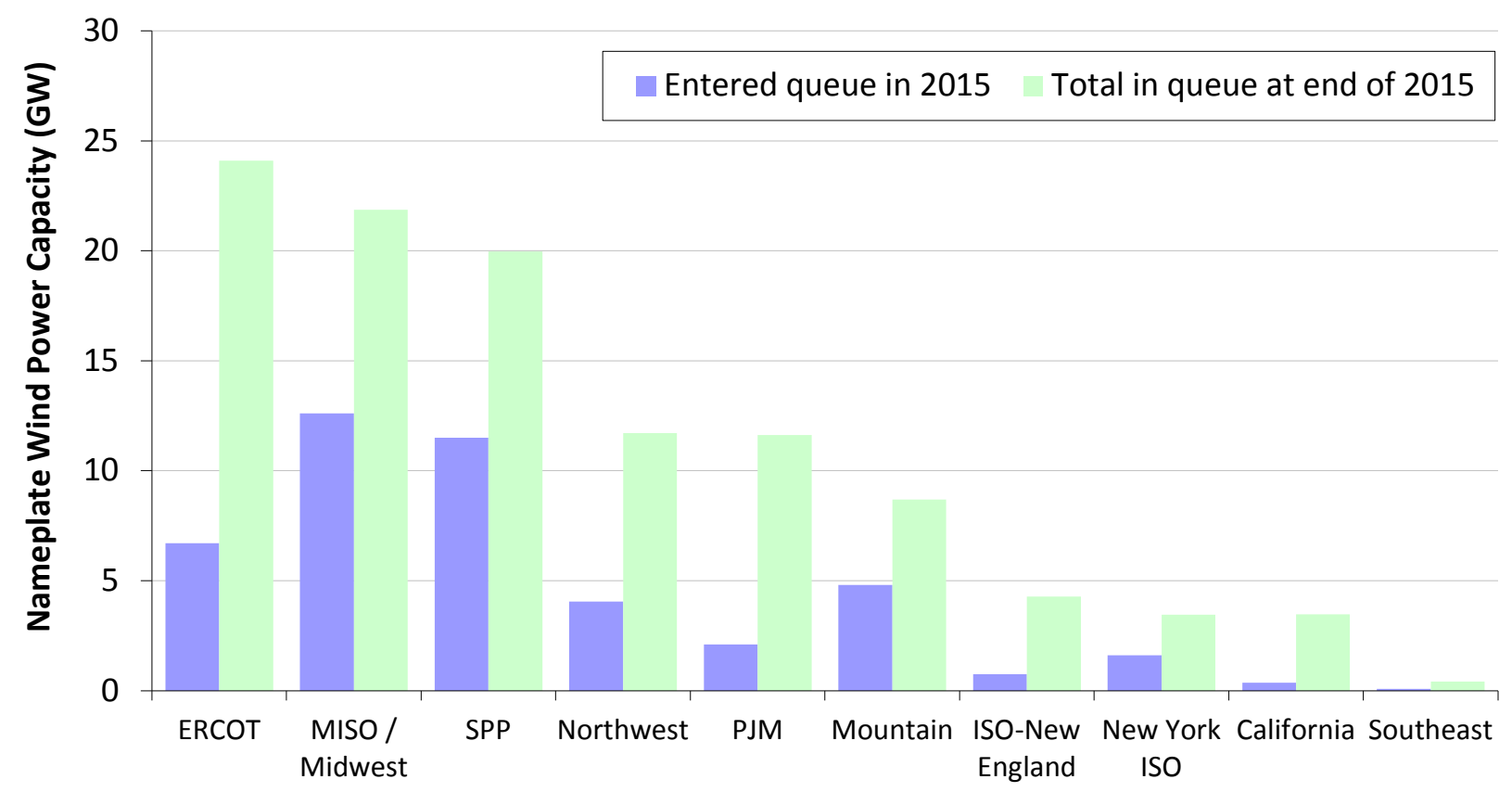

Source: Exeter Associates review of interconnection queues

Figure 8 . Wind power capacity in 34 selected interconnection queues, by region

As a measure of the near-term development pipeline, ABB (2016) estimates that - as of June 2016 - approximately $29 \mathrm{GW}$ of wind power capacity could be characterized in one of three ways: (a) under construction or in site preparation $(8 \mathrm{GW})$; (b) in development and permitted (11 $\mathrm{GW}$ ); or (c) in development with a pending permit and/or regulatory applications ( $9 \mathrm{GW})$. These totals are similar to last year at approximately the same time (June 2015), indicating that the development pipeline remains strong. AWEA (2016b), meanwhile, reports that more than 15 GW of wind power capacity was under construction or at an advanced stage of development at the end of the first quarter of 2016. Supporting these figures, EIA (2016c) reports over $15 \mathrm{GW}$ of planned wind power additions for 2016 and 2017. 


\section{Industry Trends}

\section{GE and Vestas captured 73\% of the U.S. wind power market in 2015}

Of the 8,598 MW of wind installed in 2015, 40\% (3,468 MW) deployed turbines from GE Wind, with Vestas coming in second $(2,870 \mathrm{MW}, 33 \%$ market share), followed by Siemens $(1,219$ MW, 14\%) (Figure 9 and Table 3). ${ }^{16}$ Other suppliers included Acciona (465 MW), Gamesa (402 MW), Nordex (138 MW), Sany (20 MW), and Goldwind (8 MW). Some recent OEM consolidation has also occurred, with Nordex merging with Acciona, GE acquiring Alstom, and more recently in mid-2016, Siemens merging with Gamesa.

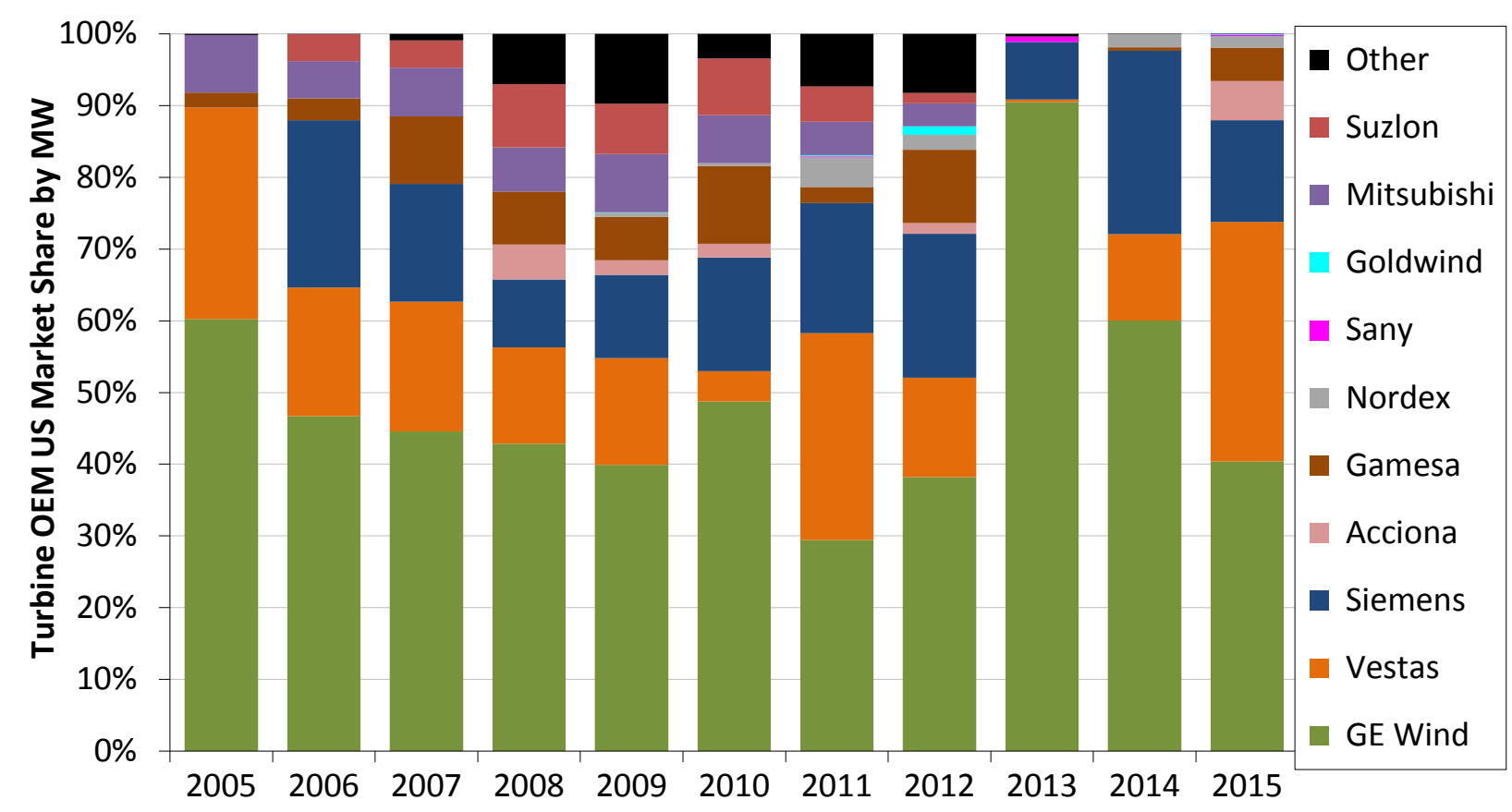

Source: AWEA project database

Figure 9. Annual U.S. market share of wind turbine manufacturers by MW, 2005-2015

According to Navigant (2016a), Goldwind and Vestas were the top two suppliers of turbines worldwide in 2015, followed by GE, Siemens, and Gamesa. On a worldwide basis, Chinese turbine manufacturers continued to occupy positions of prominence, with five of the top 10 spots in the ranking; to date, however, the growth of Chinese turbine manufacturers has been based almost entirely on sales to the Chinese market (though both Goldwind and Sany turbines were installed in the U.S. in 2015, with a limited number of Chinese turbines also installed in earlier years). Other than GE, no other U.S.-owned utility-scale turbine manufacturer plays a meaningful role in global or U.S. large-wind-turbine supply.

\footnotetext{
${ }^{16}$ Market share is reported in MW terms and is based on project installations in the year in question.
} 
Table 3. Annual U.S. Turbine Installation Capacity by Manufacturer

\begin{tabular}{|l|r|r|r|r|r|r|r|r|r|r|r|r|}
\hline & \multicolumn{10}{|c|}{ Turbine Installations (MW) } \\
\hline Manufacturer & 2005 & 2006 & 2007 & 2008 & 2009 & 2010 & 2011 & 2012 & 2013 & 2014 & 2015 \\
\hline GE Wind & 1,431 & 1,146 & 2,342 & 3,585 & 3,995 & 2,543 & 2,006 & 5,016 & 984 & 2,912 & 3,468 \\
\hline Vestas & 699 & 439 & 948 & 1,120 & 1,489 & 221 & 1,969 & 1,818 & 4 & 584 & 2,870 \\
\hline Siemens & 0 & 573 & 863 & 791 & 1,162 & 828 & 1,233 & 2,638 & 87 & 1,241 & 1,219 \\
\hline Acciona & 0 & 0 & 0 & 410 & 204 & 99 & 0 & 195 & 0 & 0 & 465 \\
\hline Gamesa & 50 & 74 & 494 & 616 & 600 & 566 & 154 & 1,341 & 0 & 23 & 402 \\
\hline Nordex & 0 & 0 & 3 & 0 & 63 & 20 & 288 & 275 & 0 & 90 & 138 \\
\hline Sany & 0 & 0 & 0 & 0 & 0 & 0 & 10 & 2 & 8 & 0 & 20 \\
\hline Goldwind & 0 & 0 & 0 & 0 & 5 & 0 & 5 & 155 & 0 & 0 & 8 \\
\hline Mitsubishi & 190 & 128 & 356 & 516 & 814 & 350 & 320 & 420 & 0 & 0 & 0 \\
\hline Suzlon & 0 & 92 & 198 & 738 & 702 & 413 & 334 & 187 & 0 & 0 & 0 \\
\hline Other & 4 & 2 & 50 & 587 & 973 & 180 & 502 & 1,086 & 4 & 2 & 2 \\
\hline
\end{tabular}

Source: AWEA project database

\section{The manufacturing supply chain continued to adjust to swings in domestic demand for wind equipment}

As the cumulative capacity of U.S. wind projects has grown over the last decade, foreign and domestic turbine equipment manufacturers have localized and expanded operations in the United States. Yet, the wind industry's domestic supply chain continues to deal with conflicting pressures: an upswing in near- to medium-term expected growth, but also strong international competitive pressures and possible reduced demand over time as the PTC is phased down. As a result, though many manufacturers increased the size of their U.S. workforce in 2015, market expectations for significant supply-chain expansion have become more pessimistic.

Figure 10 presents a non-exhaustive list of the more than 145 wind turbine and component manufacturing and assembly facilities operating in the United States at the end of 2015, focusing on the utility-scale wind market. ${ }^{17}$ Figure 11 segments those facilities by major component.

Only one new wind-related manufacturing facility opened in 2015: MM Composite, a composite parts manufacturer that had previously operated solely within the Siemens Fort Madison, Iowa blade facility. Located in Mount Pleasant, Iowa, the new facility will allow MM Composites to increase its overall workforce. Also announced in 2015 was a planned 2016 opening of a tower manufacturing facility in Amarillo, Texas by GRI Renewables. That facility is expected to employ up to 300 workers and manufacture up to 400 towers annually when it reaches full

\footnotetext{
${ }^{17}$ The data on existing, new, and announced manufacturing facilities presented here differ from those presented in AWEA (2016a) due, in part, to methodological differences. For example, AWEA includes data on a large number of smaller component suppliers that are not included in this report; the figure presented here also does not include research and development and logistics centers, or materials suppliers. As a result, AWEA (2016a) reports a much larger number of wind-related manufacturing facilities, over 500 in total.
} 
production. At the same time, at least three existing wind turbine or component manufacturing facilities were consolidated, closed, or stopped serving the industry in 2015.

Notwithstanding the recent supply chain consolidation and slow additions of new facilities, there remain a large number of domestic manufacturing facilities. Additionally, several manufacturers either expanded their workforce in 2015 to meet demand (e.g., Vestas, LM Windpower, MFG Aberdeen), remodeled facilities to meet industry standards (e.g., LM Windpower,), or began expansions of existing facilities (e.g., Vestas, MFG Aberdeen). As also shown in Figure 10, turbine and component manufacturing facilities are spread across the country. Many manufacturers have chosen to locate in markets with substantial wind power capacity or near already established large-scale original equipment manufacturers (OEMs). However, even states that are relatively far from major wind power markets have manufacturing facilities. Most states in the Southeast, for example, have wind manufacturing facilities despite the fact that there are few wind power projects in that region. Workforce considerations, transportation costs, and state and local incentives are among the factors that typically drive location decisions.

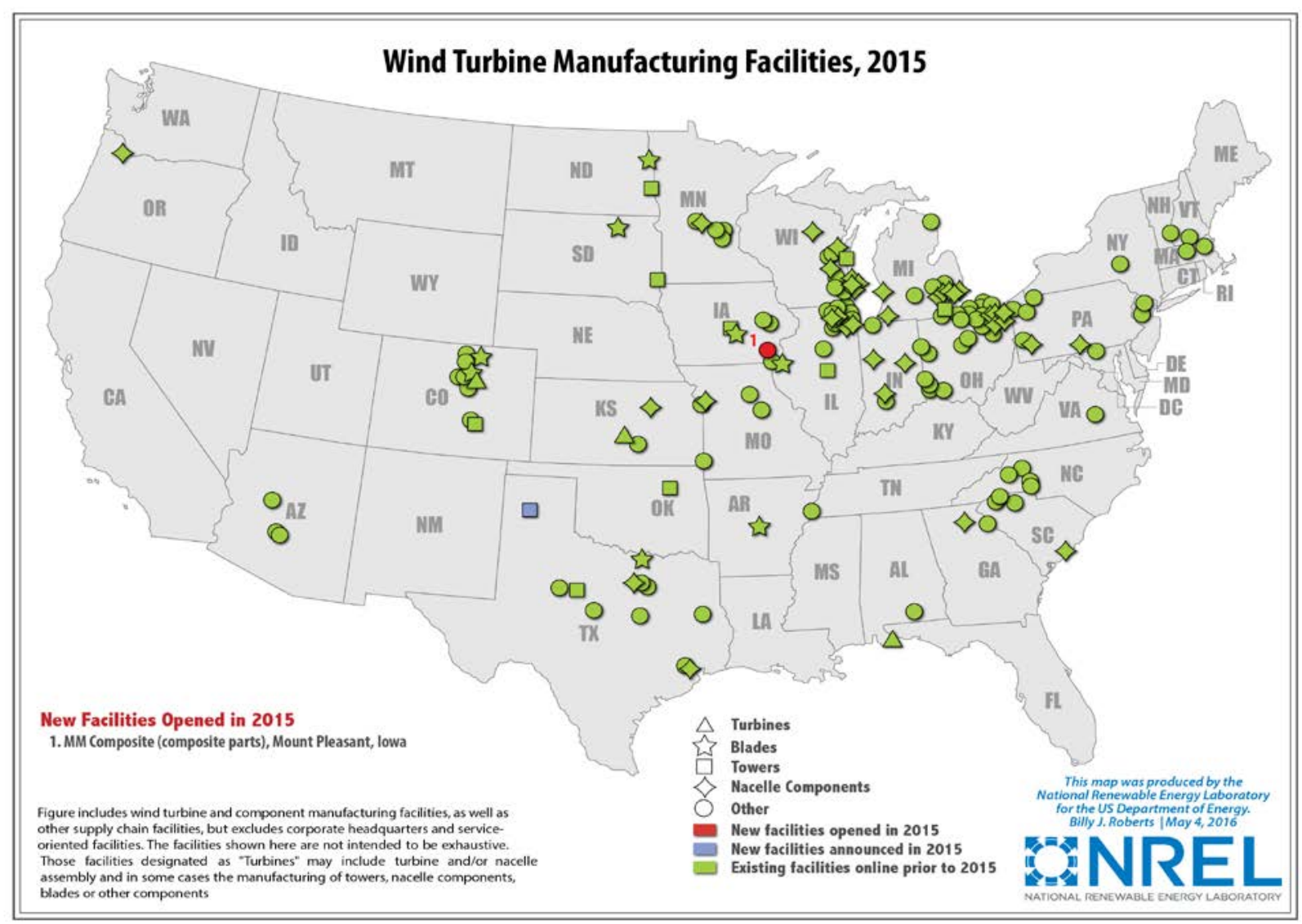

Figure 10. Location of existing and new turbine and component manufacturing facilities

Among the many other facets of the domestic supply chain, in 2010, 9 of the 11 wind turbine OEMs with the largest shares of the U.S. market owned at least one domestic manufacturing 
facility (Acciona, Clipper, DeWind, Gamesa, GE, Nordex, Siemens, Suzlon, and Vestas). ${ }^{18}$ Since that time, a number of these facilities have been closed, in part reflecting the increased concentration of the U.S. wind industry among the three top OEMs, demand uncertainty, and a desire to consolidate production at centralized facilities overseas in order to gain economies of scale. For example, though no final decision has been announced regarding Alstom's Amarillo, Texas facility, the plant was idled when the GE/Alstom merger was announced. Similarly, the Nordex/Acciona merger has left the future of the Acciona West Branch, Iowa facility in question. The plant is currently idled. Nonetheless, the three major OEMs active in the U.S. market (GE, Vestas, Siemens) still had one or more operating manufacturing facilities in the United States at the end of 2015. In contrast, a decade earlier (2004), there was only one active utility-scale wind energy OEM assembling nacelles in the United States (GE).

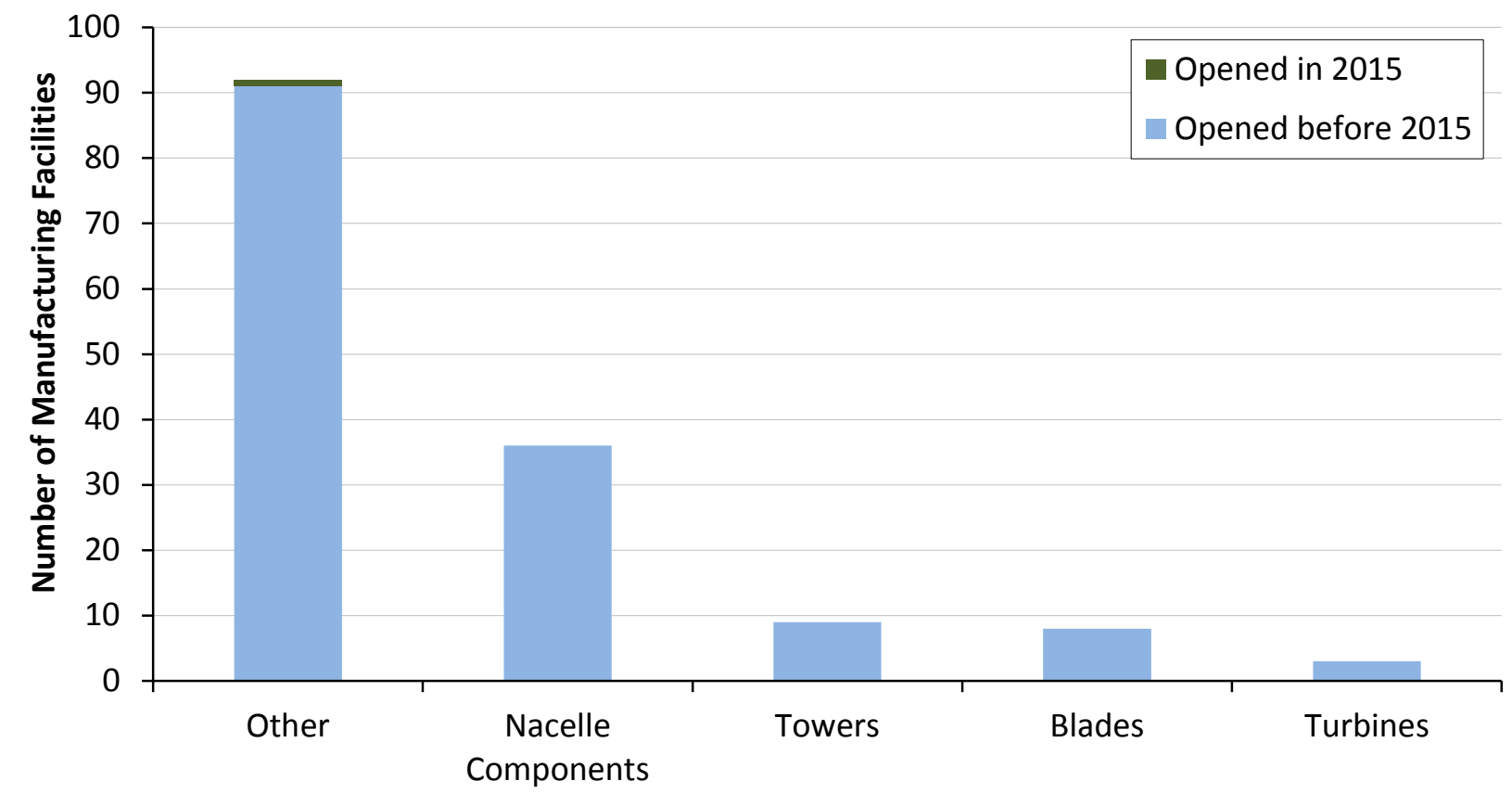

Note: Manufacturing facilities that produce multiple components are included in multiple bars. "Other" includes facilities that produce items such as: enclosures, power converters, slip-rings, inverters, electrical components, tower internals, climbing devices, couplings, castings, rotor hubs, plates, walkways, doors, bearing cages, fasteners, bolts, magnetics, safety rings, struts, clamps, transmission housings, embed rings, electrical cable systems, yaw/pitch control systems, bases, generator plates, slew bearings, flanges, anemometers, and template rings.

Source: National Renewable Energy Laboratory

Figure 11. Number of operating wind turbine and component manufacturing facilities in the U.S.

In aggregate, domestic turbine nacelle assembly capability — defined here as the "maximum" nacelle assembly capability of U.S. plants if all were operating at maximum utilization - grew from less than $1.5 \mathrm{GW}$ in 2006 to more than $13 \mathrm{GW}$ in 2012, before dropping to roughly 10 GW in 2015 (Figure 12; Bloomberg NEF 2015a, AWEA 2016a). In addition, AWEA (2016a) reports that U.S. manufacturing facilities have the capability to produce 10,500 individual blades $(\sim 7 \mathrm{GW})$ and more than 3,100 towers $(\sim 6.2 \mathrm{GW})$ annually. Figure 12 contrasts this

\footnotetext{
${ }^{18}$ Nacelle assembly is defined here as the process of combining the multitude of components included in a turbine nacelle to produce a complete turbine nacelle unit.
} 
equipment manufacturing capability with past U.S. wind additions as well as near-term forecasts of future U.S. installations (see Chapter 9, "Future Outlook"). It demonstrates that domestic manufacturing capability for blades, towers, and nacelle assembly is reasonably well balanced against anticipated near-term market demand. Such comparisons should be made with care, however, because maximum factory utilization is uncommon, and because turbine imports into and exports from the United States also impact the balance of supply and demand.

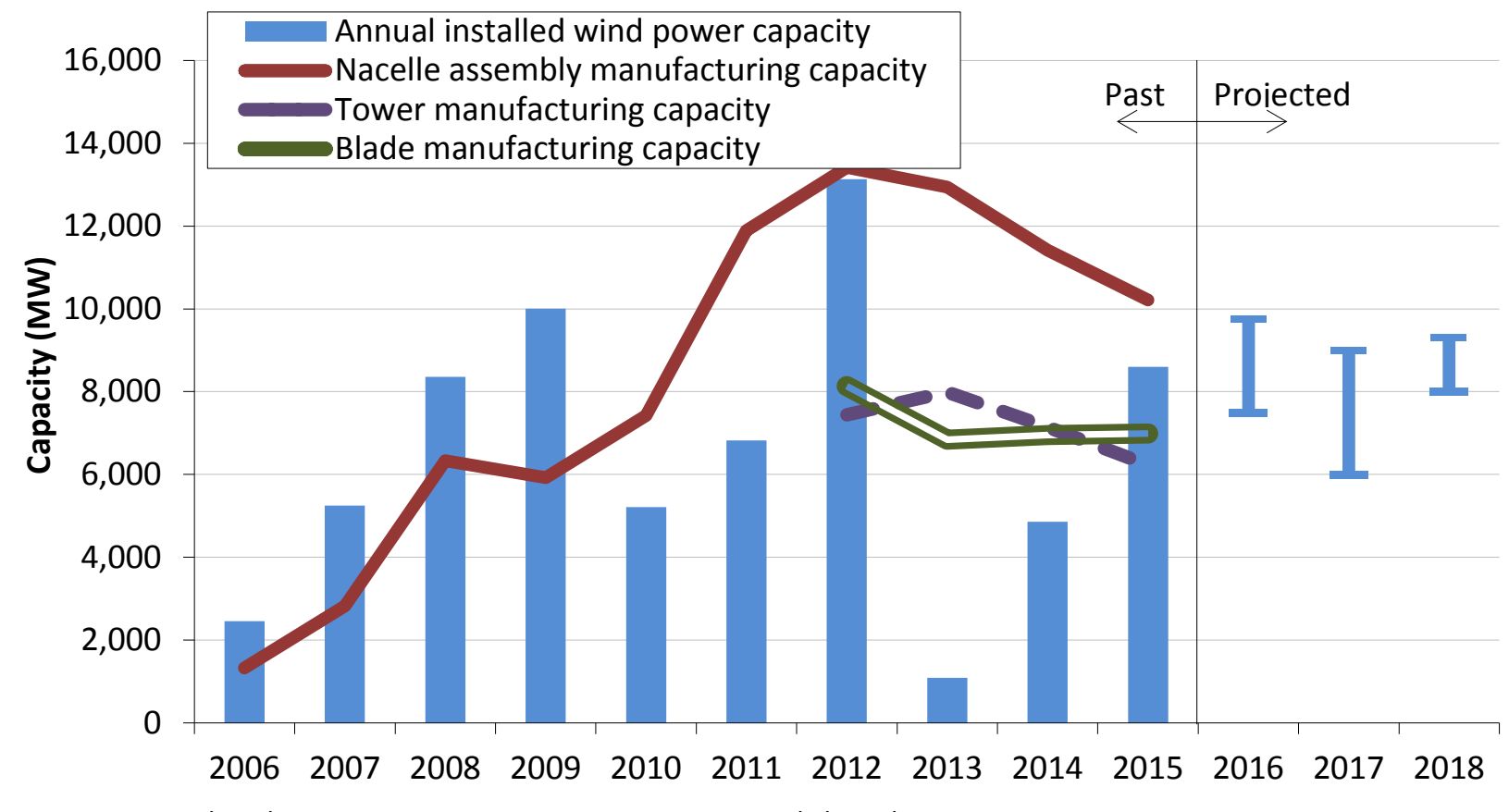

Source: AWEA, Bloomberg NEF, EIA, IHS, Navigant, MAKE, UBS, Berkeley Lab

Figure 12. Domestic wind manufacturing capability vs. U.S. wind power installations

Fierce competition throughout the supply chain has caused many manufacturers to execute costcutting measures globally and domestically in recent years. As a result of these cost savings, coupled with booming demand, the profitability of turbine OEMs has generally rebounded over the last three years, after a number of years in decline (Figure 13). ${ }^{19}$ Moreover, with recent and near-term expected continued strong growth in U.S. wind installations, wind-related job totals in the U.S. reached a new all-time high in 2015. AWEA (2016a) estimates that the wind industry employed 88,000 full-time ${ }^{20}$ workers in the United States at the end of 2015 - an increase of more than 15,000 from the end of 2014. The 88,000 jobs include, among others, those in the manufacturing and supply chain $(\sim 21,000)$; construction, development, and transportation $(\sim 38,000)$; and plant operations $(\sim 19,000)$. Consistent with the growth in wind power construction activity, the largest increase from 2014 to 2015 was seen in the construction, development, and transportation category.

\footnotetext{
${ }^{19}$ Figure 13 only reports data for those OEMs that are "pure-play" wind turbine manufacturers. GE and Siemensamong the largest turbine suppliers in the U.S. market (along with Vestas) — are not included because they are multinational conglomerates that do not report segmented financial data for their wind turbine divisions. Figure 13 depicts both EBIT (i.e., "earnings before interest and taxes," also referred to as "operating profit") and EBITDA (i.e., "earnings before interest, taxes, depreciation, and amortization") margins.

${ }^{20}$ Jobs are reported as full-time equivalents. For example, two people working full-time for 6 months are equal to one full-time job in that year.
} 


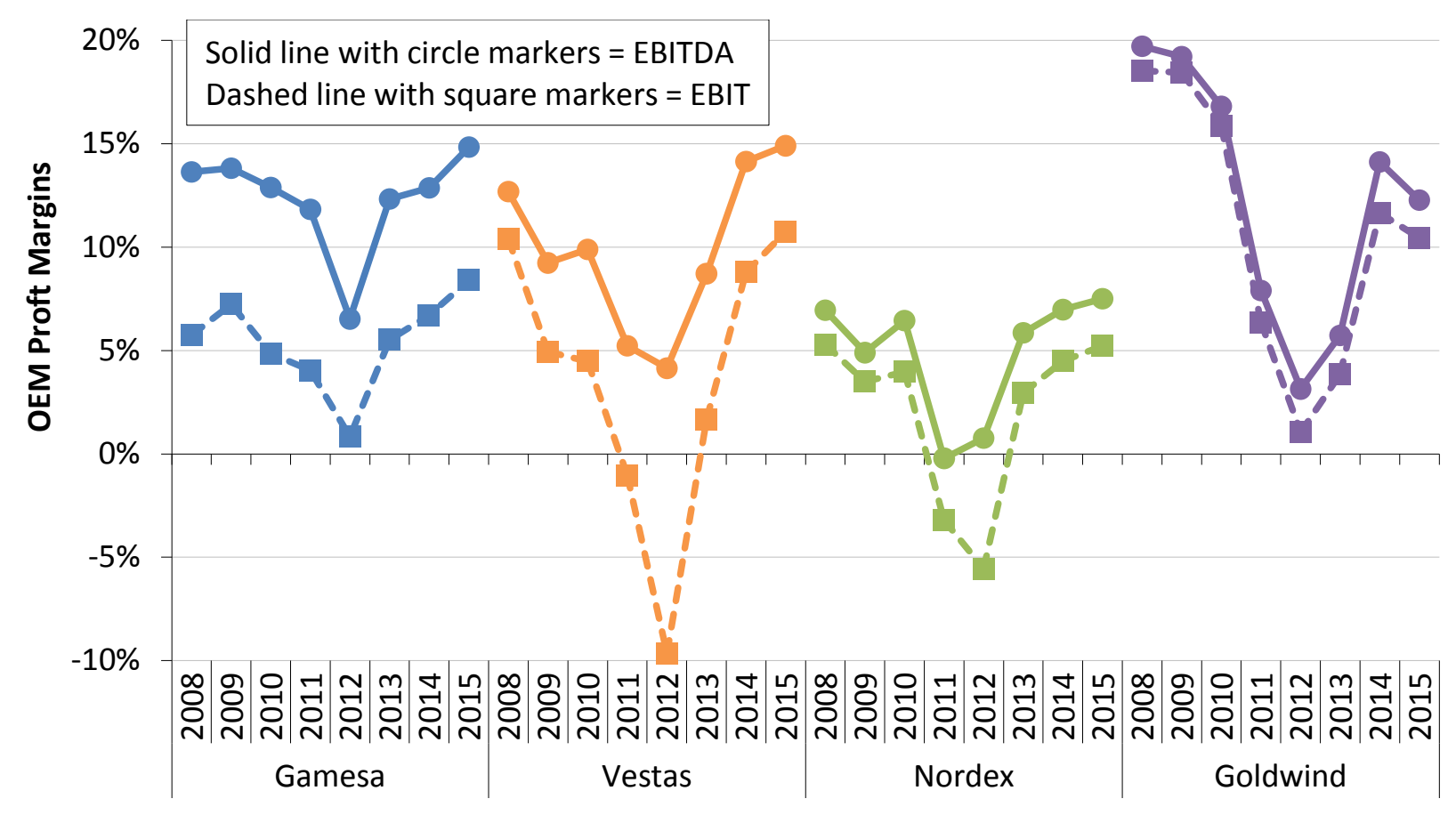

Note: EBITDA = earnings before interest, taxes, depreciation and amortization

Source: OEM annual reports and financial statements

Figure 13. Turbine OEM global profitability over time

\section{Domestic manufacturing content is strong for some wind turbine components, but the U.S. wind industry remains reliant on imports}

The U.S. wind sector is reliant on imports of wind equipment, though the level of dependence varies by component: some components have a relatively high domestic share, whereas other components remain largely imported. These trends are revealed, in part, by data on wind power equipment trade from the U.S. Department of Commerce. ${ }^{21}$

Figure 14 presents data on the dollar value of estimated imports to the United States of windrelated equipment that can be tracked through trade codes. Specifically, the figure shows imports of wind-powered generating sets and nacelles (i.e., nacelles with blades, nacelles without blades, and, when imported as part of the same transaction, other turbine components) as well as imports of select turbine components that are shipped separately from the generating sets and nacelles. ${ }^{22}$ The selected wind turbine components included in the figure consist only of those that can be tracked through trade codes: towers, generators (and generator parts), and blades and hubs.

Import estimates should be viewed with particular caution because the underlying data used to produce the Figure 14 are based on trade categories that are not all exclusive to wind energy (e.g., they could include generators for non-wind applications). Some of the import estimates

\footnotetext{
${ }^{21}$ See the appendix for further details on data sources and methods used in this section, including the specific trade codes considered.

${ }^{22}$ Wind turbine components such as blades, towers, and generators are included in the data on wind-powered generating sets and nacelles if shipped in the same transaction. Otherwise, these component imports are reported separately.
} 
shown in Figure 14 therefore required assumptions about the fraction of larger trade categories likely to be represented by wind turbine components. The error bars in Figure 14 account for uncertainty in these assumed fractions. In 2012 and 2013, all trade categories shown were either specific to or largely restricted to wind power, and so no error bars are shown. After 2013, only nacelles (when shipped alone) are included in a trade category that is not largely exclusive to wind, and so the error bars shown for 2014 and 2015 only reflect the uncertainty in nacelle imports. More generally, as noted earlier, Figure 14 excludes comprehensive data on the import of wind equipment, as not all such equipment is clearly identified in trade categories. The impact of this omission on import and domestic content is discussed later.

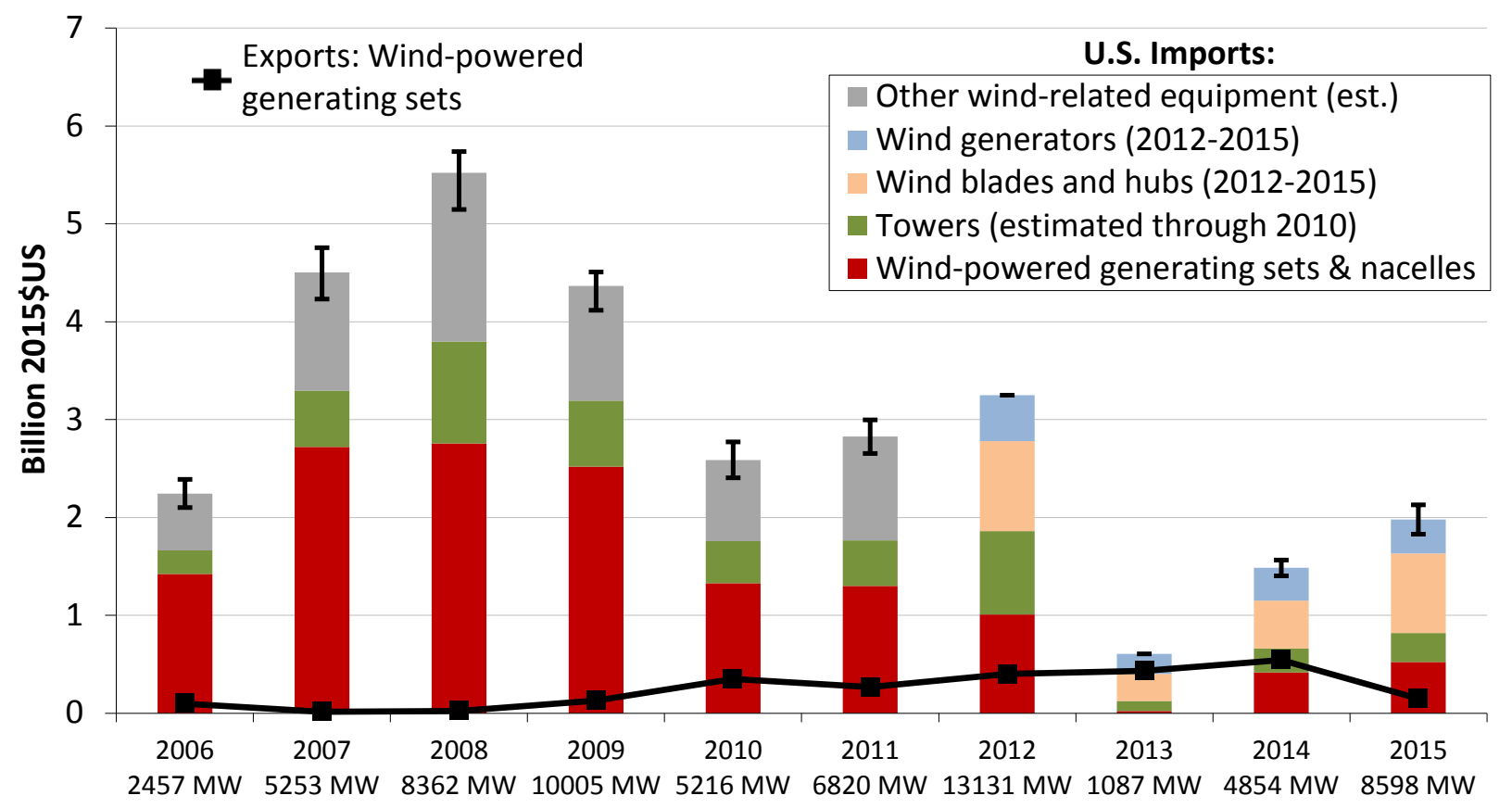

Source: Berkeley Lab analysis of data from USITC DataWeb: http://dataweb.usitc.gov

Figure 14. Estimated imports of wind-powered generating sets, towers, generators, and blades and hubs, as well as exports of wind-powered generating sets and towers and lattice masts

As shown, the estimated imports of tracked wind-related equipment into the United States substantially increased from 2006-2008, before falling through 2010, increasing somewhat in 2011 and 2012, and then dropping sharply in 2013 with the simultaneous drop in U.S. wind installations. In 2014 and 2015, as U.S. wind installations bounced back, so did imports of windrelated turbine equipment. These overall trends are driven by a combination of factors: changes in the share of domestically manufactured wind turbines and components (versus imports), changes in the annual rate of wind power capacity installations, and changes in wind turbine prices. Because imports of wind turbine component parts occur in additional, broad trade categories different from those included in Figure 14, the data presented here understate the aggregate amount of wind equipment imports into the United States.

Figure 14 also shows that exports of wind-powered generating sets from the United States have generally increased over time, rising from just \$16 million in 2007 to $\$ 544$ million in 2014 . The year 2015 was a notable exception to this trend, however, with exports falling to \$149 million. The largest destination markets for these exports over the entire 2006-2015 timeframe were 
Canada (60\%) and Brazil (27\%); 2015 exports were also dominated by Canada (52\%) and Brazil (19\%). U.S. exports of 'towers and lattice masts' in 2015 totaled an additional \$63 million (down from a peak of $\$ 170$ million in 2012), with $41 \%$ of these exports going to Canada and $28 \%$ going to Uruguay. The trade data for tower exports do not differentiate between tubular towers (primarily used in wind power applications) and other types of towers, unlike the import classification for towers from 2011-2015, which does differentiate. Although some of the tower exports are wind-related, the exact proportion is not known. Other wind turbine component exports are not reported because such exports are likely a small and/or uncertain fraction of broader trade category totals. Despite overall growth in exports from 2007 to 2014, the United States remained a sizable net importer of wind turbine equipment over this period. The sharp decrease in exports in 2015 may indicate that the fast-rising U.S. wind market absorbed much of the local production of wind turbine equipment.

Figure 15 shows the total value of selected, tracked wind-specific imports to the United States in 2015 , by country of origin, as well as the main "districts of entry" ${ }^{23}$ : forty percent of the import value in 2015 came from Asia (led by China), 38\% from Europe (led by Spain), and 22\% from the Americas (led by Brazil). The principal districts of entry for this wind equipment were Houston-Galveston, TX (29\%), Great Falls, MT (16\%), and Laredo, TX (9\%).

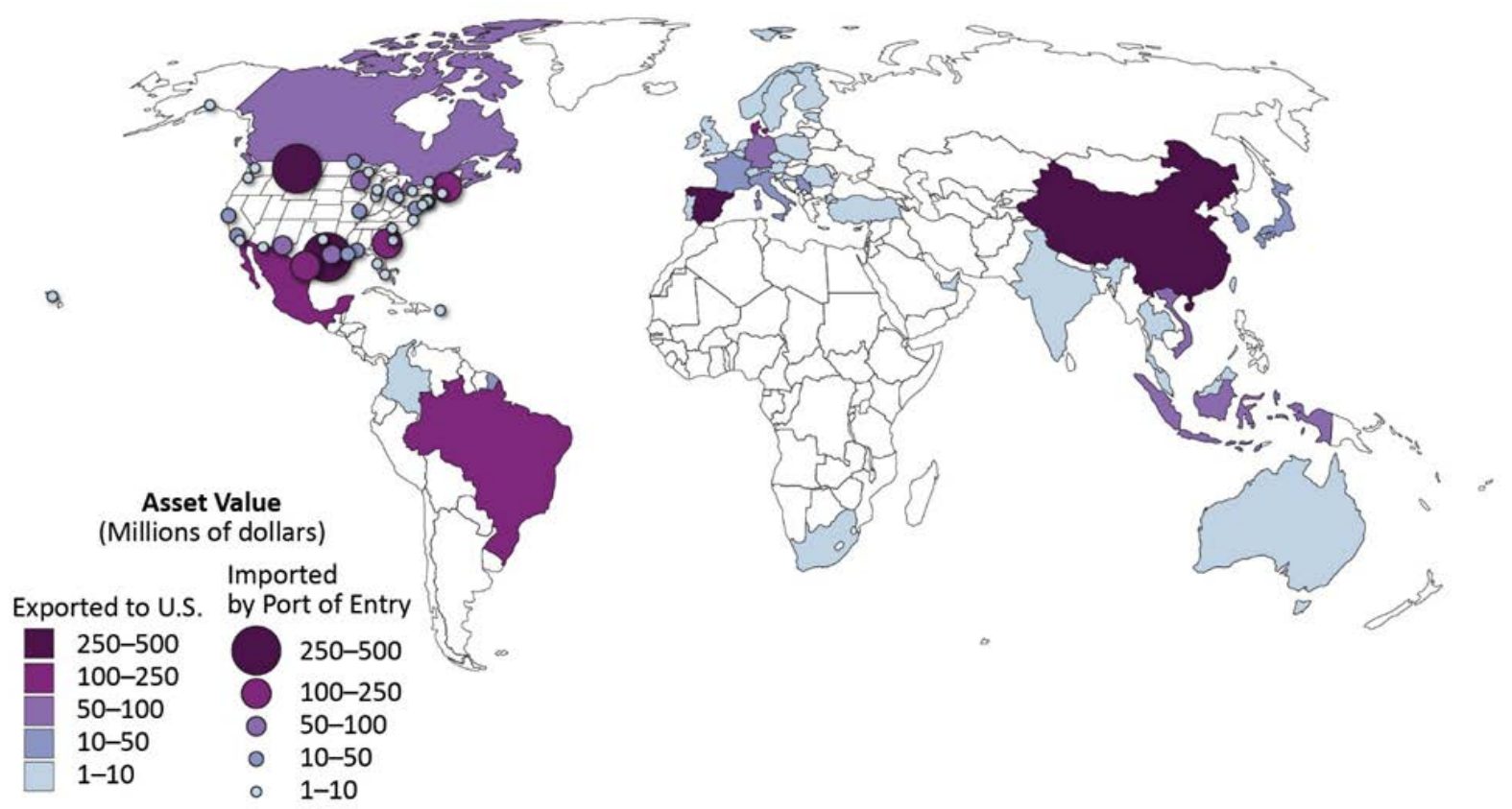

Figure 15. Summary map of tracked wind-specific imports in 2015: countries of origin and U.S. districts of entry

\footnotetext{
${ }^{23}$ The trade categories included here are all of the wind-specific import categories for 2015 (see the appendix for details), and so the 2015 total import volume considered in Figure 15 differs from that in Figure 14. As noted earlier, imports of many wind turbine component parts occur in broad trade categories not captured by those included in this analysis; additionally, in the case of nacelles without blades, the trade code is not exclusive to wind and so related imports are not included in Figure 15 (though they are included in Figure 14). As such, the data presented in Figure 15 understate the aggregate amount of wind equipment imports into the United States. Note also that "districts of entry" as used here refers to, in some cases, multiple points of entry located in the same geographic region; note also that goods may arrive at districts of entry by land, air, or sea.
} 
Looking behind the import data in more detail, and focusing on those trade codes that are largely exclusive to wind equipment, Figure 16 shows a number of trends over time in the origin of U.S. imports of wind-powered generating sets, tubular towers, wind blades and hubs, and wind generators and parts.

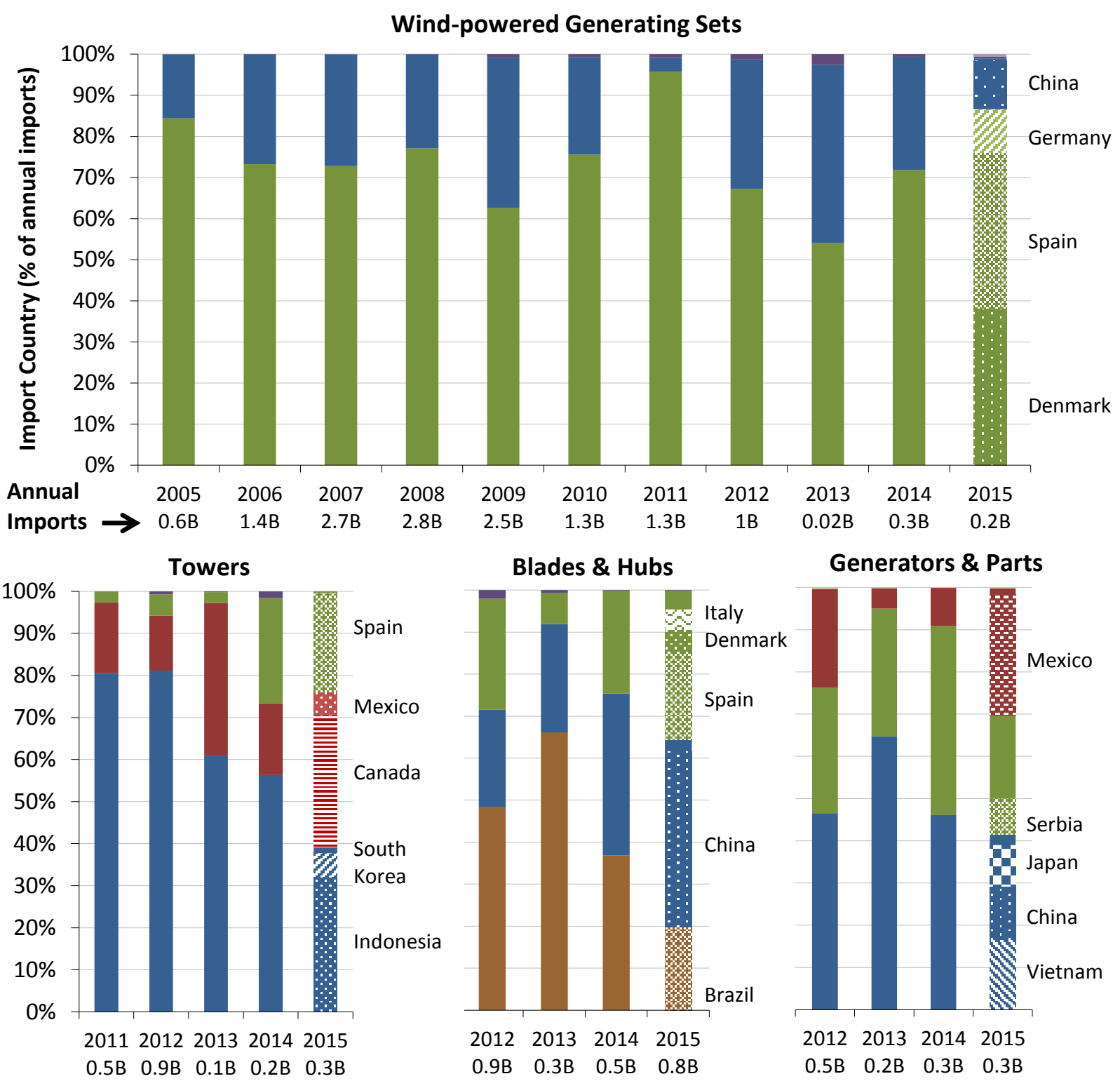

\section{Asia Europe $\quad$ North America $\quad$ South America $\quad$ Other}

Source: Berkeley Lab analysis of data from USITC DataWeb: http://dataweb.usitc.gov

Figure 16. Origins of U.S. imports of selected wind turbine equipment

For wind-powered generating sets, the primary source markets during 2005-2015 have been Europe and - to a lesser extent—Asia, with leading countries largely being those that are home to the major international turbine manufacturers: Denmark, Spain, Japan, India, and Germany. In 2015, imports of wind-powered generating sets were dominated by Denmark, Spain, Germany, 
and China, though the total import value was relatively low ( $\$ 227$ million). The share of imports of tubular towers from Asia was over 80\% in 2011 and 2012 (almost 50\% from China), with much of the remainder from Canada and Mexico. From 2013-2015, not only did the total import value decline relative to earlier years, but there were almost no imports from China and Vietnam-likely a result of the tariff measures that were imposed on wind tower manufacturers from these countries. Tower imports in 2015 came from a mix of countries from Asia (e.g., Indonesia and South Korea), Europe (e.g., Spain), and North America (e.g., Canada and Mexico). With regards to wind blades and hubs, China, Spain, and Brazil dominate as source markets (various other European countries play a somewhat lesser role), with China steadily increasing its market share over time. Finally, the import origins for wind-related generators and generator parts were distributed across a number of largely Asian and European countries, in addition to Mexico, from 2012 through 2015.

Because trade data do not track all imports of wind equipment, it is not possible to use those data to establish a clear overall distinction between import and domestic content. The trade data also do not allow for a precise estimate of the domestic content of specific wind turbine components. Nonetheless, based on those data and a variety of assumptions, Table 4 presents rough estimates of the domestic content for a subset of the major wind turbine components used in U.S. wind power projects in 2015. As shown, domestic content is strong for large, transportation-intensive components such as towers, blades and hubs, and nacelle assembly.

Table 4. Approximate Domestic Content of Major Components in 2015

\begin{tabular}{|c|c|c|}
\hline Towers & Blades \& Hubs & Nacelle Assembly \\
\hline $80-85 \%$ & $50-70 \%$ & $>85 \%$ of nacelle assembly \\
\hline
\end{tabular}

These figures, however, understate the wind industry's reliance on turbine and component imports. This is because significant wind-related imports occur under trade categories not captured in Table 4, including wind equipment (such as generator, mainframe, converter, pitch and yaw systems, main shaft, bearings, bolts, controls) and manufacturing inputs (such as foreign steel and oil used in domestic manufacturing). ${ }^{24}$

An alternative interview-based approach to estimating domestic content indicates overall domestic content of all wind turbine equipment used in the United States of about 40\% in 2012. When considering balance-of-plant costs as well, overall project-level domestic content in 2012 reached roughly $60 \%$. These interviews further revealed that domestic content is relatively high for blades, towers, nacelle assembly and nacelle covers, supporting the more recent analysis presented in Table 4. The domestic content of most of the equipment internal to the nacellemuch of which is not specifically tracked in wind-specific trade data-is considerably lower, typically well below $20 \%{ }^{25}$

\footnotetext{
${ }^{24}$ On the other hand, this analysis also assumes that all components imported into the United States are used for the domestic market and not used to assemble wind-powered generating sets that are exported from the United States. If this were not the case, the resulting domestic fraction would be higher than that presented here.

${ }^{25}$ The interviews and analysis were conducted by GLWN, under contract to Berkeley Lab.
} 


\section{The project finance environment remained strong in $\mathbf{2 0 1 5}$}

Most of the financing deals that closed in 2015 stemmed from the Tax Increase Prevention Act of 2014, which in late December 2014 extended the PTC's "construction start" deadline for one additional year, from the end of 2013 to the end of 2014 (effectively providing developers with just two weeks during which to start construction in order to qualify for the PTC). Subsequently, in March 2015, the IRS extended its safe harbor guidance for another year as well, enabling wind projects that had met the end-of-2014 construction start deadline to qualify for the PTC (without having to prove continuous effort) if online by the end of 2016.

As a result, 2015 was a big, somewhat rushed year for wind project finance. This was particularly true in the tax equity market, where project sponsors raised anywhere from $\$ 5.9$ billion (AWEA 2016a) to $\$ 6.4$ billion (Chadbourne \& Parke 2016b) of new tax equity in 2015up slightly from $\$ 5.7-\$ 5.8$ billion in 2014 and the largest single-year amount on record. On the debt side, AWEA (2016a) reports that 2,078 MW of new and existing wind capacity raised $\$ 2.9$ billion in debt in 2015, up from the $\$ 2.2$ billion raised in 2014, but well below the higher levels seen in previous years when the Section 1603 grant was available. ${ }^{26}$ Given the short lead time with the December 2014 PTC extension, most of the projects financed in 2015 will achieve commercial operations in 2016.

As shown in Figure 17, tax equity yields drifted slightly lower in 2015, to just below $8 \%$ on an after-tax unlevered basis. Debt interest rates bounced around somewhat, but ultimately headed lower throughout the year, with the 15-year benchmark fixed all-in interest rate starting off 2016 below $4 \%\left(\sim 2.5 \%\right.$ on a post-tax basis $\left.{ }^{27}\right)$ for the first time in the more-than-eleven-year history of the graph. As a result, the spread between tax equity yields and 15-year term debt (on a post-tax basis) stood at more than 5\% as of May 2016 - its highest level since 2009. The intransigence of this spread continues to vex those wind project owners that lack tax appetite, and so must finance their projects with relatively expensive tax equity rather than increasingly cheap debt (Chadbourne \& Parke 2016a). Partnership flip structures ${ }^{28}$ remained the dominant tax equity vehicle, while banks continued to focus more on shorter-duration loans (7-10 year mini-perms

\footnotetext{
${ }^{26}$ From 2009-2012 (i.e., the years in which the Section 1603 grant was available), some project sponsors who lacked tax appetite financed their projects using the grant in combination with project-level term debt, carrying forward depreciation losses as necessary and foregoing tax equity altogether. With the grant no longer available, most projects now elect the PTC (instead of the ITC), and rely upon third-party tax equity investors to monetize the losses and credits. Because most tax equity investors will not allow leverage on projects in which they invest (Chadbourne \& Parke 2016a, 2016b), the expiration of the Section 1603 grant for wind and the correspondingly greater reliance on the PTC could be a contributor to the decline in debt raised by new wind projects in 2013 through 2015.

${ }^{27}$ The returns of equity investors in renewable projects are often expressed on an after-tax basis, because of the significant value that federal tax benefits provide to such projects (e.g., after-tax returns can be higher than pre-tax returns). In order to accurately compare the cost of debt (which is quoted on a pre-tax basis) to tax equity (described in after-tax terms), one must convert the pre-tax debt interest rate to its after-tax equivalent (to reflect the taxdeductibility of interest payments) by multiplying it by $65 \%$, or $100 \%$ minus an assumed marginal tax rate of $35 \%$. ${ }^{28}$ A "partnership flip" is a project finance structure in which the developer or project sponsor partners with a thirdparty tax equity investor to jointly invest in and own the project. Initially, allocations of tax benefits are skewed heavily in favor the tax equity partner (which is able to efficiently monetize the tax benefits), but eventually "flip" in favor of the project sponsor partner once the tax benefits have been largely exhausted. Cash is also allocated between the partners, with one or more "flip" events, but in recent years has been increasingly directed towards the project sponsor to the extent possible, in order to support back leverage or dividend payments to YieldCo investors.
} 
remained the norm ${ }^{29}$ ), leaving longer-duration, fully amortizing loans to institutional lenders (Chadbourne \& Parke 2016b).

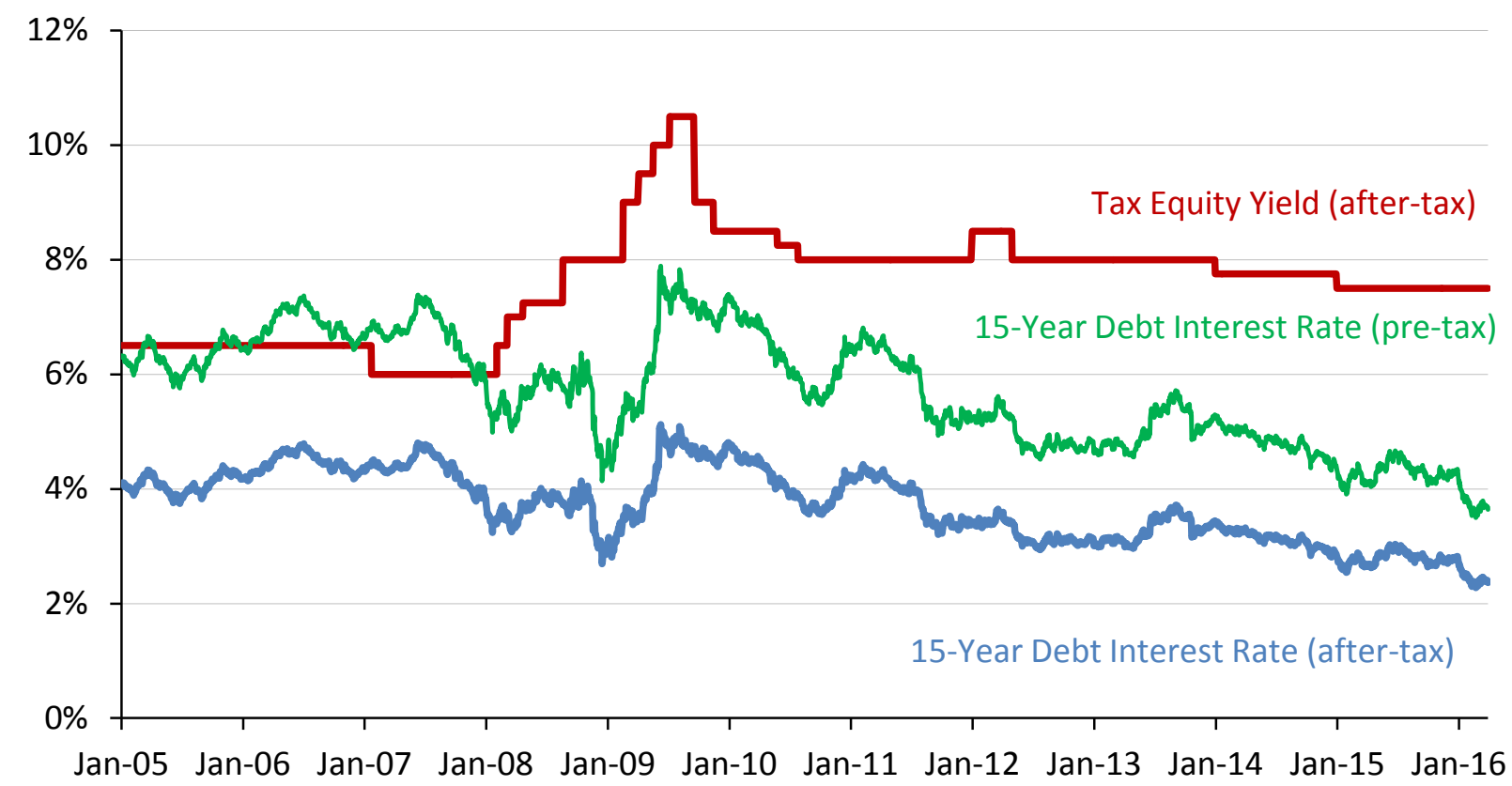

Source: Federal Reserve Board (2016), Bloomberg NEF (2016e)

Figure 17. Cost of 15-year debt and tax equity for utility-scale wind projects over time

Looking ahead, financing in both the tax equity and debt markets is likely to remain active in 2016 and beyond, thanks to the five-year tax credit extension (with phase down) that became law in late December 2015 (see Chapter 8, Policy and Market Drivers, for more details on this longterm extension and phase-down). In May 2016, the IRS also increased the safe harbor window from two years to four years, effectively allowing a wind project that starts construction before the end of 2016 and achieves commercial operations before the end of 2020 to qualify for the PTC at full value. The tax credit will progressively diminish for projects that start construction in 2017-2019 (and that achieve commercial operations from 2021-2023), which suggests that 2016 and 2017 could represent the peak of project finance activity for the foreseeable future (see pages 68-69 for a lengthier discussion of the PTC phase down schedule).

\section{IPPs own the vast majority of wind assets built in 2015}

Independent power producers (IPPs) own 7,290 MW or $85 \%$ of the $8,598 \mathrm{MW}$ of new wind capacity installed in the United States in 2015 (Figure 18). More than 1,000 MW are owned by investor-owned utilities (IOUs), including MidAmerican (502 MW), Xcel Energy (350 MW), Montana-Dakota Utilities (107.5 MW), and Northwestern Energy (80 MW), while publicly

${ }^{29}$ A "mini-perm" is a relatively short-term (e.g., 7-10 years) loan that is sized based on a much longer tenor (e.g., 15-17 years) and therefore requires a balloon payment of the outstanding loan balance upon maturity. In practice, this balloon payment is often paid from the proceeds of refinancing the loan at that time. Thus, a 10-year mini-perm might provide the same amount of leverage as a 17-year fully amortizing loan but with refinancing risk at the end of 10 years. In contrast, a 17-year fully amortizing loan would be repaid entirely through periodic principal and interest payments over the full tenor of the loan (i.e., no balloon payment required and no refinancing risk). 
owned utilities (POUs) do not own any of the new wind power capacity brought online in 2015 . Finally, $266 \mathrm{MW}(3 \%)$ fall into the "other" category of projects owned by neither IPPs nor utilities (e.g., towns, schools, businesses, farmers); notably, IKEA owns most of this capacity $(263 \mathrm{MW})$ through two wind projects - one in Illinois and one in Texas. ${ }^{30}$ Of the cumulative installed wind power capacity at the end of 2015, IPPs own $83 \%$ and utilities own $15 \%$ (13\% IOU and $2 \%$ POU), with the remaining $2 \%$ falling into the "other" category.
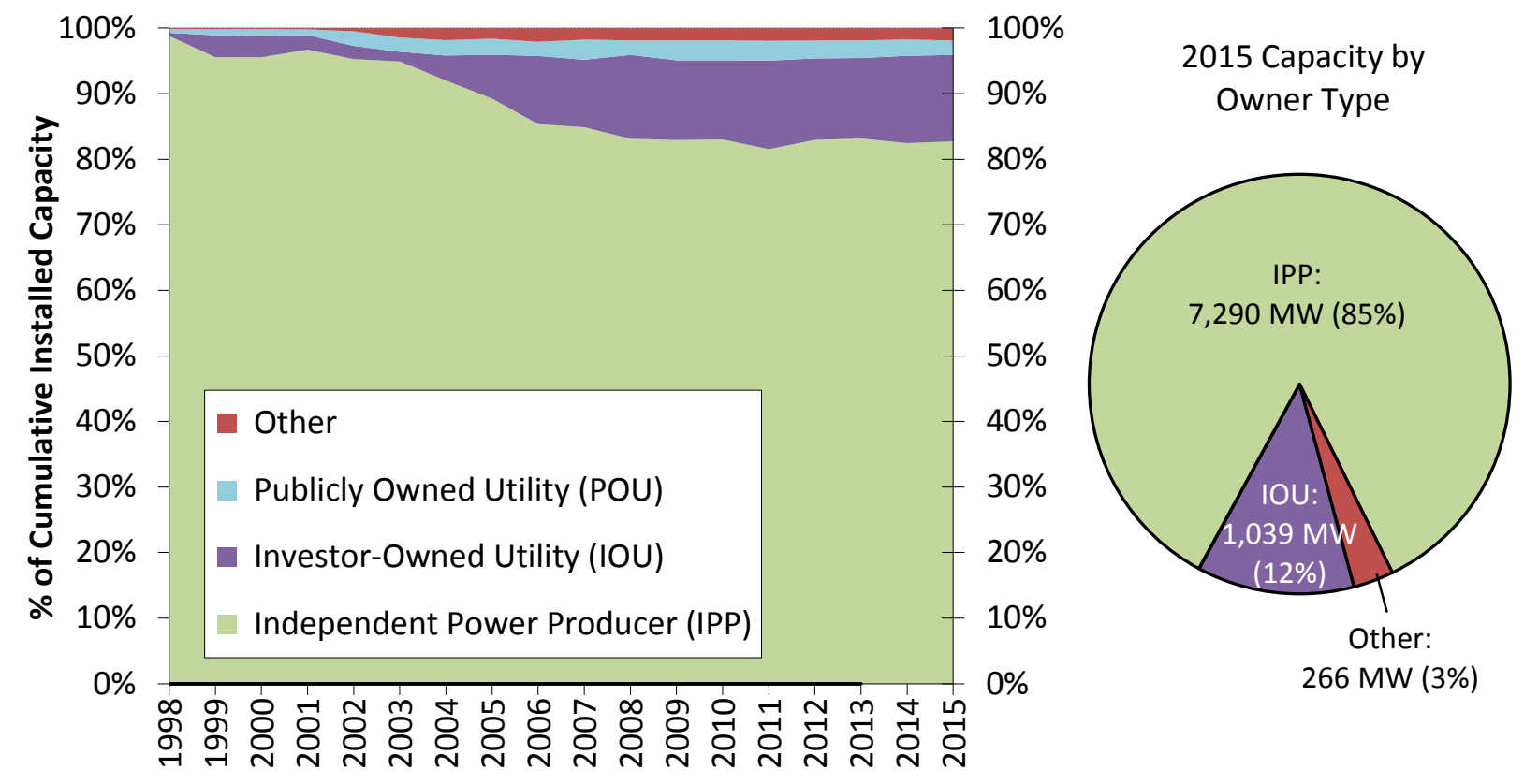

Source: Berkeley Lab estimates based on AWEA project database

Figure 18. Cumulative and 2015 wind power capacity categorized by owner type

\section{Long-term contracted sales to utilities remained the most common off-take arrangement, but direct retail sales gained ground}

Electric utilities continued to be the dominant off-takers of wind power in 2015 (Figure 19), either owning (12\%) or buying (48\%) power from $60 \%$ of the new capacity installed last year (with the $60 \%$ split between $37 \%$ IOU and 23\% POU). On a cumulative basis, utilities own $(15 \%)$ or buy $(53 \%)$ power from $68 \%$ of all wind power capacity installed in the United States (with the 68\% split between $48 \%$ IOU and 20\% POU).

Merchant/quasi-merchant projects accounted for 29\% of all new 2015 capacity and 24\% of cumulative capacity. Merchant/quasi-merchant projects are those whose electricity sales revenue is tied to short-term contracts and/or wholesale spot electricity market prices (with the resulting

\footnotetext{
${ }^{30}$ Many of the "other" projects, along with some IPP- and POU-owned projects, might also be considered "community wind" projects that are owned by or benefit one or more members of the local community to a greater extent than typically occurs with a commercial wind project. According to AWEA (2016a), just 16.9 MW (0.2\%) of 2015 wind capacity additions qualified as community wind projects.
} 
price risk commonly hedged over a 10- to 12 -year period ${ }^{31}$ ) rather than being locked in through a long-term PPA.

Perhaps the biggest story of 2015 with respect to off-take agreements was the rise of direct retail purchasers of wind (and solar) power, including both corporate and non-corporate off-takers, which together are characterized in Figure 19 as "direct retail" off-takers. Though barely visible in the cumulative portion of Figure 19, direct retail purchases accounted for $844 \mathrm{MW}$ or $10 \%$ of the new wind power capacity installed in the United States in 2015 . This modest $10 \%$ portion is well below the $52 \%$ of total wind capacity contracted through PPAs in 2015 that involve nonutility buyers, as reported by AWEA (2016a). The difference is that the $10 \%$ pertains to projects that achieved commercial operation in 2015 , whereas the $52 \%$ pertains to PPAs that were executed in 2015 - in many cases for projects that will come online in 2016 or 2017 (or beyond). According to AWEA (2016a), this 52\% is up from 23\% in 2014 and just 5\% in 2013, suggesting that the direct retail segment of Figure 19 should continue to expand in future years.

Power marketers are defined here to include commercial intermediaries that purchase power under contract and then resell that power to others. ${ }^{32}$ Though power marketers were very active throughout the first decade of this century following the initial wave of electricity market restructuring, their influence has waned in recent years: just $6 \%$ of cumulative wind power capacity in the United States sells to power marketers, down from more than $20 \%$ in the early 2000s.

Finally, just $3 \mathrm{MW}(0.0 \%)$ of the wind power additions in 2015 that used turbines larger than 100 $\mathrm{kW}$ were interconnected on the customer side of the utility meter, with the power being consumed on site rather than sold.

\footnotetext{
${ }^{31}$ Hedges are often structured as a "fixed-for-floating" power price swap — a purely financial arrangement whereby the wind power project swaps the "floating" revenue stream that it earns from spot power sales for a "fixed" revenue stream based on an agreed-upon strike price. For some projects, the hedge is structured in the natural gas market rather than the power market.

${ }^{32}$ These intermediaries include the wholesale marketing affiliates of large IOUs, which may buy wind on behalf of their load-serving affiliates.
} 


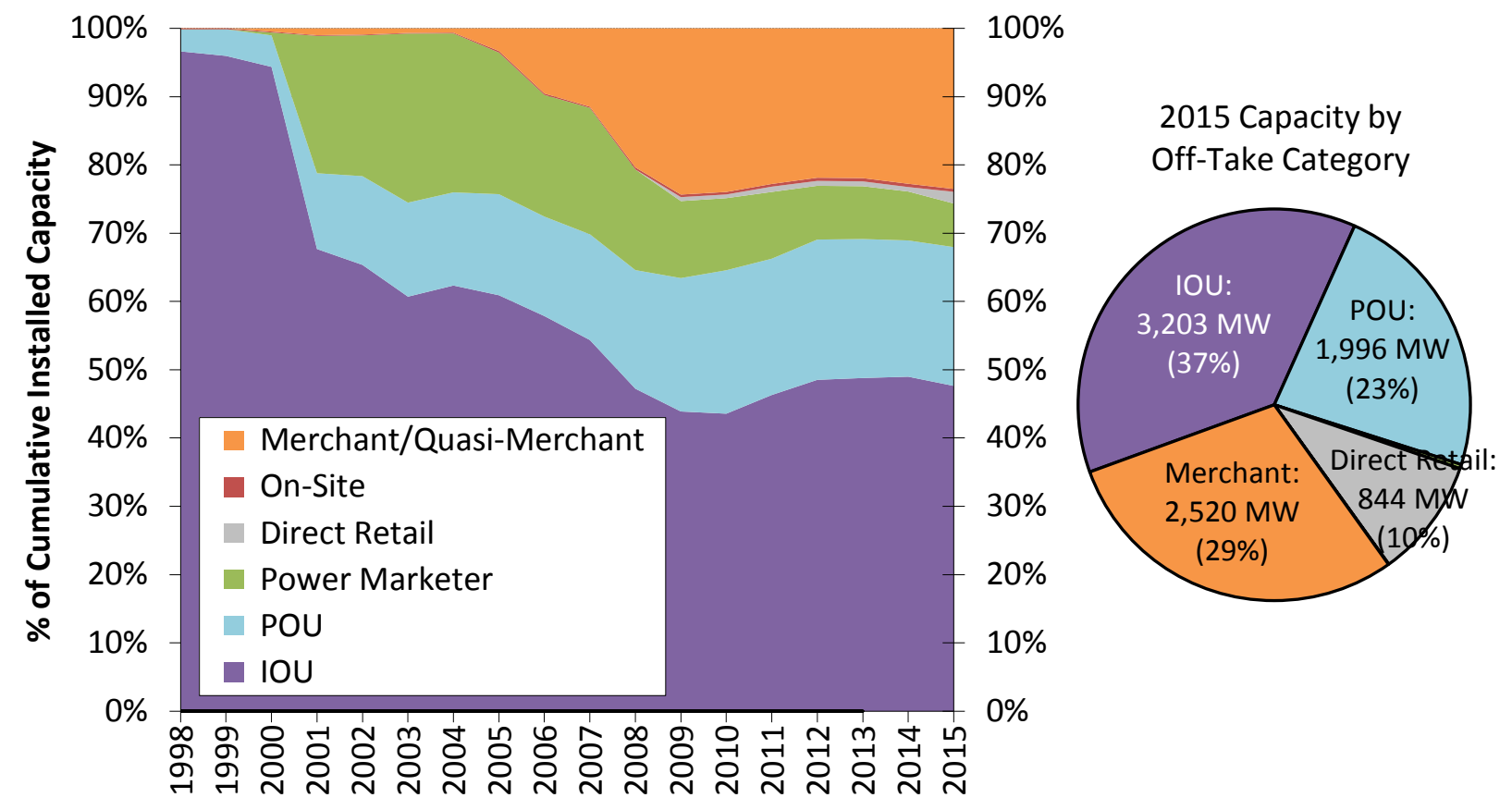

Source: Berkeley Lab estimates based on AWEA project database

Figure 19. Cumulative and 2015 wind power capacity categorized by power off-take arrangement 


\section{Technology Trends}

\section{Turbine nameplate capacity, hub height, and rotor diameter have all increased significantly over the long term}

The average nameplate capacity of the newly installed wind turbines in the United States in 2015 was $2.0 \mathrm{MW}$, up $180 \%$ since $1998-1999$ (Figure 20). ${ }^{33}$ The average hub height of turbines installed in 2015 was 82.0 meters, up 47\% since 1998-1999. Average rotor diameters have increased at a more rapid pace than hub heights in the United States, especially in recent years. The average rotor diameter of wind turbines installed in 2015 was 102.0 meters, up $113 \%$ since 1998-1999, which translates into a 355\% growth in rotor swept area. These trends in hub height and rotor scaling are two of several factors impacting the project-level capacity factors highlighted later in this report.

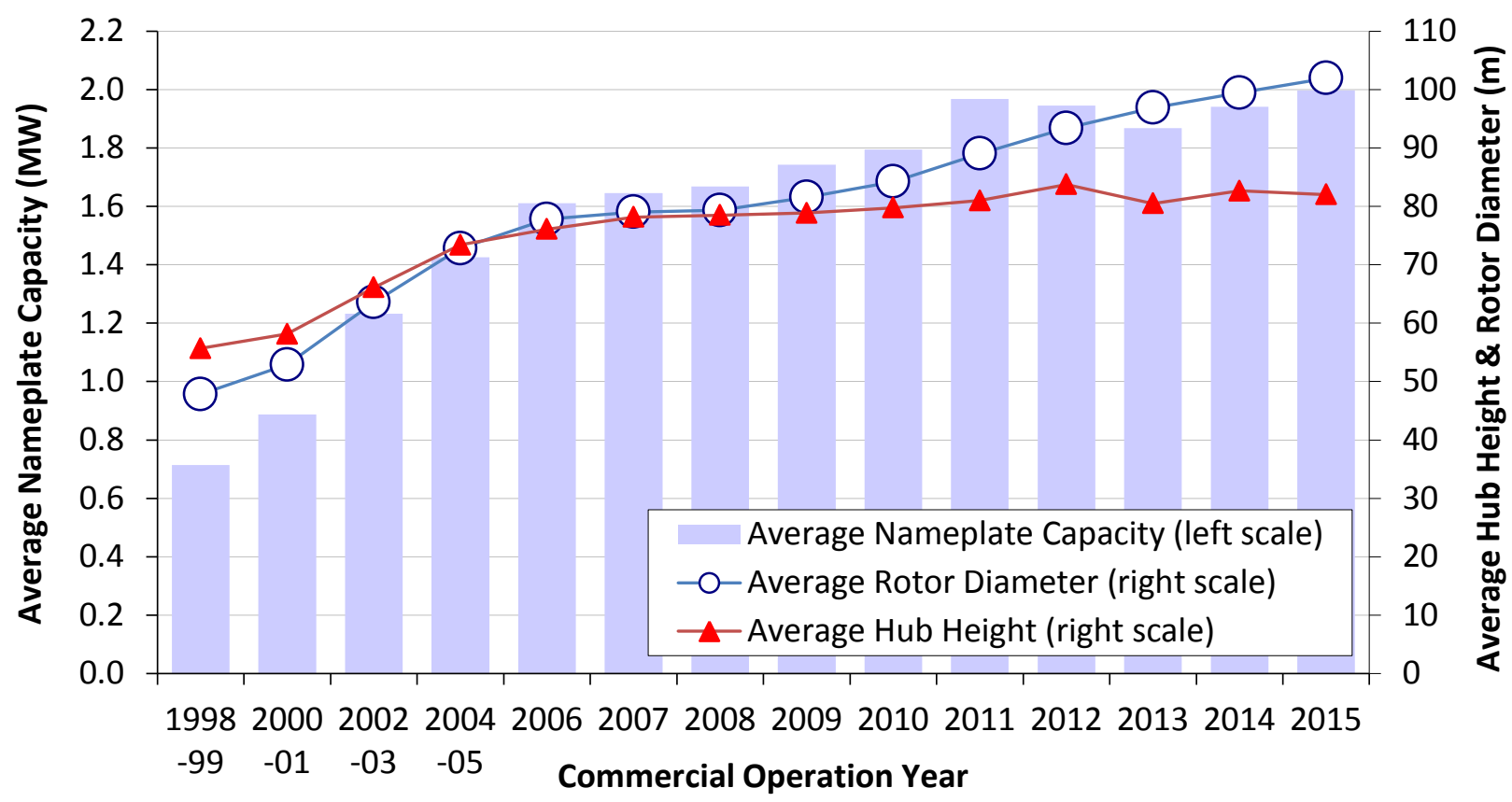

Figure 20. Average turbine nameplate capacity, rotor diameter, and hub height installed during period

\section{Growth in rotor diameter has outpaced growth in nameplate capacity and hub height in recent years}

As indicated in Figure 20, and as detailed in Figures 21-23, rotor diameter scaling has been especially significant over the last six years - more so than increases in nameplate capacity and hub heights, both of which have seen a stabilization of the long-term trend in recent years.

\footnotetext{
${ }^{33}$ Figure 20 (as well as a number of the other figures and tables included in this report) combines data into both 1and 2-year periods in order to avoid distortions related to small sample size in the PTC lapse years of 2000, 2002, and 2004; although not a PTC lapse year, 1998 is grouped with 1999 due to the small sample of 1998 projects. Though 2013 was a slow year for wind additions, it is shown separately here despite the small sample size.
} 
Starting with turbine nameplate capacity, Figure 21 presents not only the trend in average nameplate capacity (as also shown earlier, in Figure 20) but also how the prevalence of different turbine capacity ratings has changed over time. The average nameplate capacity of newly installed wind turbines has largely held steady since 2011, and the longer-term pace of growth started to slow after 2006. While it took just six years (2000-2005) for MW-class turbines to almost totally displace sub-MW-class turbines, it took another seven years (2006-2012) for multi-MW-class turbines (i.e., $2 \mathrm{MW}$ and above) to gain nearly equal market share with MWclass turbines. The years 2013 and 2014 showed some reversal of that trend, but 2015 was the first year in which $>2 \mathrm{MW}$ turbines were the majority of those installed.

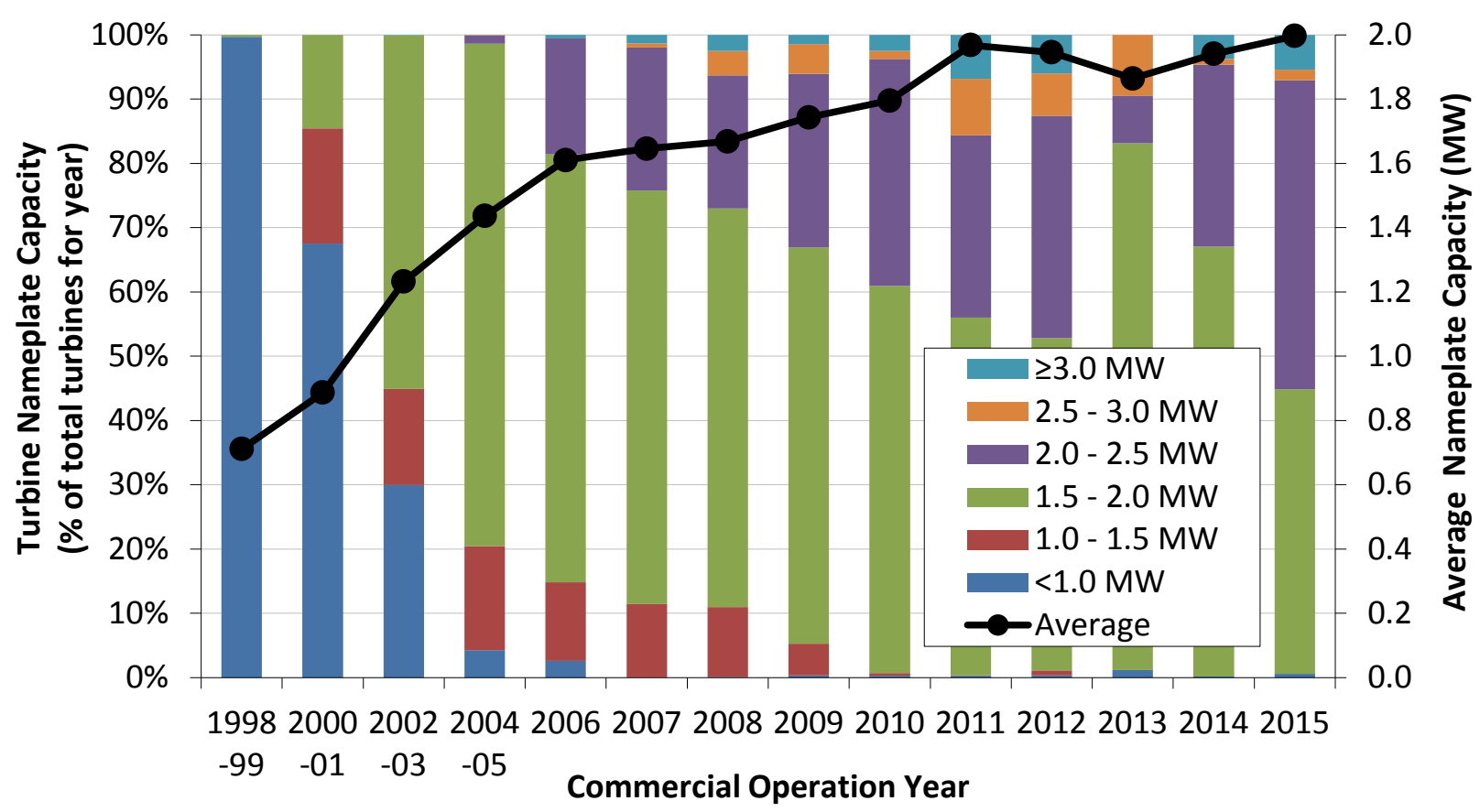

Figure 21. Trends in turbine nameplate capacity

As with nameplate capacity, the average hub height of wind turbines has largely held constant since 2011 (Figure 22). More generally, growth in average hub height has been slow since 2005, with 80 meter towers dominating the overall market. Towers that are 90 meters and taller started to penetrate the market in 2011, however, a trend that has remained steady into 2015, equating to roughly $15 \%$ of the market in that year. Finally, although we saw the emergence of $>100$ meter towers as early as 2007, that segment of the market peaked in 2012 when $16 \%$ of newly installed turbines were taller than 100 meters; since 2012, only $1 \%$ or less of newly installed turbines in each year (including 2015) have featured towers that tall. 


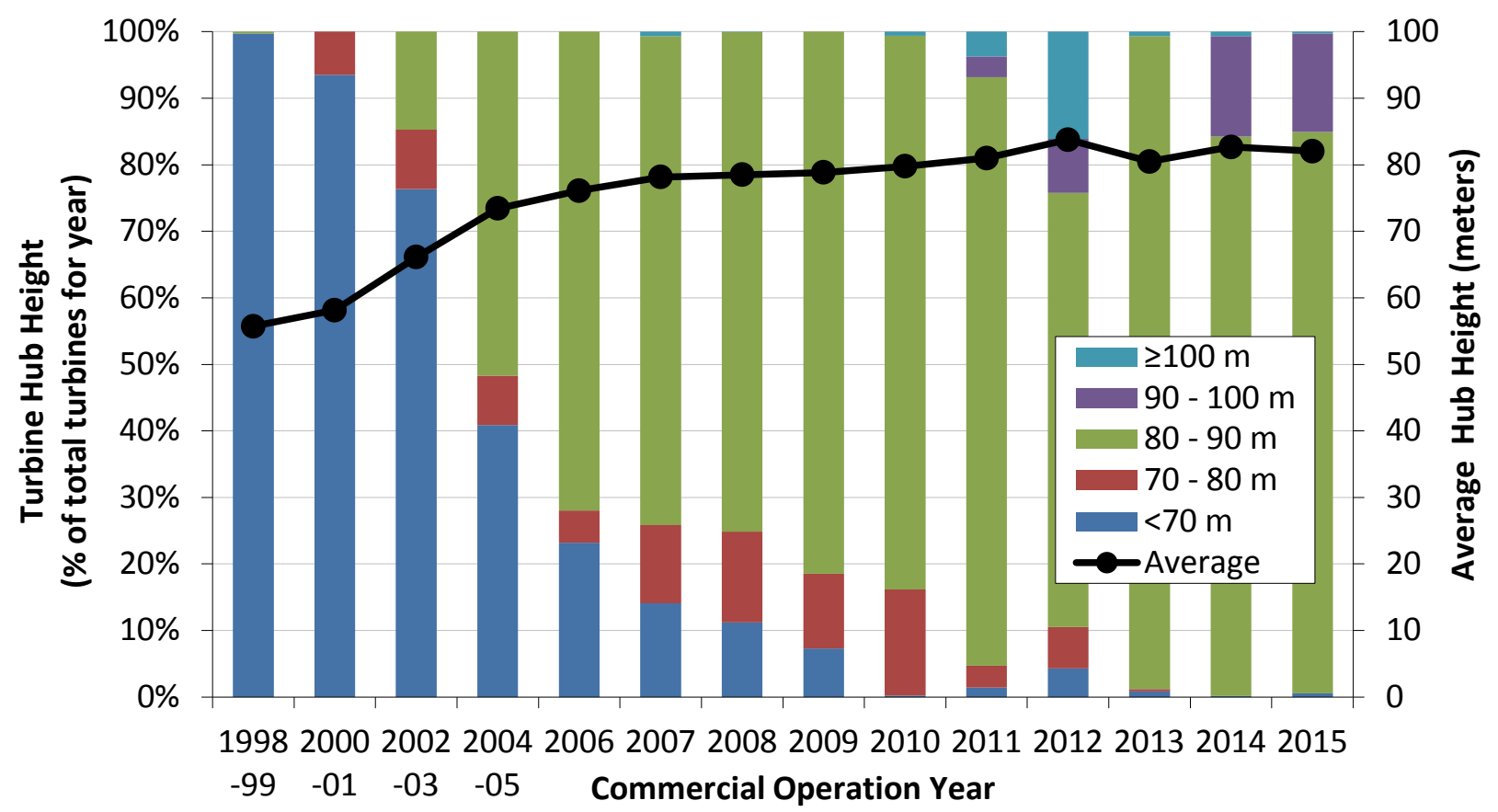

Figure 22. Trends in turbine hub height

The movement towards larger-rotor machines has dominated the U.S. industry in recent years, with OEMs progressively introducing larger-rotor options for their standard turbine offerings and introducing new turbines that feature larger rotors, despite steady average nameplate capacity (Figure 21) and hub heights (Figure 22). As shown in Figure 23, this recent increase has been especially apparent since 2009. In 2008, no turbines employed rotors that were 100 meters in diameter or larger. By 2012, 47\% of newly installed turbines featured rotors of at least that diameter, and in 2015 the percentage grew to $86 \%$. Rotor diameters of 110 meters or larger, meanwhile, started penetrating the market in 2012 ; in $2015,20 \%$ of newly installed turbines featured rotors of that size. 


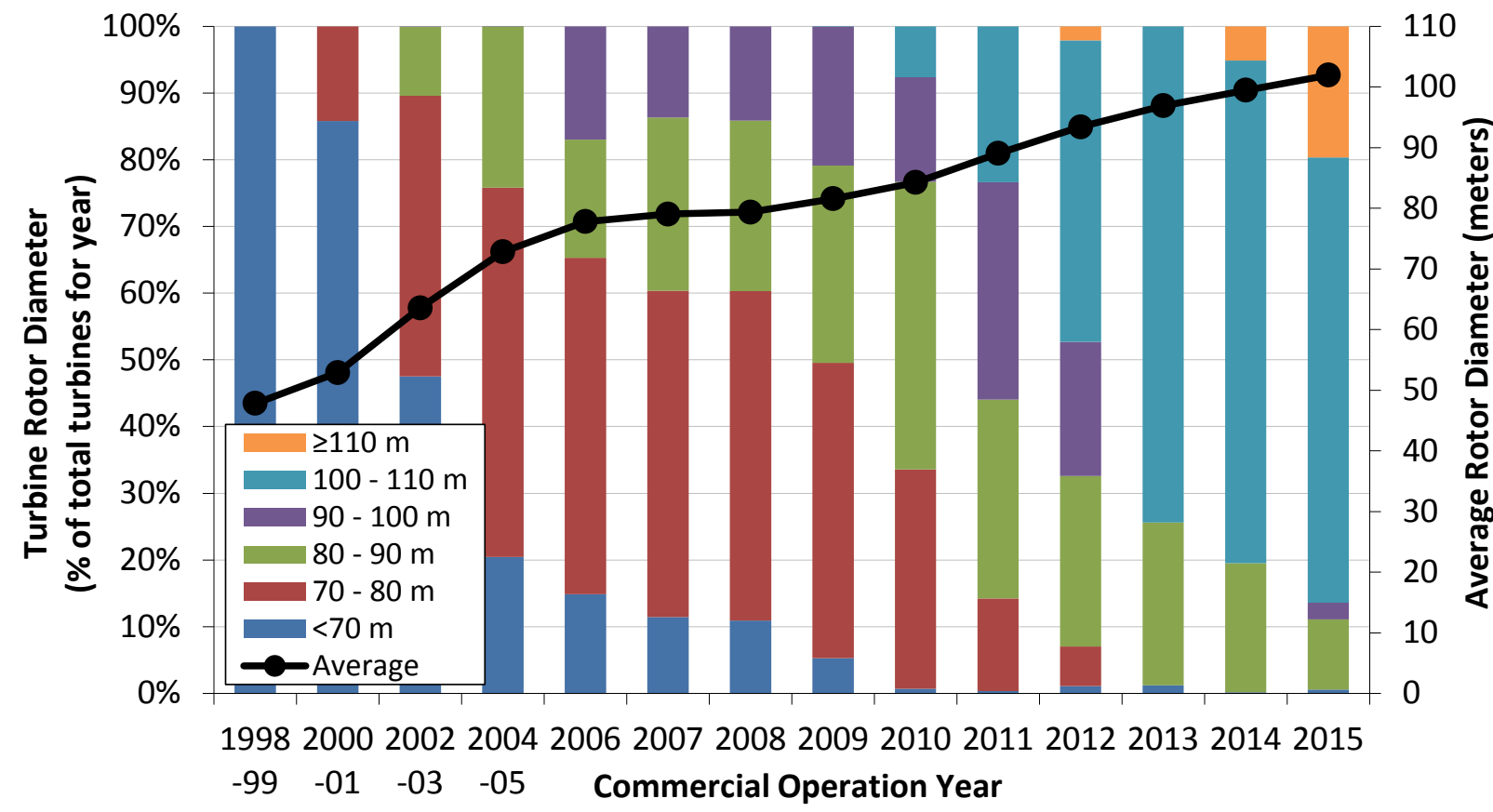

Figure 23. Trends in turbine rotor diameter

\section{Turbines originally designed for lower wind speed sites have rapidly gained market share}

Though trends in the average nameplate capacity, hub height, and rotor diameter of turbines have been notable, the growth in the swept area of the rotor has been particularly rapid. With growth in average swept area (in $\mathrm{m}^{2}$ ) outpacing growth in average nameplate capacity (in W), there has been a decline in the average "specific power" (in W/ $\mathrm{m}^{2}$ ) among the U.S. turbine fleet over time, from $394 \mathrm{~W} / \mathrm{m}^{2}$ among projects installed in $1998-1999$ to $246 \mathrm{~W} / \mathrm{m}^{2}$ among projects installed in 2015 (Figure 24). The decline in specific power was especially rapid from 2001 to 2005 and, more recently, from 2011 to 2015.

All else equal, a lower specific power will boost capacity factors, because there is more swept rotor area available (resulting in greater energy capture) for each watt of rated turbine capacity, meaning that the generator is likely to run closer to or at its rated capacity more often. In general, turbines with low specific power were originally designed for lower wind speed sites; they were intended to maximize energy capture in areas where the wind resource is modest, and where large rotor machines would not be placed under undue physical stress. As suggested in Figure 24 and as detailed in the next section, however, such turbines are now in widespread use in the United States - even in sites with high wind speeds. The impact of lower specific-power turbines on project-level capacity factors is discussed in more detail in Chapter 5. 


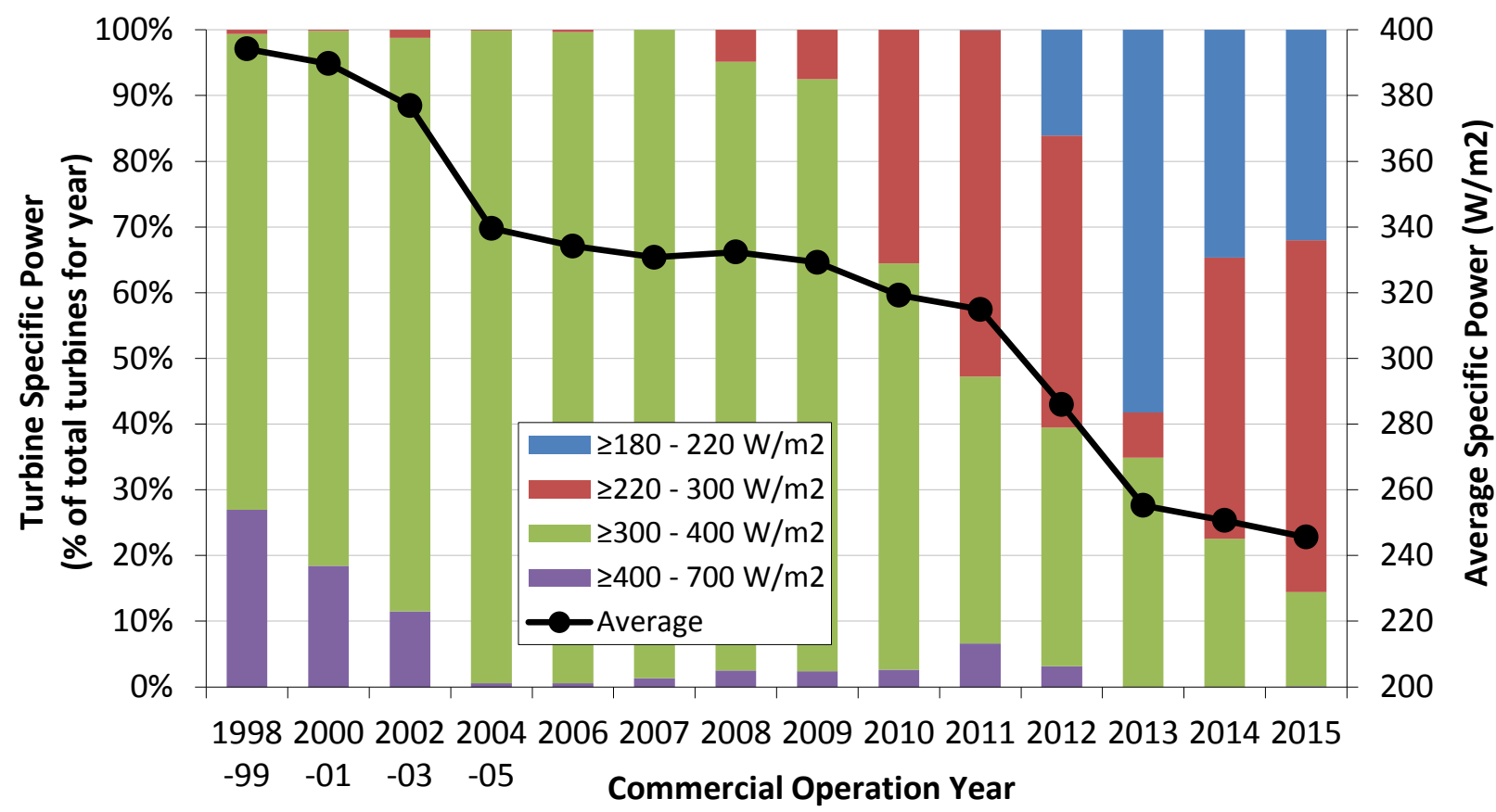

Figure 24. Trends in turbine specific power

Another indication of the increasing prevalence of machines initially designed for lower wind speeds is revealed in Figure 25, which presents trends in wind turbine installations by IEC Class. The IEC classification system considers multiple site characteristics, including wind speed, gusts, and turbulence. Class 3 turbines are generally designed for lower wind speed sites $(7.5 \mathrm{~m} / \mathrm{s}$ and below), Class 2 turbines for medium wind speed sites (up to $8.5 \mathrm{~m} / \mathrm{s}$ ), and Class 1 turbines for higher wind speed sites (up to $10 \mathrm{~m} / \mathrm{s}$ ). Some turbines are designed at the margins of two classifications, and are labeled as such (e.g., Class 2/3). Additionally, $9 \%$ of the turbines installed in 2015 were Class $\mathrm{S}$, which is outside IEC rating system. ${ }^{34}$

The U.S. wind market has clearly become increasingly dominated by IEC Class 3 turbines in recent years. In 2000-2001, Class 1 machines were prevalent. From 2002 through 2011, Class 2 machines dominated the market. Since 2011, there has been a substantial decline in the use of Class 2 turbines, and a concomitant increasing market share of Class 3 and Class $2 / 3$ turbines. In $2015,55 \%$ of the newly installed turbines were Class 3 machines, $33 \%$ were Class $2 / 3$ machines, and less than $3 \%$ of turbines were Class 2 or lower.

\footnotetext{
${ }^{34}$ The IEC 61400 Class "S" turbines in 2015 were GE Wind 1.7 MW turbines with 103 meter rotors on 80 meter towers, installed in five states. These turbines are not included in the reported average IEC class over time.
} 


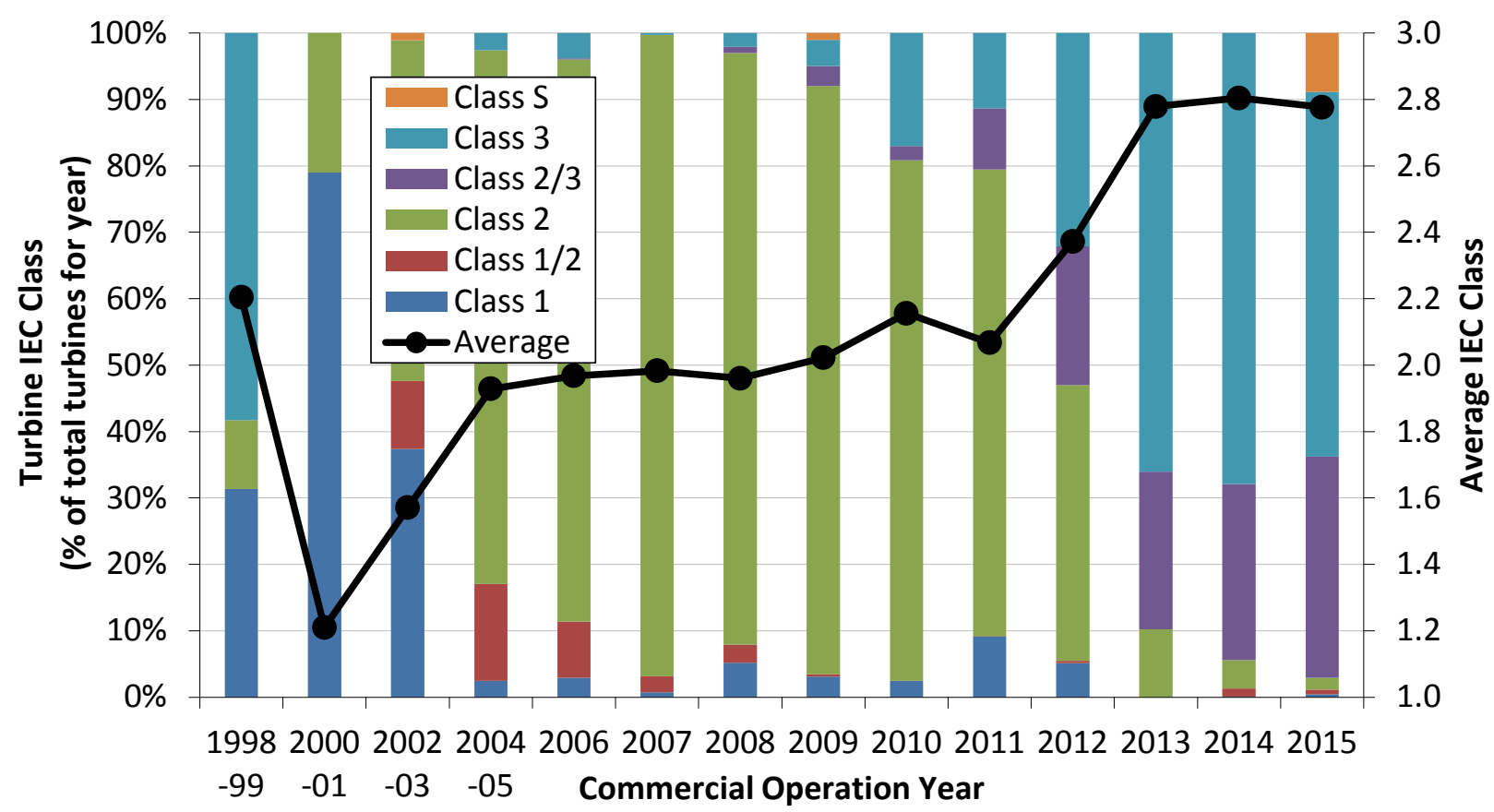

Figure 25. Trends in turbine IEC class

Moreover, Class 2, 2/3, and 3 turbine technology has not remained stagnant. Figure 26 shows the trend in average specific power across all turbines installed in each year (regardless of IEC Class, matching the average line shown in Figure 24) and also the average specific power ratings of Class 2, 2/3, and 3 (i.e., medium and lower wind speed) turbines installed in the United States. Through 2011, the progressively lower specific power of Class 2 turbines, which dominated the market, drove the overall decline in fleet-wide specific power. Since 2012, though, the continued drop in fleet-wide specific power has been driven by the penetration of the even-lower specific power of Class 3 and Class 2/3 machines. The overall trend in fleet-wide specific power has, therefore, been driven not only by the increased penetration of, initially, Class 2 and then, later, Class $2 / 3$ and 3 turbines, but also by the progressively lower specific power ratings of turbines within each of these IEC classes. ${ }^{35}$

\footnotetext{
${ }^{35}$ The average specific power for the Class S turbines installed in 2015 was $205 \mathrm{~W} / \mathrm{m}^{2}$, which further drove down the fleet-wide average for specific power in 2015.
} 


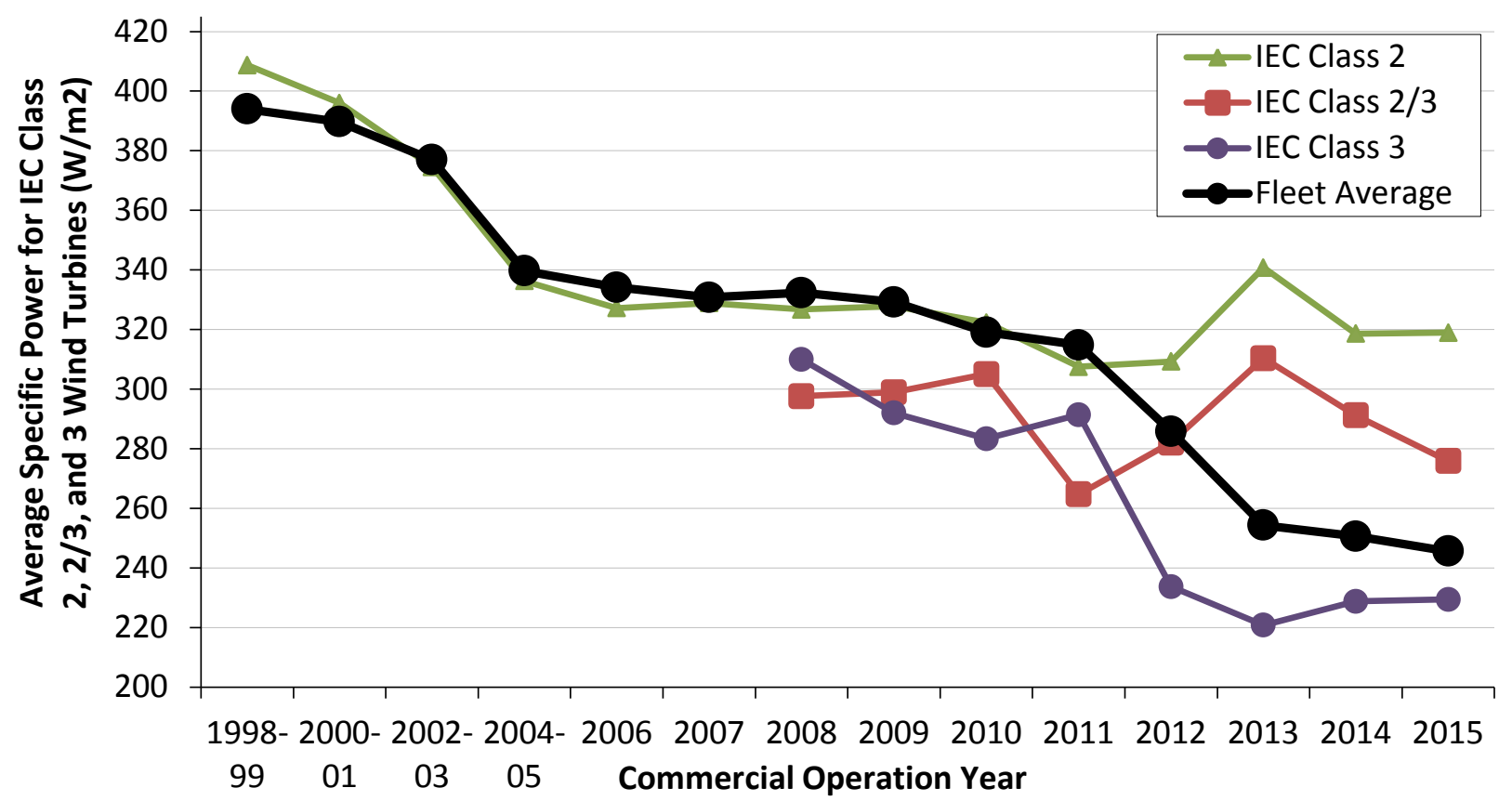

Note: specific power averages are shown only for years where there were at least 40 turbines in the respective IEC Class

Figure 26. Trends in specific power for IEC class 2, 2/3, and 3 turbines installed in the U.S.

Turbines originally designed for lower wind speeds are now regularly employed in both lower and higher wind speed sites; taller towers predominate in the Great Lakes and Northeast

One might expect that the increasing market share of turbines designed for lower wind speeds would be due to a movement by wind developers to deploy turbines in lower wind speed sites. Though there is some evidence of this movement historically (see Chapter 5), it is clear in Figures 27 and 28 that turbines originally designed for lower wind speeds are now regularly employed in all regions of the United States, and in both lower and higher wind speed sites.

Figure 27 presents the percentage of turbines installed in four distinct regions of the United States $^{36}$ (see Figure 29 for regional definitions) that have one or more of the following three attributes: (a) a higher hub height, (b) a lower specific power, and (c) a higher IEC Class. It focuses solely on turbines installed in the 2012-2015 time period. Figure 28 presents similar information, but segments the data by the wind resource quality of the site rather than by the region in which the turbines are located.

\footnotetext{
${ }^{36}$ Due to very limited sample size, we exclude the Southeast region from these graphs and related discussion.
} 


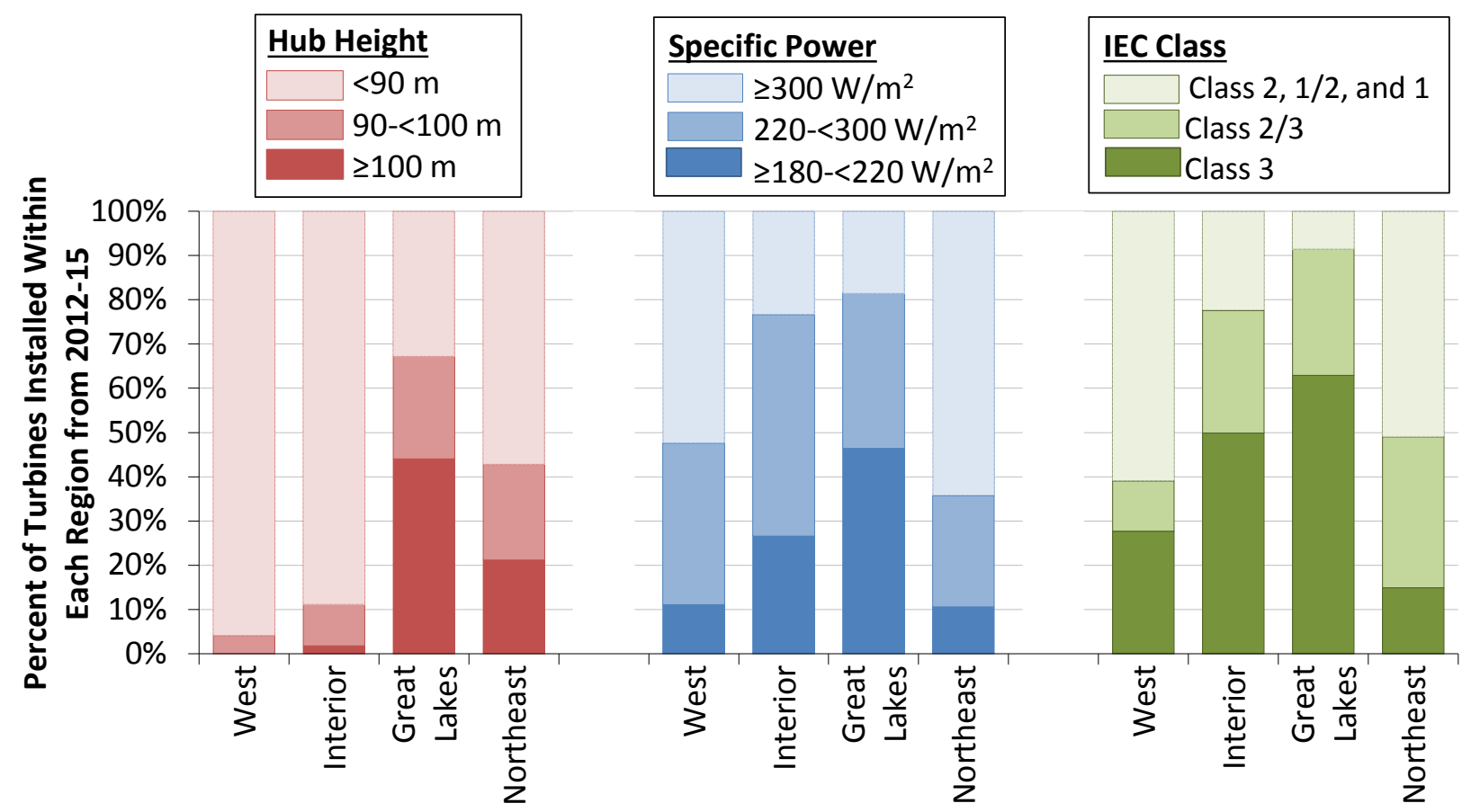

Figure 27. Deployment of turbines originally designed for lower wind speed sites, by region

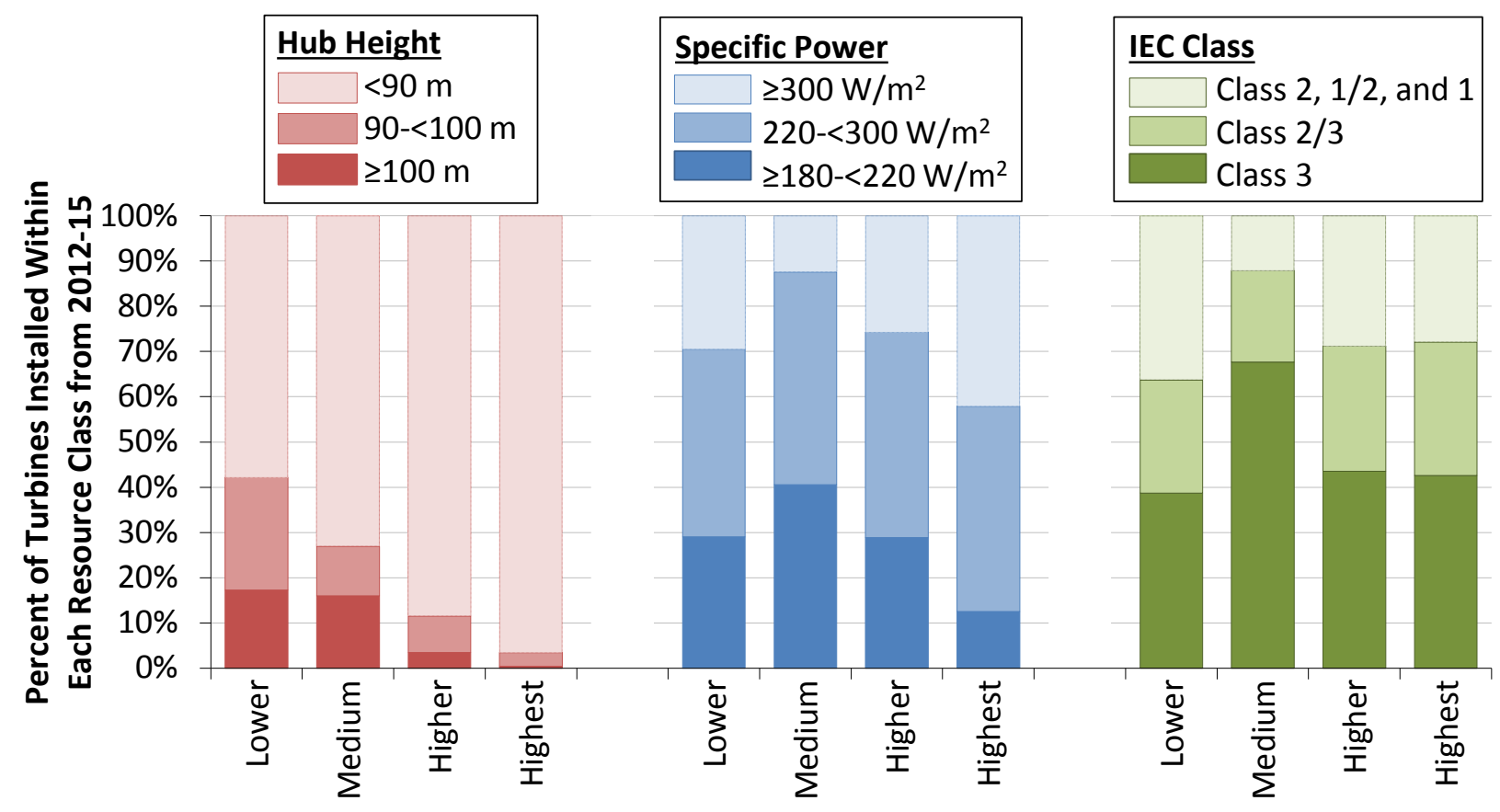

Estimated Wind Resource Quality at 80 Meters

Note: Wind resource quality is based on site estimates of gross capacity factor at 80 meters by AWS Truepower. The "Iower" category includes all projects with an estimated gross capacity factor of $<40 \%$, the "medium" category corresponds to $40 \%$ $45 \%$, the "higher" category corresponds to $45 \%-50 \%$, and the "highest" category includes any project at or exceeding $50 \%$.

Figure 28. Deployment of turbines originally designed for lower wind speed sites, by estimated wind resource quality 
Taller towers (i.e., 90 meters and above) have seen higher market share in the Great Lakes (67\%) and Northeast (43\%) than in the Interior (11\%) and West (4\%), often in sites with lower wind speeds. This is largely due to the fact that such towers are most commonly used in sites with higher-than-average wind shear (i.e., greater increases in wind speed with height) to access the better wind speeds that are typically higher up. Sites with higher wind shear are prevalent in the Great Lakes and Northeast.

Low specific power machines installed over this four-year period have been regularly deployed in all regions of the country, though their market share in the Great Lakes $(81 \%)$ and Interior (77\%) exceeds that in the West (48\%) and Northeast (36\%). Similarly, these turbines have been commonly used in all resource regimes including at sites with very high wind speeds, as shown in Figure 28. Turbines with the lowest specific power ratings $\left(180-220 \mathrm{~W} / \mathrm{m}^{2}\right)$, however, have been installed in greater proportions at lower, medium, and higher wind speed sites than at the highest wind speed sites, and are more prevalent in the Great Lakes.

Turning to IEC Class, we see a somewhat similar story. Over this period, Class 3 and Class $2 / 3$ machines have had the largest market share in the Great Lakes (91\%) and Interior (78\%) regions, but have also gained significant market in the Northeast (49\%) and West (39\%). Moreover, these turbines have been regularly deployed in both lower- and higher-quality resources sites.

In combination, these findings demonstrate that low specific power and Class 3 and 2/3 turbines, originally designed for lower wind speed sites, have established a strong foothold across the nation and over a wide range of wind speeds. In many parts of the Interior region, in particular, relatively low wind turbulence has allowed turbines designed for low wind speeds to be deployed across a wide range of site-specific resource conditions.

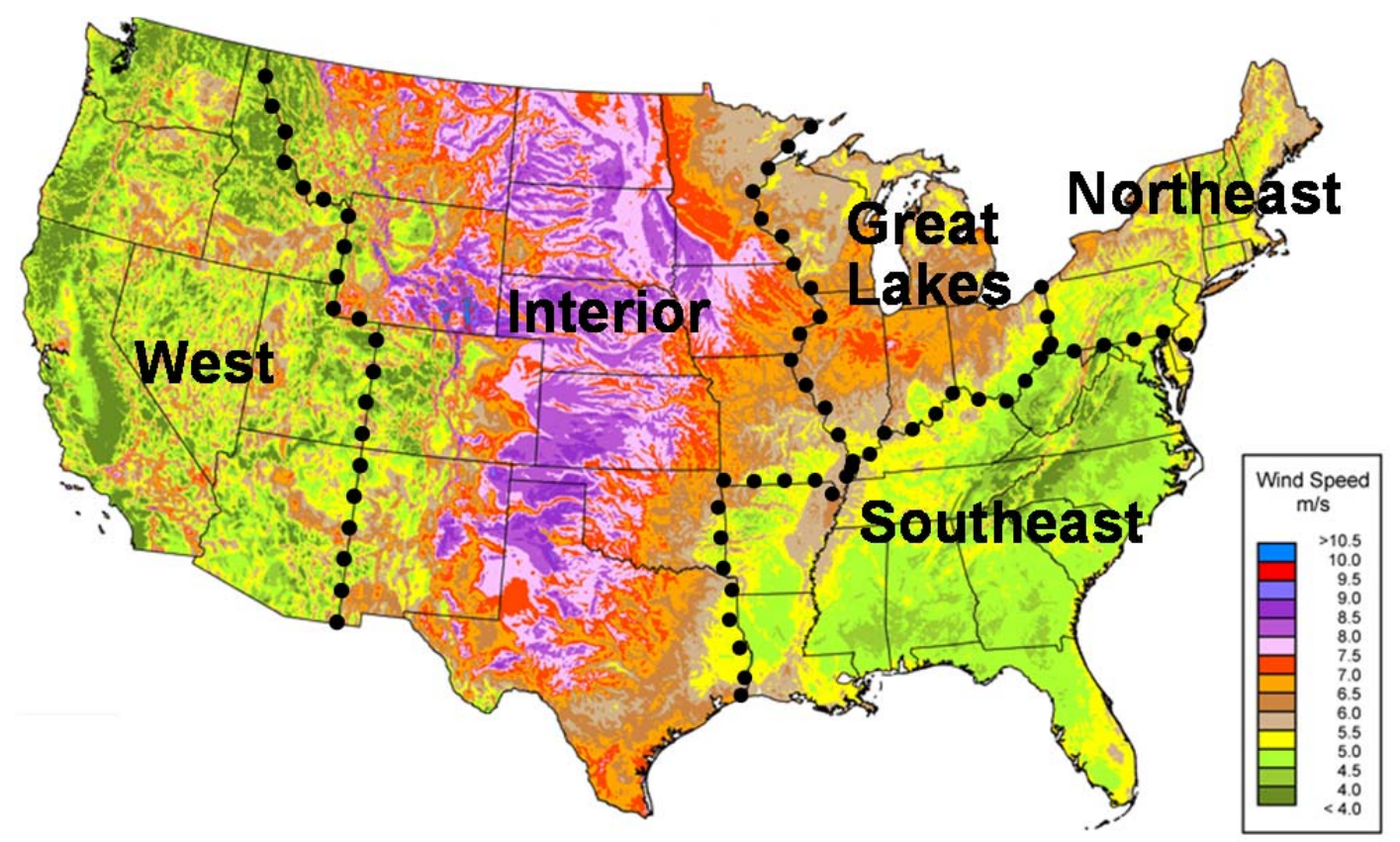

Source: AWS Truepower, National Renewable Energy Laboratory

Figure 29. Regional boundaries overlaid on a map of average annual wind speed at 80 meters 


\section{Performance Trends}

Following the previous discussion of technology trends, this chapter presents data from a Berkeley Lab compilation of project-level capacity factors. The full data sample consists of 633 wind projects built between 1998 and 2014 totaling 63,556 MW (96.5\% of nationwide installed wind capacity at the end of 2014) ${ }^{37}$ Excluded from this assessment are older projects, installed prior to 1998. The discussion is divided into three subsections: the first analyzes trends in sample-wide capacity factors over time; the second looks at variations in capacity factors by project vintage; and the third focuses on regional variations. Unless otherwise noted, all capacity factors in this chapter are reported on a net (i.e., taking into account losses from curtailment, less-than-full availability, wake effects, icing and soiling, etc.) rather than gross basis.

\section{Sample-wide capacity factors have gradually increased, but have been impacted by curtailment and inter-year wind resource variability}

The blue bars in Figure 30 show the average sample-wide capacity factor of wind projects in each calendar year among a progressively larger cumulative sample in each year, focusing on projects installed from 1998 through $2014 .^{38}$

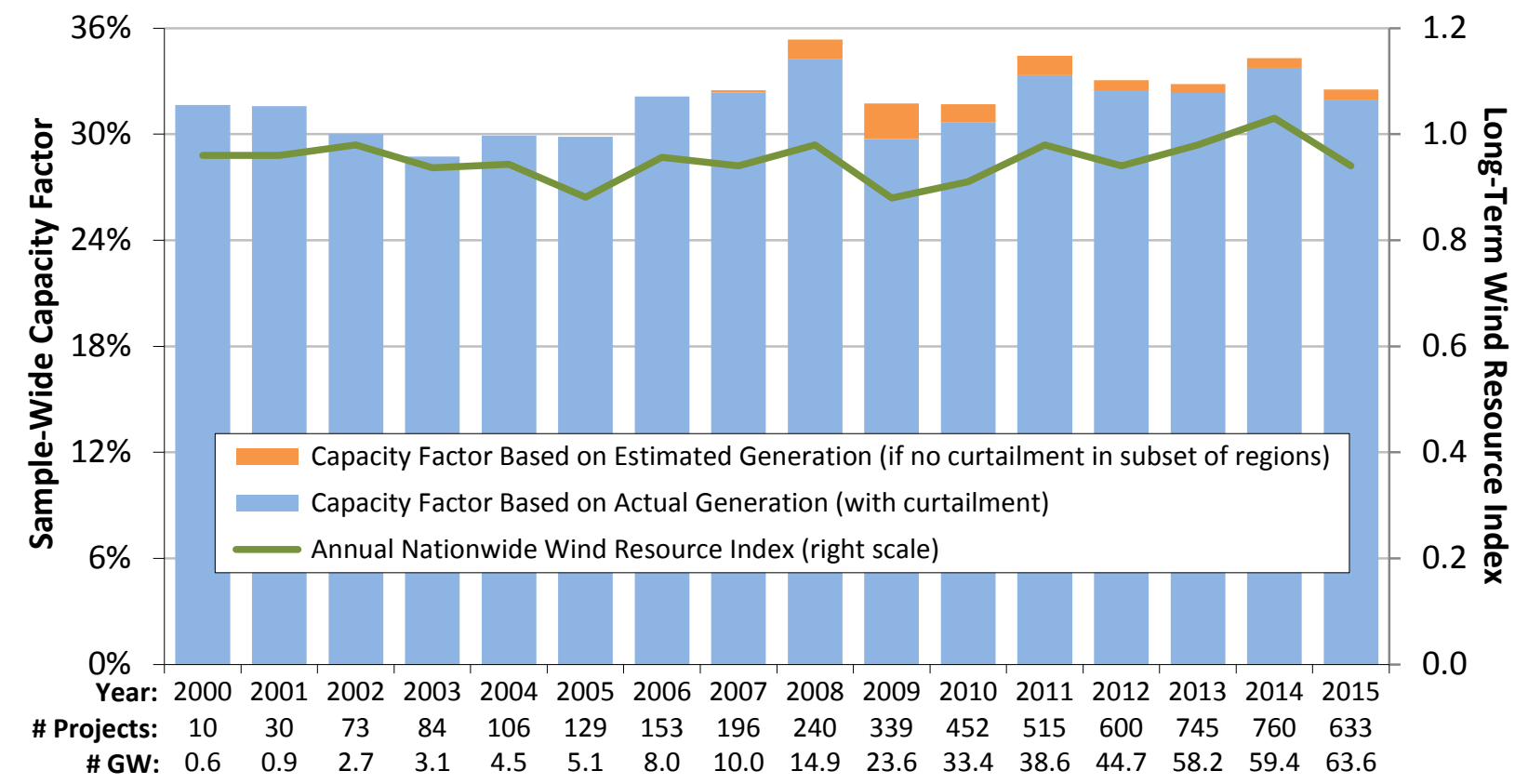

Source: Berkeley Lab

Figure 30. Average cumulative sample-wide capacity factors by calendar year

\footnotetext{
${ }^{37}$ Although some performance data for wind power projects installed in 2015 are available, those data do not span an entire year of operations. As such, for the purpose of this section, the focus is on projects with commercial operation dates from 1998 through 2014.

${ }^{38}$ There are fewer individual projects - although more capacity - in the 2015 cumulative sample than there are in 2014. This is due to the sampling method used by EIA, which focuses on a subset of larger projects throughout the year, before eventually capturing the entire sample some months after the year has ended. As a result, it might be late 2016 before EIA reports 2015 performance data for all of the wind power projects that it tracks, and in the meantime this report is left with a smaller sample consisting mostly of the larger projects in each state.
} 
Viewed this way - on a cumulative, sample-wide basis - one might expect to see a gradual improvement in capacity factor over time, as newer turbines with taller towers and lower specific power are added to the fleet. In general, the data support this trend; capacity factors averaged $32.8 \%$ between 2011 and 2015 versus $31.8 \%$ between 2006 and 2010 versus $30.3 \%$ between 2000 and 2005. However, several factors influence the apparent strength of this time-based trend. Two of those factors are discussed below-wind energy curtailment and inter-year variability in the strength of the wind resource. Two additional factors - the average quality of the resource in which projects are located and performance degradation as projects age - are discussed in the next section.

Wind Power Curtailment. Curtailment of wind project output can occur due to transmission inadequacy, minimum generation limits, other forms of grid inflexibility, and/or environmental restrictions - all but the last of which could help to push local wholesale power prices negative, thereby potentially triggering curtailment for economic reasons, particularly among wind projects that do not receive the PTC. Curtailment might be expected to increase as wind energy penetrations rise. That said, in areas where curtailment has been particularly problematic in the past - principally in Texas - steps taken to address the issue have significantly mitigated the concern. For example, Figure 31 shows that only $1.0 \%$ of potential wind energy generation within ERCOT was curtailed in 2015, down sharply from $17 \%$ in 2009 , roughly $8 \%$ in both 2010 and 2011, and nearly $4 \%$ in 2012. Primary causes for the decrease were the Competitive Renewable Energy Zone transmission line upgrades, most of which were completed by the end of 2013, and a move to more-efficient wholesale electric market designs.

Elsewhere, the only regions shown in Figure 31 in which wind curtailment exceeded 1\% in 2015 were MISO at $5.4 \%$ (as much of the new wind buildout continues to be located within this ISO) and ISO-NE at $2.4 \%$ (a rough estimate that the grid operator suspects is understated). Except for BPA, all of the regions shown in Figure 31 track both "forced" (i.e., required by the grid operator for reliability reasons) and "economic" (i.e., voluntary as a result of wholesale market prices) curtailment. BPA (which did not report in 2014 or 2015) tracks only forced curtailment, which means that its modest curtailment estimates for 2010-2013 may understate the true level of curtailment experienced by wind power projects in the region.

In aggregate, assuming a $33 \%$ average capacity factor, the total amount of curtailed wind generation tracked in Figure 31 for 2015 equates to the annual output of roughly 1,125 MW of wind power capacity. Looked at another way, wind power curtailment has reduced sample-wide average capacity factors in recent years. While the blue bars in Figure 30 reflect actual capacity factors - i.e., including the negative impact of curtailment events - the orange bars add back in the estimated amount of wind generation that has been forced to curtail in recent years within the seven areas shown in Figure 31, to estimate what the sample-wide capacity factors would have been absent this curtailment. As shown, sample-wide capacity factors would have been on the order of 0.5-2 percentage points higher nationwide from 2008 through 2015 absent curtailment in just this subset of regions. Estimated capacity factors would have been even higher if comprehensive forced and economic curtailment data were available for all regions. ${ }^{39}$

\footnotetext{
${ }^{39}$ Excluding BPA (for which 2015 data were not available), the six regions included in Figure 31 collectively contributed $72 \%$ of total U.S. wind generation in 2015 .
} 


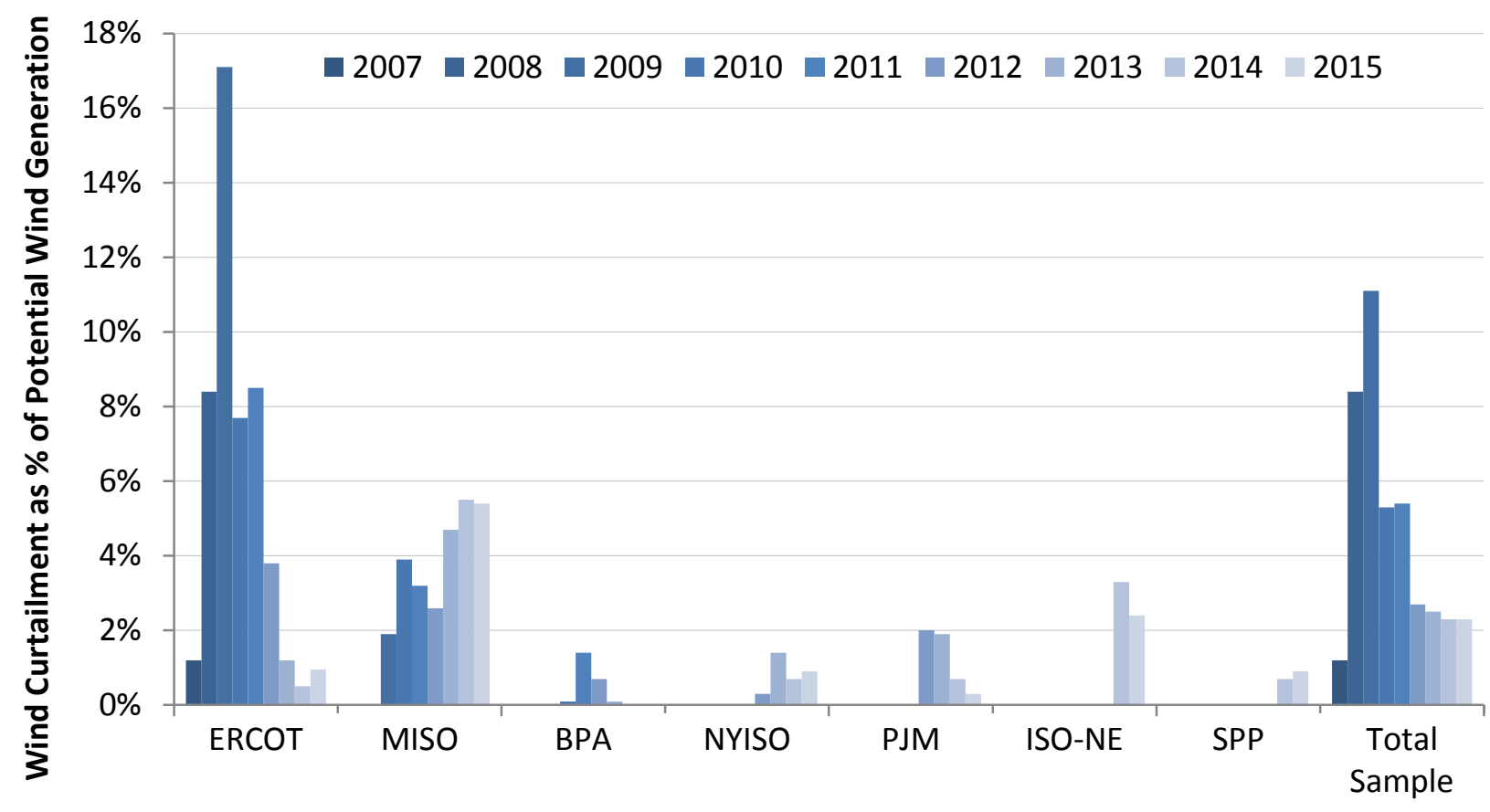

Note: BPA's 2014 and 2015 curtailment estimates were unavailable at the time of publication. A portion of BPA's curtailment from 2010-13 is estimated assuming that each curtailment event lasts for half of the maximum possible hour for each event. SPP's 2014 curtailment estimate is for March through December only. PJM's 2012 curtailment estimate is for June through December only. Except for BPA, which tracks only forced curtailment, all other percentages shown in the figure represent both forced and economic curtailment.

Source: ERCOT, MISO, BPA, NYISO, PJM, ISO-NE, SPP

Figure 31. Estimated wind curtailment by region as a percentage of potential wind generation

Inter-Year Wind Resource Variability. The strength of the wind resource varies from year to year, partly in response to significant persistent weather patterns such as El Niño/La Niña. A relatively strong El Niño had a significant impact in the first two quarters of 2015, contributing to wind speeds that were significantly below normal throughout much of the U.S. Although wind speeds recovered in the third and fourth quarters, annual average deviations of $6 \%$ or more for all of 2015 were common, particularly in the West and southern Great Plains states, where much of the wind capacity in the U.S. is located (AWS Truepower 2016).

The green line in Figure 30 also shows that 2015 was generally a bad wind year, at least in terms of the national average wind energy resource as measured by one large project sponsor. ${ }^{40}$ It is also evident from the figure that movements in sample-wide capacity factor from year to year are influenced by the natural inter-year variability in the strength of the national wind resource.

\footnotetext{
${ }^{40}$ The green line in Figure 30 estimates changes in the strength of the average nationwide wind resource from year to year and is derived from data presented by NextEra Energy Resources in its quarterly earnings reports.
} 


\section{The impact of technology trends on capacity factor becomes more apparent when parsed by project vintage}

One way to partially control for the time-varying influences described in the previous section (e.g., annual wind resource variations or changes in the amount of wind curtailment) is to focus exclusively on capacity factors in a single year, such as $2015 .{ }^{41}$ As such, while Figure 30 presents sample-wide capacity factors in each calendar year, Figure 32 instead shows only capacity factors in 2015, broken out by project vintage. Wind power projects built in 2015 are again excluded, as full-year performance data are not yet available for those projects.

Figure 32 shows an increase in weighted-average 2015 capacity factors when moving from projects installed in the 1998-1999 period to those installed in the 2004-2005 period.

Subsequent project vintages through 2011, however, show little if any improvement in average capacity factors recorded in 2015 . This pattern of stagnation is finally broken by projects installed in 2012, and even more so by 2013- and 2014-vintage projects. The average 2015 capacity factor among projects built in 2014 reached $41.2 \%$, compared to an average of $31.2 \%$ among all projects built from 2004-2011, and 25.8\% among all projects built from 1998-2003.

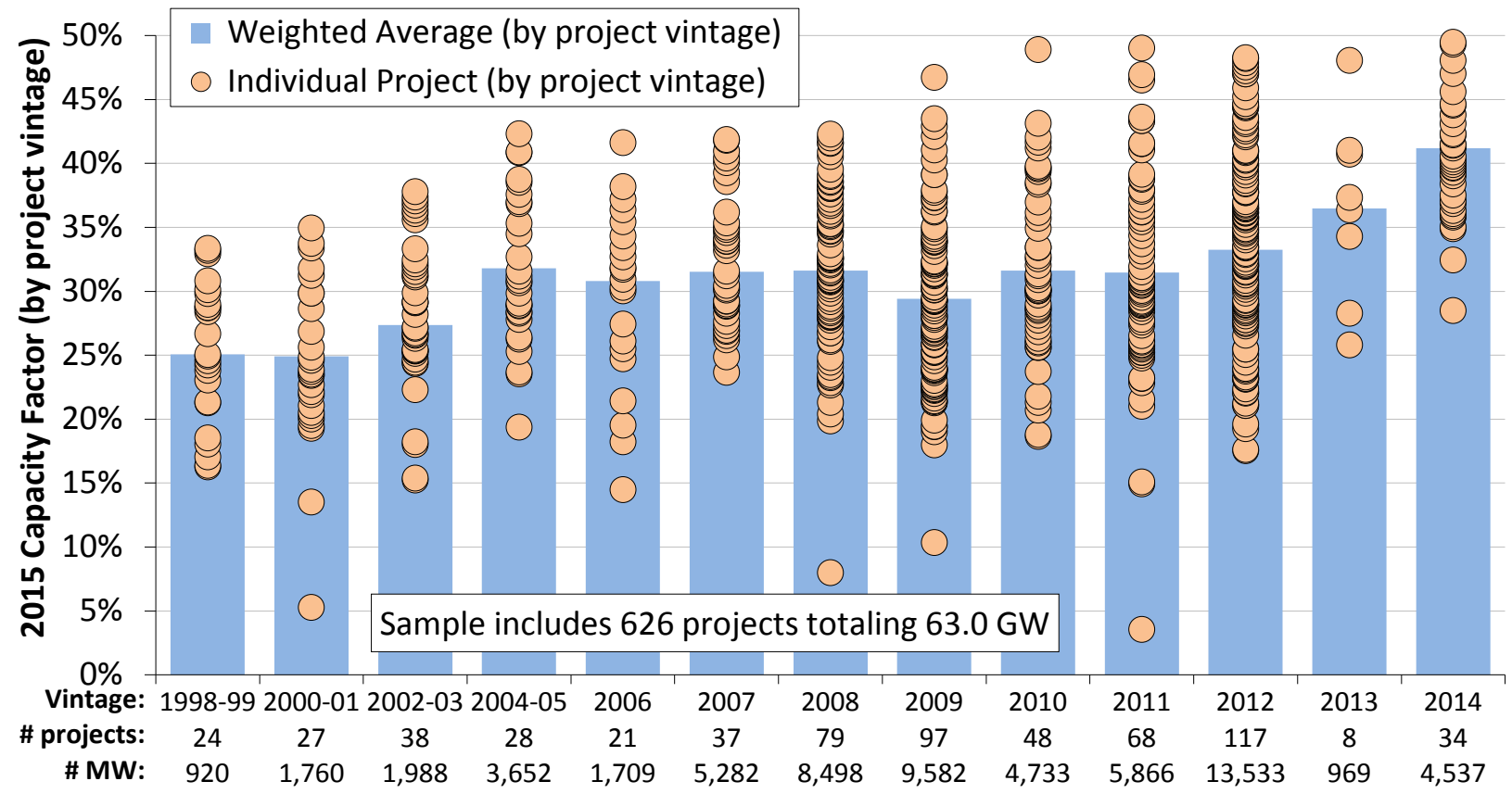

Source: Berkeley Lab

Figure 32. Calendar year 2015 capacity factors by project vintage

The trends in average capacity factor by project vintage seen in Figure 32 can largely be explained by three underlying influences shown in Figure 33: a trend towards progressively lower specific power ratings (note that Figure 33 actually shows the inverse of specific power, so

\footnotetext{
${ }^{41}$ Although focusing just on 2015 does control (at least loosely) for some of these known time-varying impacts, it also means that the absolute capacity factors shown in Figure 32 may not be representative over longer terms if 2015 was not a representative year in terms of the strength of the wind resource (as mentioned above, it was not - wind speeds were well below normal across much of the U.S. in 2015) or wind power curtailment.
} 
that a declining specific power is correlated directionally with a higher capacity factor) and higher hub heights - both of which should boost capacity factors, all else equal — as well as a progressive build-out of lower-quality wind resource sites through 2012 (which should hurt capacity factors, all else equal), followed by deployment at more energetic sites in 2013 and 2014. In addition, as shown later in Figure 36, project vintage itself could be a fourth driver, given the possible degradation in performance among older projects.

The first two of these influences - the decline in average "specific power" (i.e., W/m² of rotor swept area) and the increase in average hub height among more recent turbine vintages - have already been well-documented in Chapter 4, but are shown yet again in Figure 33 (again, with specific power shown in inverse form, to correlate with capacity factor movements) in index form, relative to projects built in 1998-99. All else equal, a lower average specific power will boost capacity factors, because there is more swept rotor area available (resulting in greater energy capture) for each watt of rated turbine capacity, meaning that the generator is likely to run closer to or at its rated capacity more often. Meanwhile, at sites with positive wind shear, increasing turbine hub heights can help the rotor to access higher wind speeds.

Counterbalancing the decline in specific power and the increase in hub height, however, has been a tendency to build new wind projects in lower-quality wind resource areas, ${ }^{42}$ at least through 2012 - and especially among projects installed from 2009 through $2012^{43}$ — as shown by the wind resource quality index in Figure 33. This trend reversed course in 2013 and even more so in 2014 , as deployment increasingly shifted to the Interior region.

\footnotetext{
${ }^{42}$ Estimates of wind resource quality are based on site estimates of gross capacity factor at 80 meters, as derived from nationwide wind resource maps created for NREL by AWS Truepower. We index the values to those projects built in 1998-99. Further details are found in the Appendix.

${ }^{43}$ Several factors could have driven this trend, especially in the 2009 to 2012 period. First, the increased availability of low-wind-speed turbines that feature higher hub heights and a lower specific power may have enabled the economic build-out of lower-wind-speed sites. Second, developers may have reacted to increasing transmission constraints over this period (or other siting constraints, or even just regionally differentiated wholesale electricity prices) by focusing on those projects in their pipeline that may not be located in the best wind resource areas but that do have access to transmission (or higher-priced markets, or readily available sites without long permitting times). Finally, federal and/or state policy could be partly responsible. For example, wind projects built in the 4-year period from 2009 through 2012 were able to access a 30\% cash grant (or ITC) in lieu of the PTC. Because the dollar amount of the grant (or ITC) was not dependent on how much electricity a project generates, it is possible that developers seized this limited opportunity to build out the less-energetic sites in their development pipelines. Additionally, state RPS requirements sometimes require or motivate in-state or in-region wind development in lower wind resource regimes.
} 


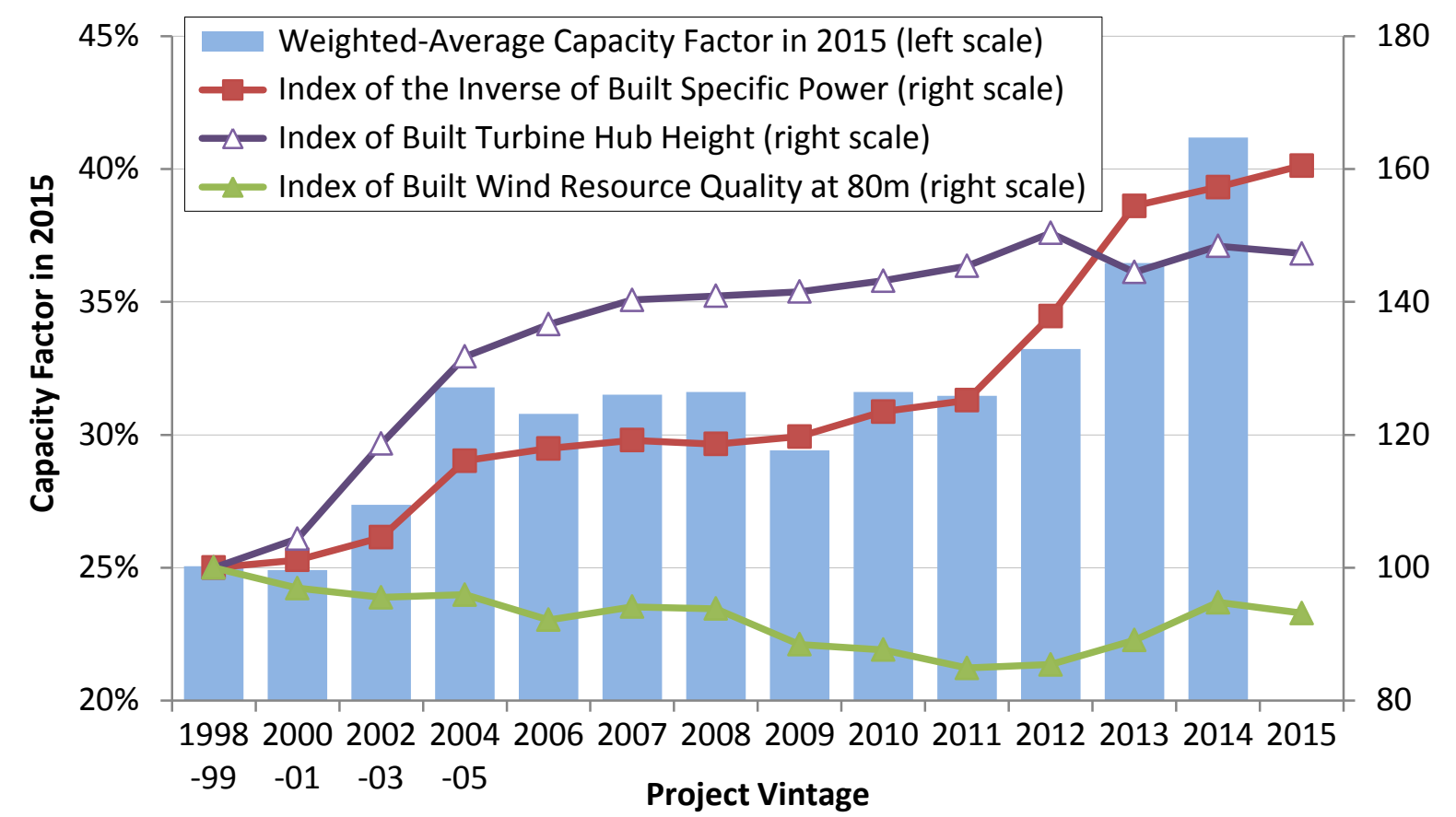

Note: In order to have all three indices be directionally consistent with their influence on capacity factor, this figure indexes the inverse of specific power (i.e., a decline in specific power causes the index to increase rather than decrease).

Source: Berkeley Lab

Figure 33. 2015 capacity factors and various drivers by project vintage

In Figure 33, the significant improvement in average 2015 capacity factors from those projects built in 1998-2001 to those built in 2004-2005 is driven by both an increase in hub height and a decline in specific power, and despite a shift towards somewhat-lower-quality wind resource sites. The stagnation in average capacity factor that subsequently persisted through 2011-vintage projects reflects relatively flat trends in both hub height and specific power, coupled with an ongoing decline in wind resource quality at built sites. Finally, capacity factors began to move higher among 2012-vintage projects, and continued even higher among 2013- and 2014-vintage projects, driven by a sharp reduction in average specific power coupled with a marked improvement in the quality of wind resource sites (average hub height stayed relatively constant over this period). Looking ahead to 2016, 2015-vintage projects are likely to perform similarly to those built in 2014 on average, given only modest changes in these three underlying drivers among the 2015 fleet.

To help disentangle the competing influences of turbine design evolution and lower wind resource quality on capacity factor, Figure 34 controls for each. Across the x-axis, projects are grouped into four different categories, depending on the wind resource quality estimated for each site. Within each wind resource category, projects are further differentiated by their specific power. As one would expect, projects sited in higher wind speed areas generally realized higher 2015 capacity factors than those in lower wind speed areas, regardless of specific power.

Likewise, within each of the four wind resource categories along the x-axis, projects that fall into a lower specific power range realized significantly higher 2015 capacity factors than those in a higher specific power range. 


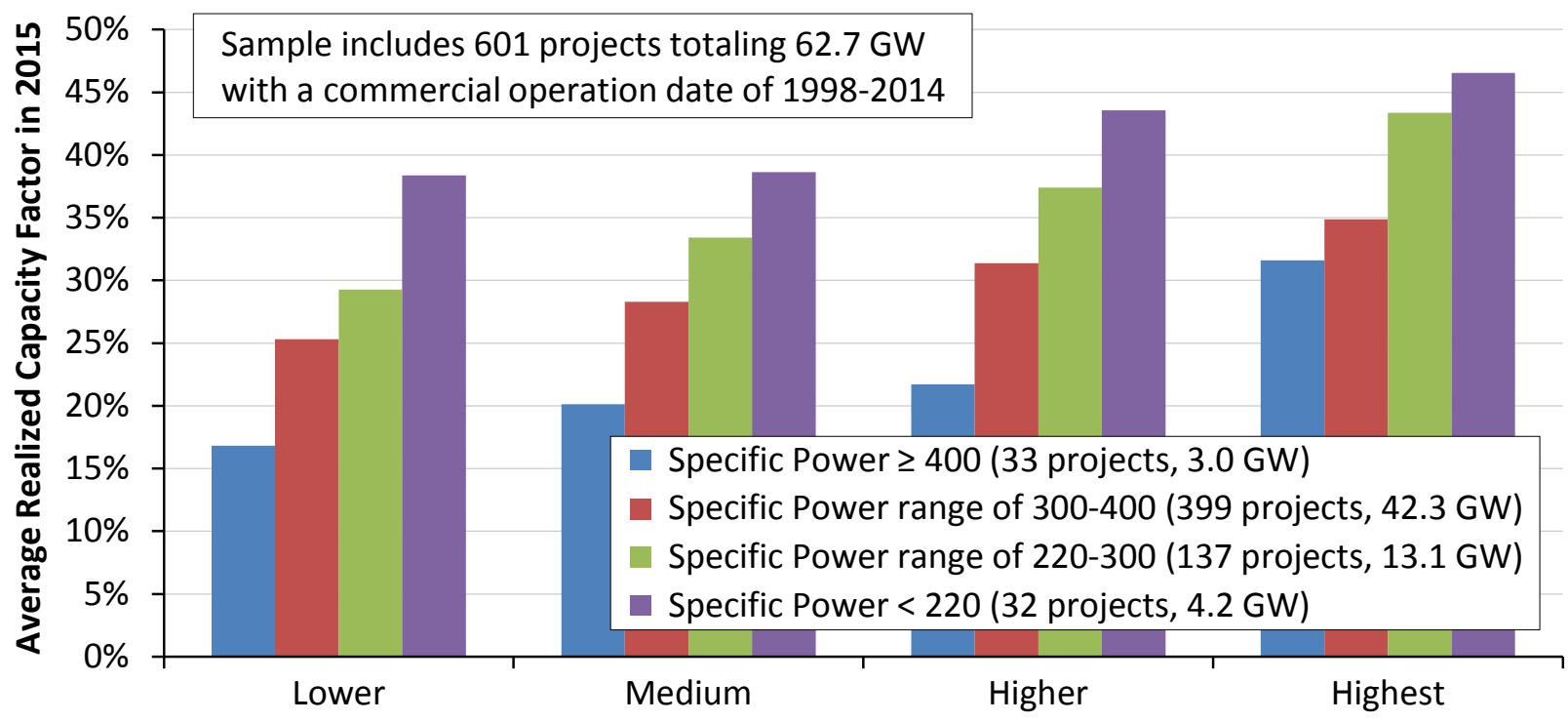

181 projects, $13.2 \mathrm{GW} 110$ projects, $14.1 \mathrm{GW} 148$ projects, $18.4 \mathrm{GW} 162$ projects, $16.9 \mathrm{GW}$

\section{Estimated Wind Resource Quality at Site}

Note: Wind resource quality is based on site estimates of gross capacity factor at 80 meters by AWS Truepower. The "lower" category includes all projects with an estimated gross capacity factor of $<40 \%$, the "medium" category corresponds to $40 \%-$ $45 \%$, the "higher" category corresponds to $45 \%-50 \%$, and the "highest" category includes any project at or exceeding $50 \%$.

Source: Berkeley Lab

Figure 34. Calendar year 2015 capacity factors by wind resource quality and specific power

As a result, it is clear that turbine design changes (specifically, lower specific power, but also, to a lesser extent, higher hub heights) are driving realized capacity factors higher among projects located within a given wind resource regime. This finding is further illustrated in Figure 35, which again groups projects into the same four different categories of wind resource quality, and then reports average realized 2015 capacity factors by commercial operation date within each category. ${ }^{44}$ As before, projects sited in higher wind speed areas have, on average, higher capacity factors. More importantly, although there is some variability in the year-to-year trends, it is clear that within each of the four wind resource categories there has been an improvement in capacity factors over time, by commercial operation date.

\footnotetext{
${ }^{44}$ The figure only includes those data points representing at least three projects in any single resource-year pair. Among 2013-vintage projects, only the "lower" wind resource quality grouping meets this sample size threshold. In addition, the "medium" wind resource quality grouping lacks sufficient sample size in both 2006 and 2014. In years where insufficient sample size prohibits the inclusion of a data point, dashed lines are used to interpolate from the prior year to the subsequent year.
} 


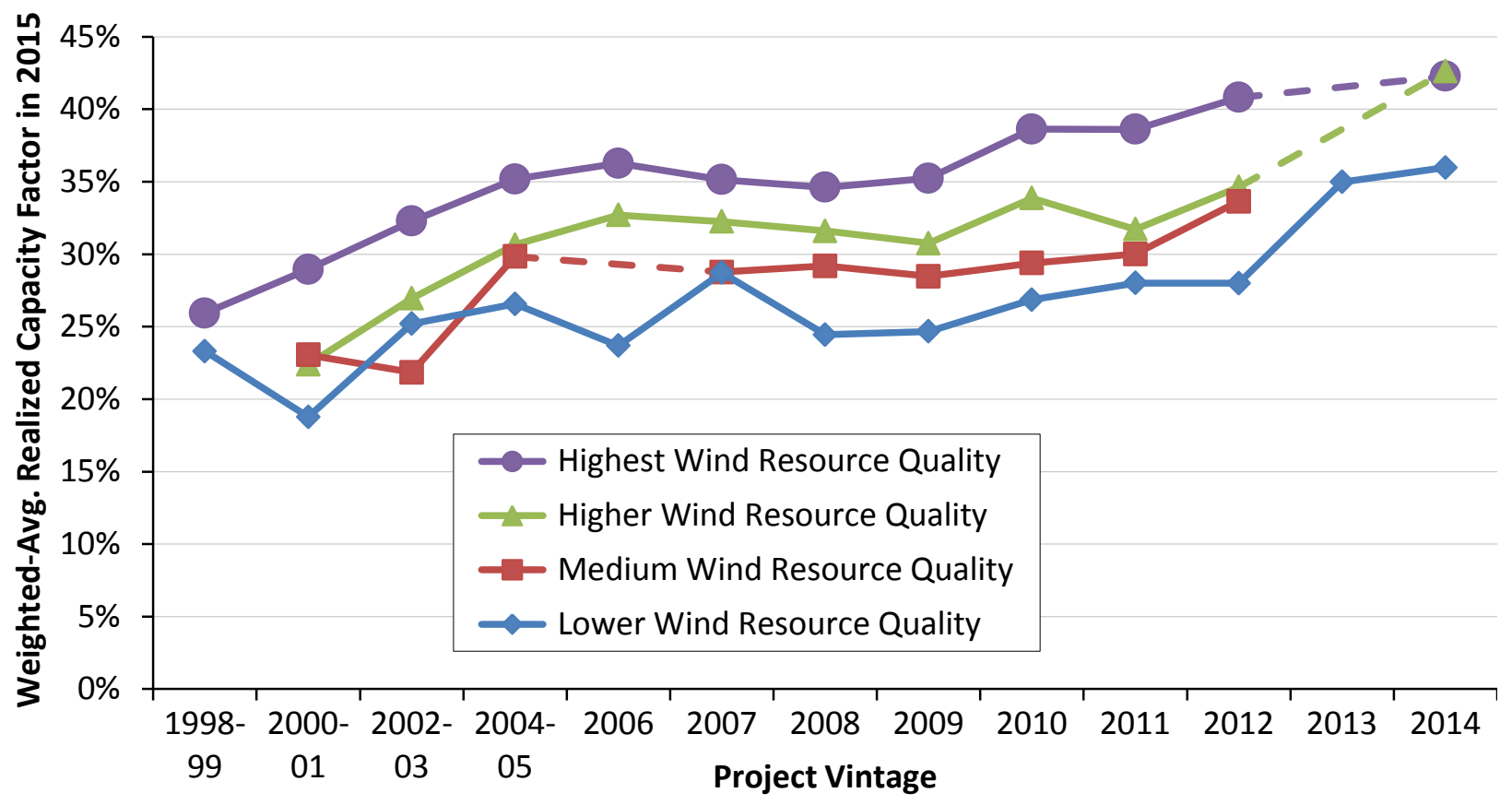

Source: Berkeley Lab

Figure 35. Calendar year 2015 capacity factors by project vintage and wind resource quality

One final variable that could be influencing the apparent improvement in 2015 capacity factors among more recent project vintages is project age. If wind turbine (and project) performance tends to degrade over time, then older projects - e.g., those built from 1998-2001 — may have performed worse than more recent vintages in 2015 simply due to their relative age. Figure 36 explores this question by graphing both median (with $10^{\text {th }}$ and $90^{\text {th }}$ percentile bars) and capacityweighted average capacity factors over time, where time is defined as the number of full calendar years after each individual project's commercial operation date (COD), and where each project's capacity factor is indexed to $100 \%$ in year one (in order to focus solely on changes to each project's capacity factor over time, rather than on absolute capacity factor values).

Figure 36 suggests some amount of performance degradation, particularly once projects age beyond 7-10 years-i.e., a period that roughly corresponds to the initial warranty period, as well as the PTC period. Such degradation among older projects could help to partially explain why, for example, in Figure 30 the sample-wide capacity factors in 2000 and 2001 exceeded 30\%, while in Figure 32 the 1998-2001 project vintages (i.e., consisting of essentially the same set of projects) posted average capacity factors of just $25 \%$ in 2015. 


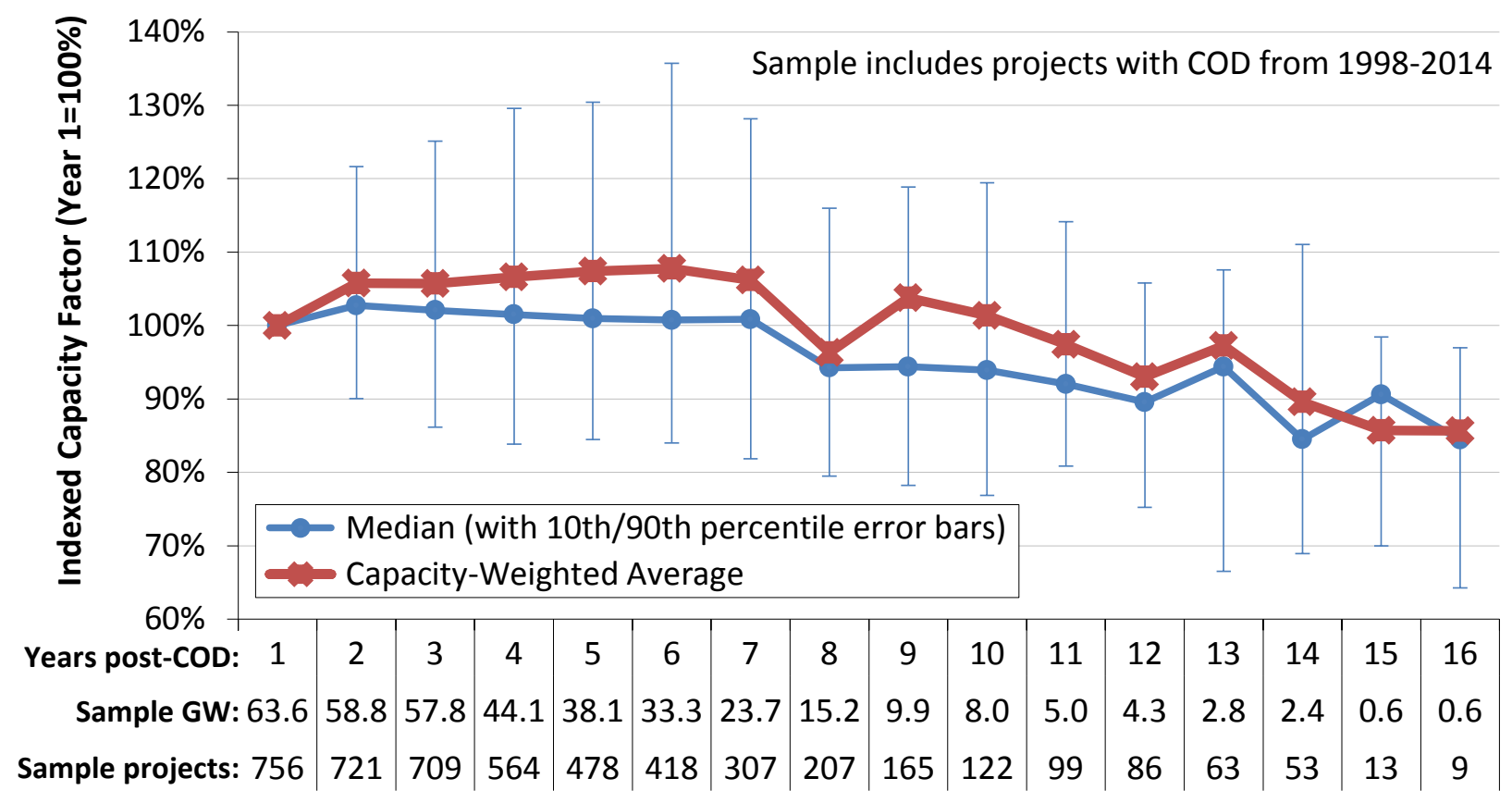

Source: Berkeley Lab

Figure 36. Post-COD changes in capacity factors over time suggest performance degradation

The median values in Figure 36 regularly fall below the capacity-weighted average values, suggesting that smaller projects tend to degrade more, and more rapidly, than larger projects. This difference could perhaps be attributable to less-stringent or -responsive O\&M protocols among smaller projects. The PTC could be another influence, if smaller projects have instead more commonly opted for the ITC or its cash counterpart, the Section 1603 grant-neither of which depends on performance. Finally, the up-tick in year two for both the median and capacity-weighted average values could partly reflect the initial production ramp-up period that is commonly experienced by wind projects as they work through and resolve initial "teething" issues during their first year of operations.

Although all of these suppositions surrounding Figure 36 are intriguing and worthy of further study, a number of caveats are in order. First, no attempt was made to correct for inter-year variation in the strength of the wind resource. Although the potential impact of this omission is likely muted by the fact that year five (for example) for one project will be a different calendar year than year five for another project, inter-year resource variation could still play a role.

Second, the sample is not the same in each year. The sample shrinks as the number of post-COD years increases, and is increasingly dominated by older projects using older turbine technology that may not be representative of today's turbines. Third, as with all figures presented in this chapter, turbine decommissioning is accounted for by adjusting the nameplate project capacity as appropriate over time (all the way to zero if a project is fully decommissioned), such that each figure, including Figure 36, shows the performance of those turbines that are operating in each period, rather than relative to the original nameplate capacity. 


\section{Regional variations in capacity factors reflect the strength of the wind resource and adoption of new turbine technology}

The project-level spread in capacity factors shown in Figure 32 is enormous, with 2015 capacity factors ranging from a minimum of $28.5 \%$ to a maximum of $49.5 \%$ among those projects built in 2014 (this spread is even wider for projects built in earlier years). Some of the spread in projectlevel capacity factors - for projects built in 2014 and earlier - is attributable to regional variations in average wind resource quality. As such, Figure 37 shows the regional variation in 2015 capacity factors (using the regional definitions shown in Figure 29, earlier) based on just the sample of wind power projects built in 2014 .

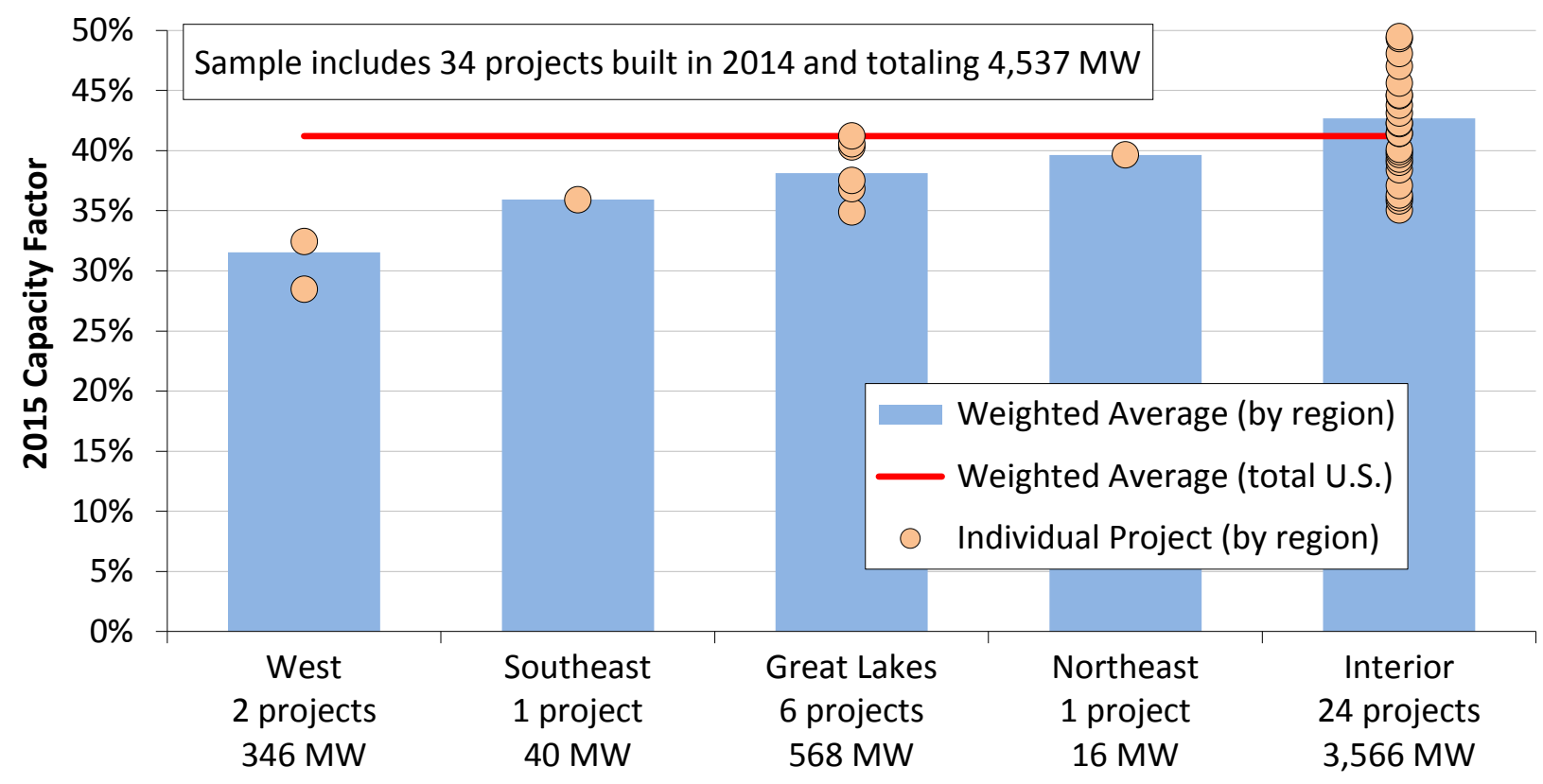

Source: Berkeley Lab

Figure 37. Calendar year 2015 capacity factors by region: 2014 vintage projects only

Although four of the five regions have a very limited sample (attributable to the fact that nearly $80 \%$ of the total capacity installed in 2014 was located in the Interior region), focusing only on this most recent vintage of projects is nevertheless appropriate in light of the significant disparity in average 2015 capacity factors among 2014 projects versus earlier vintages (see Figures 32 or 33). In other words, were Figure 37 to include vintages prior to 2014 in an effort to boost sample size, the stark differences in 2015 capacity factor across vintages could partially mask any regional differences. Focusing on just the two regions that include more than two projects in Figure 37, generation-weighted average capacity factors are the highest in the Interior region $(42.7 \%)$ and a bit lower in the Great Lakes (38.1\%). ${ }^{45}$ Even within these regions, however, there

\footnotetext{
${ }^{45}$ Given the relatively small sample size in many regions, as well as the possibility that certain regions may have experienced a particularly good or bad wind resource year or different levels of wind energy curtailment in 2015, care should be taken in extrapolating these results. For example, many projects (of various vintages) located in Wyoming and Idaho - both states that faced significantly below-normal wind speeds in 2015 (AWS Truepower 2016) - experienced 2015 capacity factors that were as much as 8 to 9 percentage points below normal, while at the
} 
can still be considerable spread - e.g., 2015 capacity factors range from $35 \%$ up to $49.5 \%$ among projects installed in the Interior region in 2014.

Some of this intra-regional variation can be explained by turbine technology. Figure 38 also provides a regional breakdown, although in this case it includes projects built from 2012-2014, which are further differentiated by average specific power. Including older vintages in Figure 38 is both more necessary (i.e., in order to have sufficient sample within each region to enable a specific power breakout) and less problematic (i.e., given that Figure 38 controls for the impact of specific power) than it would have been for Figure 37.

As one would expect, within each of the four regions along the $\mathrm{x}$-axis, projects using turbines that fall into a lower specific power range generally have higher realized capacity factors than those in a higher specific power range.

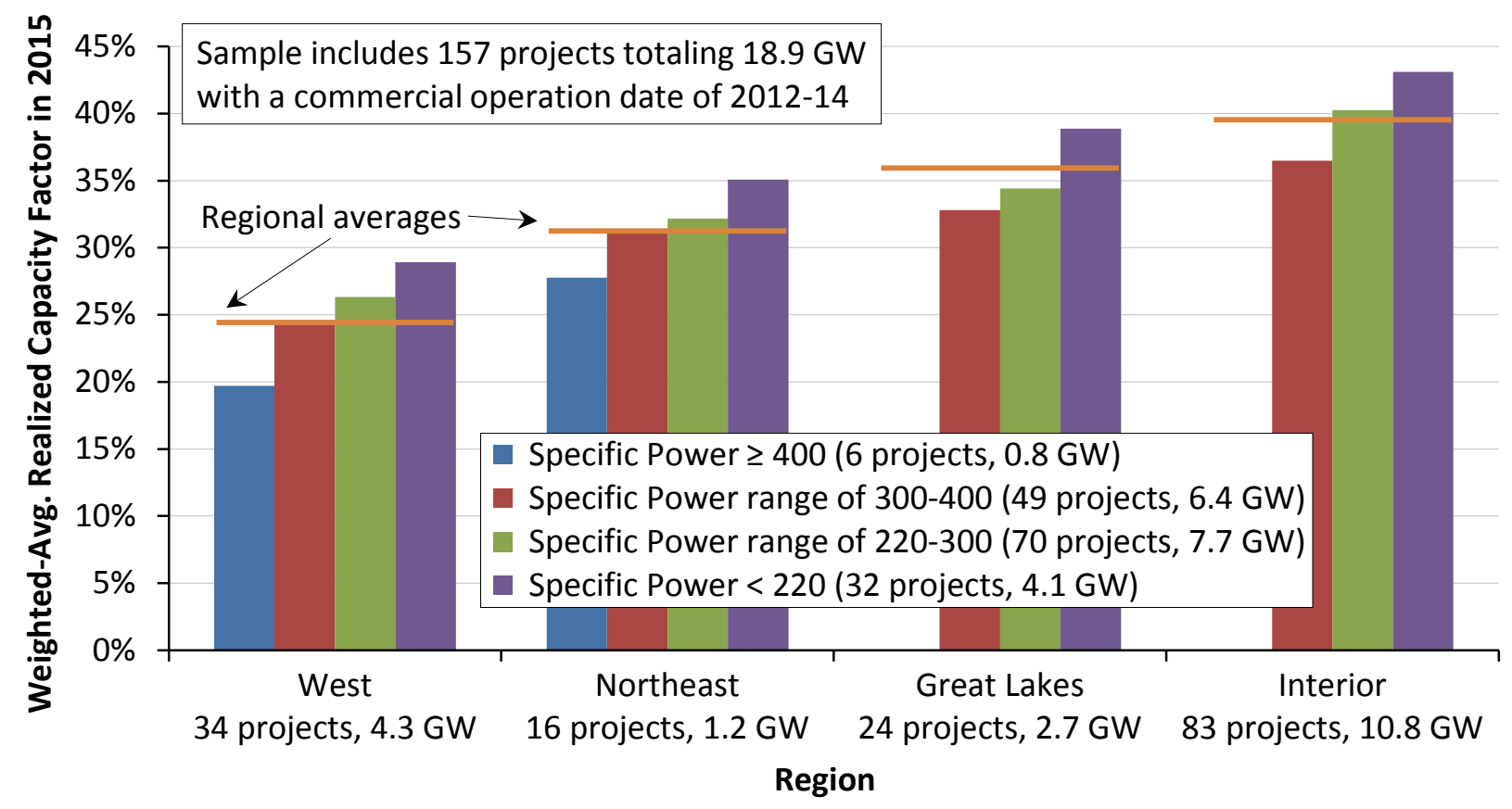

Source: Berkeley Lab

Figure 38. Calendar year 2015 capacity factors by region and specific power

As shown earlier in Chapter 4 ("Technology Trends"), the rate of adoption of turbines with lower specific power ratings has varied by region. For example, Figure 27 (earlier) shows that $46 \%$ of all turbines installed in the Great Lakes region from 2012-2015 have a specific power rating of less than $220 \mathrm{~W} / \mathrm{m}^{2}$, while the comparable number in the West is $11 \%$. Similarly, $67 \%$ of all turbines installed in the Great Lakes region from 2012-2015 have tower heights of at least 90 meters, compared to $4 \%$ in the West. The relative degree to which these regions have embraced these turbine design enhancements influences, to some extent, their ranking in Figures 37 and 38.

other extreme many projects in Minnesota, Wisconsin, and Michigan - states that were largely spared the weak winds of 2015 (AWS Truepower 2016) - reported higher-than-normal capacity factors in 2015. 
Taken together, Figures 30-38 suggest that, in order to understand trends in empirical capacity factors, one needs to consider (and ideally control for) a variety of factors. These include not only wind power curtailment and the evolution in turbine design, but also a variety of spatial and temporal wind resource considerations - such as the quality of the wind resource where projects are located, inter-year wind resource variability, and even project age. 


\section{Cost Trends}

This chapter presents empirical data on both the upfront and operating costs of wind projects in the United States. It begins with a review of wind turbine prices, followed by total installed project costs, and then finally O\&M costs. Sample size varies among these different datasets, and is therefore discussed within each section of this chapter.

\section{Wind turbine prices remained well below levels seen several years ago}

Wind turbine prices have dropped substantially since 2008, despite continued technological advancements that have yielded increases in hub heights and especially rotor diameters. Prices maintained their low levels in 2015, aided in part by the strength of the U.S. dollar.

Berkeley Lab has gathered price data for 121 U.S. wind turbine transactions totaling 30,480 MW announced from 1997 through 2015, but this sample includes only nine transactions (1,460 MW) announced in 2014 or 2015. Sources of turbine price data vary, including SEC and other regulatory filings, as well as press releases and news reports. Most of the transactions included in the Berkeley Lab dataset include turbines, towers, delivery to site, and limited warranty and service agreements. ${ }^{46}$ Nonetheless, wind turbine transactions differ in the services included (e.g., whether towers and installation are provided, the length of the service agreement, etc.), turbine characteristics (and therefore performance), and the timing of future turbine delivery, driving some of the observed intra-year variability in transaction prices.

Unfortunately, collecting data on U.S. wind turbine transaction prices is a challenge, in that only a fraction of the announced turbine transactions have publicly revealed pricing data. Partly as a result, Figure 39-which depicts these U.S. wind turbine transaction prices - also presents data from two other sources: (1) Vestas on that company's global average turbine pricing from 2005 through 2015, as reported in Vestas' financial reports; and (2) Bloomberg NEF (2016a) on that company's global average turbine price index by contract signing date.

After hitting a low of roughly $\$ 750 / \mathrm{kW}$ from 2000 to 2002 , average wind turbine prices increased by approximately $\$ 800 / \mathrm{kW}$ (more than $100 \%$ ) through 2008 , rising to an average of more than $\$ 1,500 / \mathrm{kW}$. The increase in turbine prices over this period was caused by several factors, including a decline in the value of the U.S. dollar relative to the Euro; increased materials, energy, and labor input prices; a general increase in turbine manufacturer profitability due in part to strong demand growth; increased costs for turbine warranty provisions; and an upscaling of turbine size, including hub height and rotor diameter (Bolinger and Wiser 2011).

\footnotetext{
${ }^{46}$ Because of data limitations, the precise content of many of the individual transactions is not known.
} 


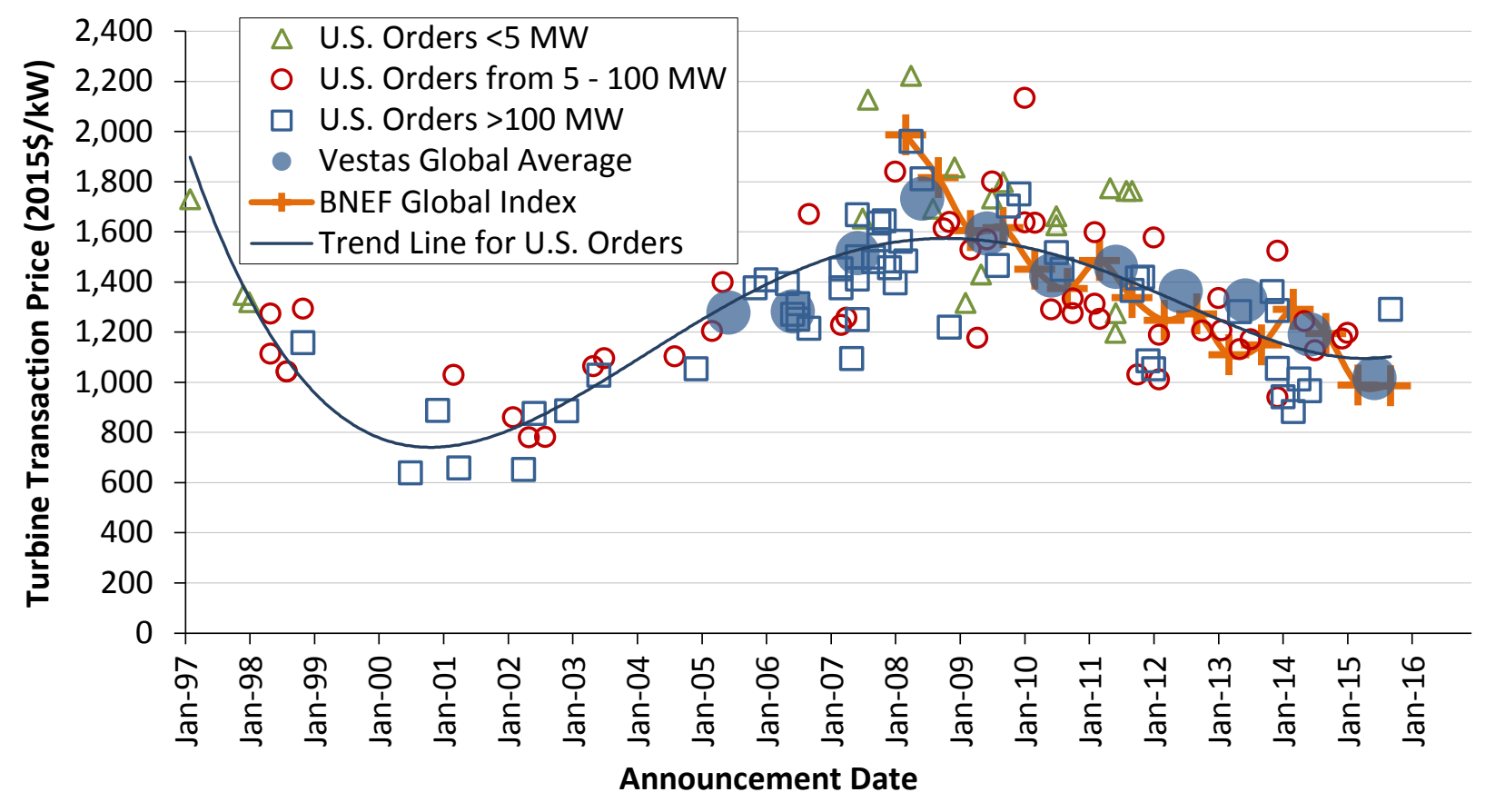

Source: Berkeley Lab

Figure 39. Reported wind turbine transaction prices over time

Since 2008, wind turbine prices have declined substantially, reflecting a reversal of some of the previously mentioned underlying trends that had earlier pushed prices higher as well as increased competition among manufacturers and significant cost-cutting measures on the part of turbine and component suppliers. As shown in Figure 39, our limited sample of recently announced U.S. turbine transactions shows pricing in the $\$ 850-\$ 1,250 / \mathrm{kW}$ range. Bloomberg NEF (2016b) reports average pricing for recent North American contracts of roughly $\$ 1,000 / \mathrm{kW}$. Data from Vestas confirm these pricing points, with average global sales prices in 2015 of $\$ 1,020 / \mathrm{kW}$, when denominated in U.S. dollars.

Overall, these figures suggest price declines of $20 \%-40 \%$ since late 2008 . Moreover, these declines have been coupled with improved turbine technology (e.g., the recent growth in average hub heights and rotor diameters shown in Chapter 4) and more favorable terms for turbine purchasers (e.g., reduced turbine delivery lead times and less need for large frame-agreement orders, longer initial O\&M contract durations, improved warranty terms, and more-stringent performance guarantees). These price reductions and improved terms have exerted downward pressure on total project costs and wind power prices, whereas increased rotor diameters and hub heights are improving capacity factors and further reducing wind power prices.

\section{Lower turbine prices have driven reductions in reported installed project costs}

Berkeley Lab also compiles data on the total installed cost of wind power projects in the United States, including data on 44 projects completed in 2015 totaling 5,772 MW, or $67 \%$ of the wind power capacity installed in that year. In aggregate, the dataset (through 2015) includes 789 completed wind power projects in the continental United States totaling 60,032 MW and equaling roughly $81 \%$ of all wind power capacity installed in the United States at the end of 2015. In general, reported project costs reflect turbine purchase and installation, balance of plant, 
and any substation and/or interconnection expenses. Data sources are diverse, however, and are not all of equal credibility, so emphasis should be placed on overall trends in the data rather than on individual project-level estimates.

As shown in Figure 40, the average installed costs of projects declined from the beginning of the U.S. wind industry in the 1980 s through the early 2000 s, and then increased-reflecting turbine price changes - through the latter part of the last decade. Whereas turbine prices peaked in 2008/2009, however, project-level installed costs appear to have peaked in 2009/2010, with substantial declines since that time. That changes in average installed project costs would lag behind changes in average turbine prices is not surprising and reflects the normal passage of time between when a turbine supply agreement is signed (the time stamp for Figure 39) and when those turbines are actually installed and commissioned (the time stamp for Figure 40). ${ }^{47}$

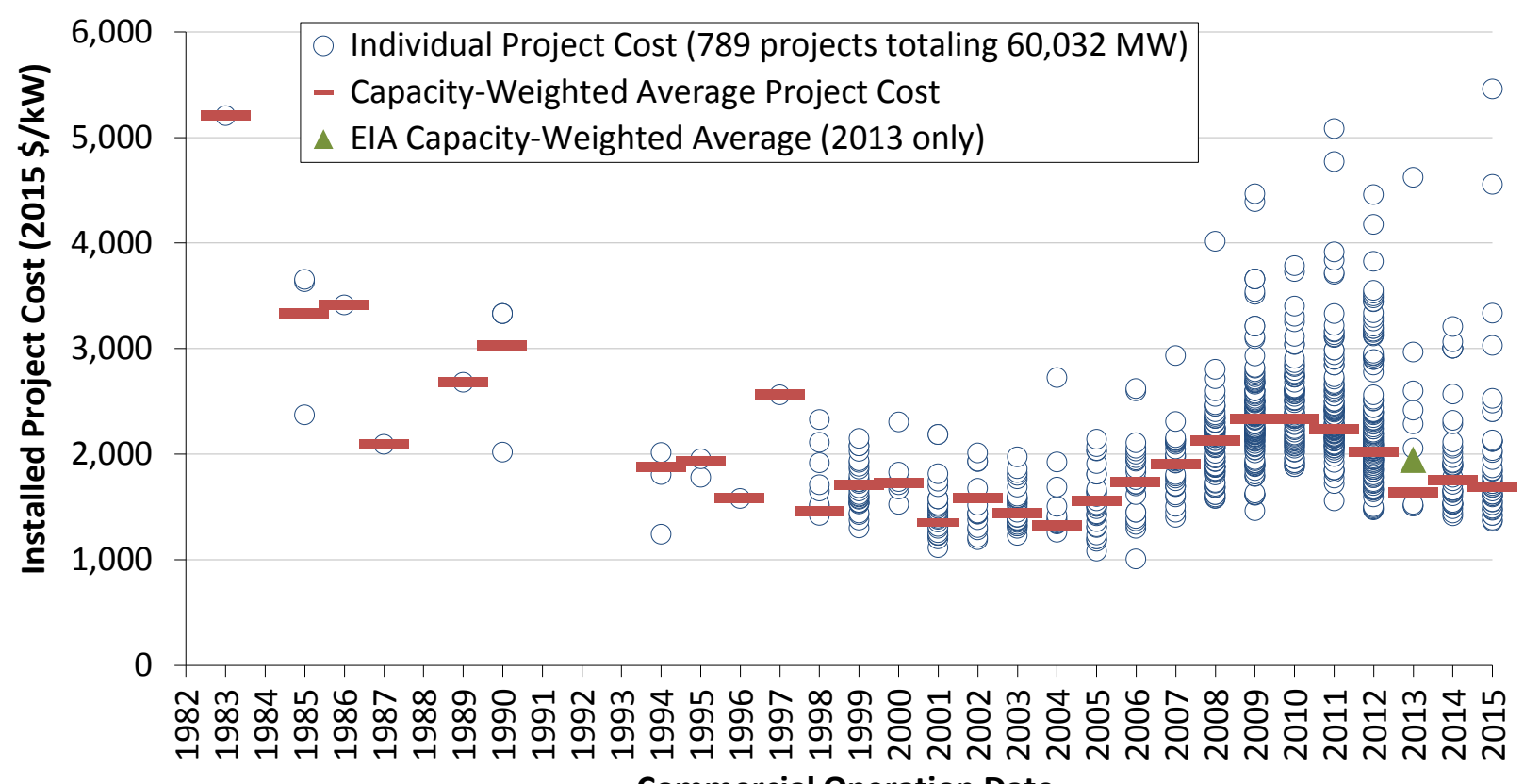

Commercial Operation Date

Source: Berkeley Lab (some data points suppressed to protect confidentiality), Energy Information Administration

Figure 40. Installed wind power project costs over time

In 2015, the capacity-weighted average installed project cost within our sample stood at roughly $\$ 1,690 / \mathrm{kW}$, down $\$ 640 / \mathrm{kW}$ or $27 \%$ from the apparent peak in average reported costs in 2009 and 2010. Early indications from a limited sample of 18 projects (totaling $3.4 \mathrm{GW}$ ) currently under construction and anticipating completion in 2016 suggest no material change in capacityweighted average installed costs in $2016 .^{48}$

\footnotetext{
${ }^{47}$ For projects placed in service from 2009 through 2012, Figure 40 partly reflects installed cost estimates derived from publicly available data from the Section 1603 cash grant program. In some cases (although exactly which are unknown), the Section 1603 grant data likely reflect the fair market value rather than the installed cost of wind power projects; in such cases, the installed cost estimates shown in Figure 40 will be artificially inflated.

${ }^{48}$ Learning curves have been used extensively to understand past cost trends and to forecast future cost reductions for a variety of energy technologies, including wind energy. Learning curves start with the premise that increases in the cumulative production or installation of a given technology lead to a reduction in its costs. The principal
} 
Also included in Figure 40 is a single weighted-average data point for 2013 from the EIA, which has recently begun to collect installed cost data through its Form 860 survey instrument.

Although the EIA's capacity-weighted average cost for 2013 is higher than that derived from our sample (which is perhaps skewed to the low side by one sizable project in a year when little capacity was built), it is nevertheless aligned with the declining cost trend from 2009 to 2015 . The EIA plans to report average data for 2014 and 2015 later in 2016; we will include these additional data points in future editions of this report.

\section{Installed costs differed by project size, turbine size, and region}

Average installed project costs exhibit economies of scale, especially at the lower end of the project size range. Figure 41 shows that among the sample of projects installed in 2015, there is a substantial drop in per-kW average installed costs when moving from projects of $5 \mathrm{MW}$ or less to projects in the 5-20 MW range. As project size increases further, however, economies of scale appear to be somewhat less prevalent. A few notable high-cost projects are called out in Figure 41; all are from the high-cost Northeast region, with the two highest-cost projects either using sub-MW turbines (NY) or representing the first utility-scale wind installation in a state (CT). ${ }^{49}$

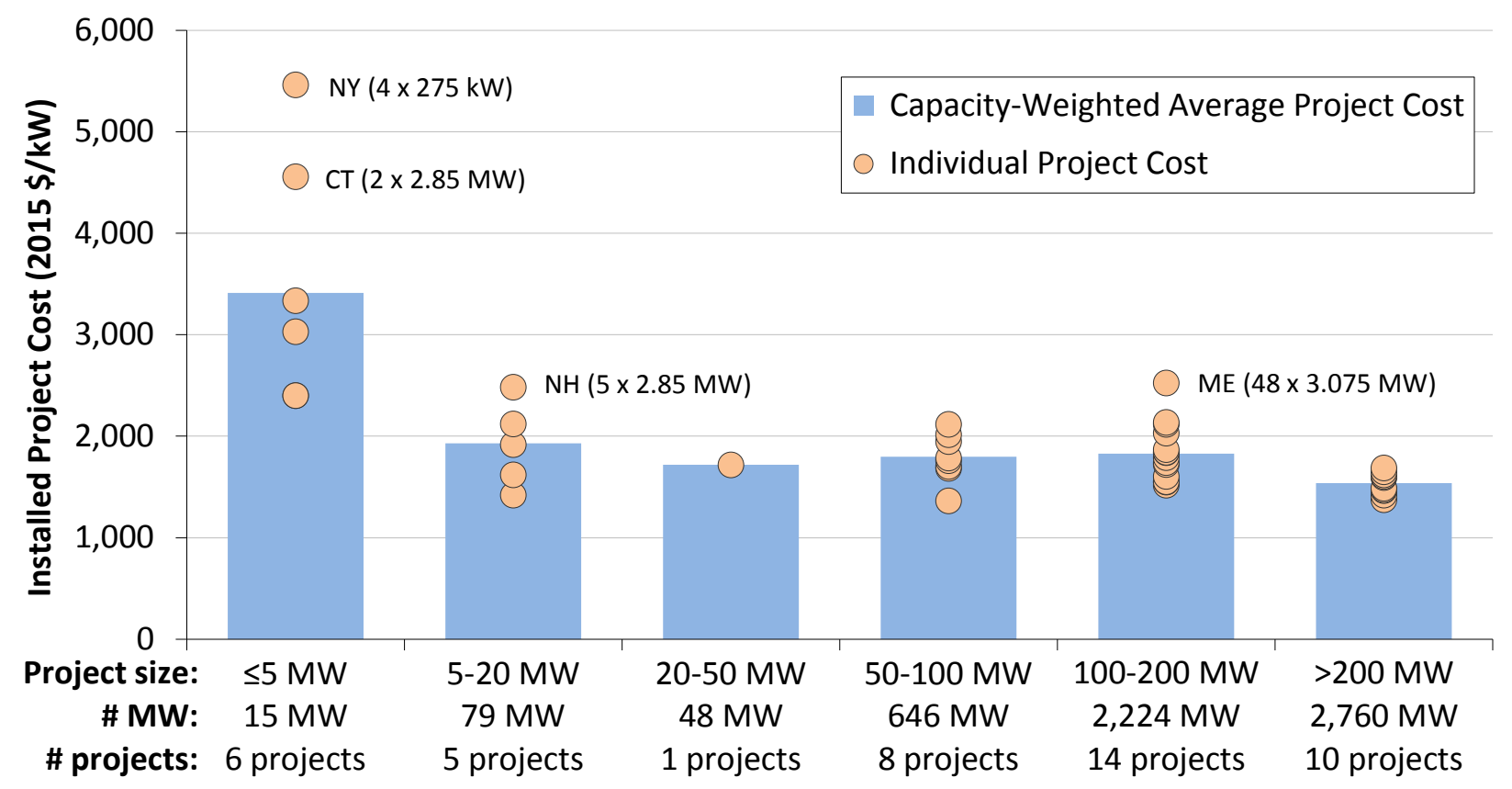

Source: Berkeley Lab

Figure 41. Installed wind power project costs by project size: 2015 projects

parameter calculated by learning curve studies is the learning rate: for every doubling of cumulative production/installation, the learning rate specifies the associated percentage reduction in costs. Considering the full time series of installed cost data presented in Figure 40 (from 1982 through 2015) in conjunction with global cumulative wind power installations over that same period results in a learning rate of $6.5 \%$.

${ }^{49}$ The relatively high $\$ / \mathrm{kW}$ cost of the Connecticut project is also partly due to the fact that the project's nameplate capacity - which serves as the denominator of the $\$ / \mathrm{kW}$ cost estimate - is capped at $5 \mathrm{MW}$, even though the two $2.85 \mathrm{MW}$ turbines are capable of generating a total of $5.7 \mathrm{MW}$. If $\$ / \mathrm{kW}$ costs were based on $5.7 \mathrm{MW}$ rather than 5 $\mathrm{MW}$, the cost of this project would be $\$ 3,995 / \mathrm{kW}$ rather than $\$ 4,554 / \mathrm{kW}$. 
Another way to look for economies of scale is by turbine size (rather than by project size), on the theory that a given amount of wind power capacity may be built less expensively using fewer, larger turbines as opposed to more, smaller turbines. Figure 42 explores this relationship and illustrates that here too some economies of scale are evident as turbine size increasesparticularly moving from sub-MW turbines to MW class turbines. ${ }^{50}$ The same apparent high-cost projects are noted in Figure 42, with the Connecticut project seemingly more of an outlier in this case, viewed within the context of turbine capacity rather than project capacity.

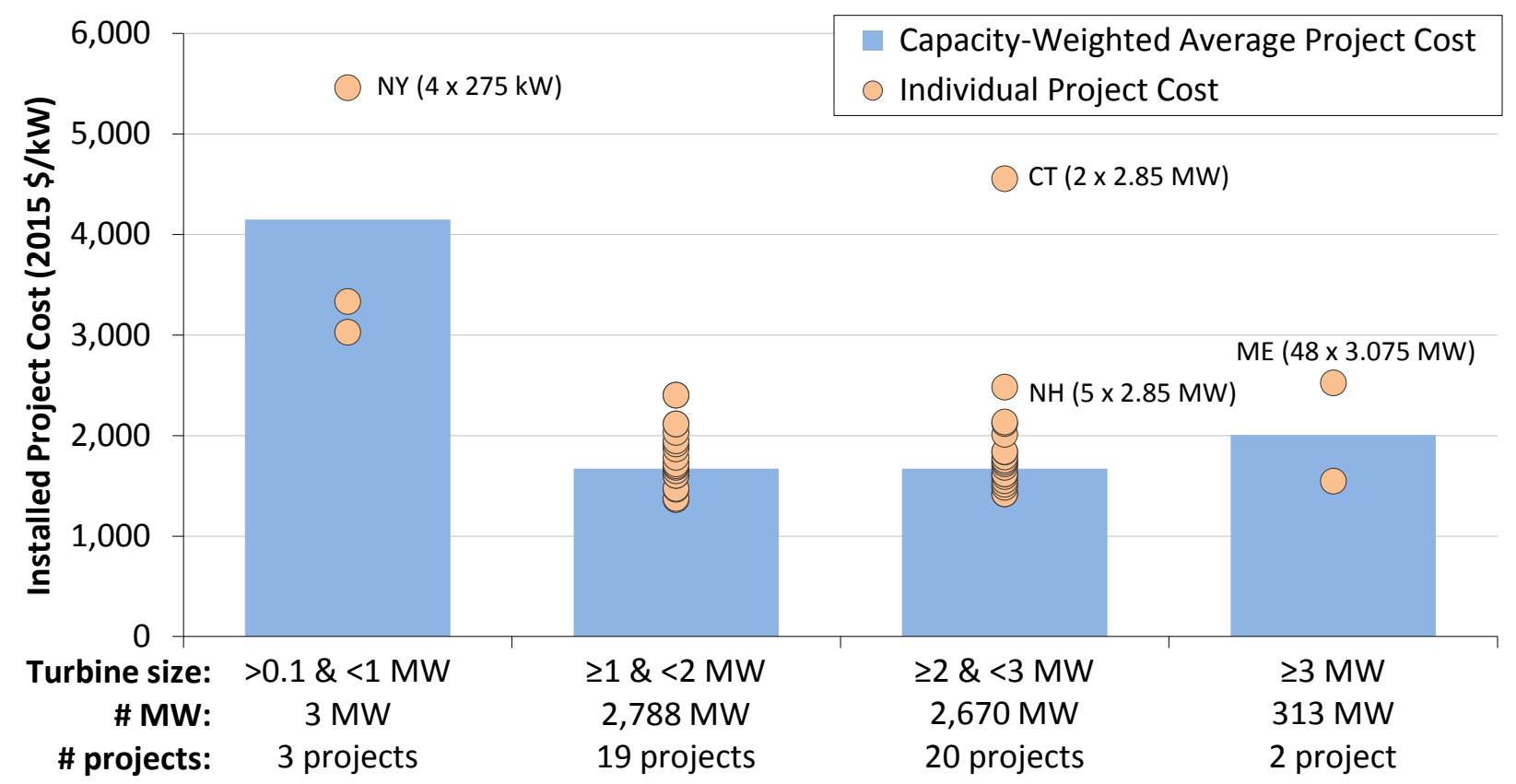

Source: Berkeley Lab

Figure 42. Installed wind power project costs by turbine size: 2015 projects

Regional differences in average project costs are also apparent and may occur due to variations in development costs, transportation costs, siting and permitting requirements and timeframes, and other balance-of-plant and construction expenditures - as well as variations in the turbines deployed in different regions (e.g., use of low-wind-speed technology in regions with lesser wind resources). Considering only projects in the sample that were installed in 2015, Figure 43 breaks out project costs among four of the five regions defined in Figure 29 (there were no projects built in the Southeast region in 2015). ${ }^{51}$ The Interior region — with by far the largest sample - was the lowest-cost region on average, with an average cost of $\$ 1,640 / \mathrm{kW}$, while the Northeast was the

\footnotetext{
${ }^{50}$ There is likely some correlation between turbine size and project size, at least at the low end of the range of each. In other words, projects of $5 \mathrm{MW}$ or less are more likely than larger projects to use individual turbines of less than 1 MW. As such, Figures 41 and 42 - both of which show scale economies at small project or turbine sizes, diminishing as project or turbine size increases - could both be reflecting the same influence, making it difficult to tease out the unique influences of turbine size from project size.

${ }^{51}$ For reference, the 73,992 MW of wind installed in the United States at the end of 2015 is apportioned among the five regions shown in Figure 29 as follows: Interior (63\%), West (19\%), Great Lakes (11\%), Northeast (6\%), and Southeast (1\%). The remaining installed U.S. wind power capacity is located in Hawaii, Alaska, and Puerto Rico and is typically excluded from our analysis sample due to the unique issues facing wind development in these three isolated states/territories.
} 
highest-cost region (although with a sample of just four projects, two of which stand out as unusually high-cost projects). ${ }^{52}$ Viewed within this regional context, the Maine and New Hampshire projects identified as high-cost in Figures 41 and 42 no longer appear as such in Figure 43, while two new single-turbine projects involving sub-MW turbines in the Interior and Great Lakes regions now stand out as high-cost projects for the first time.

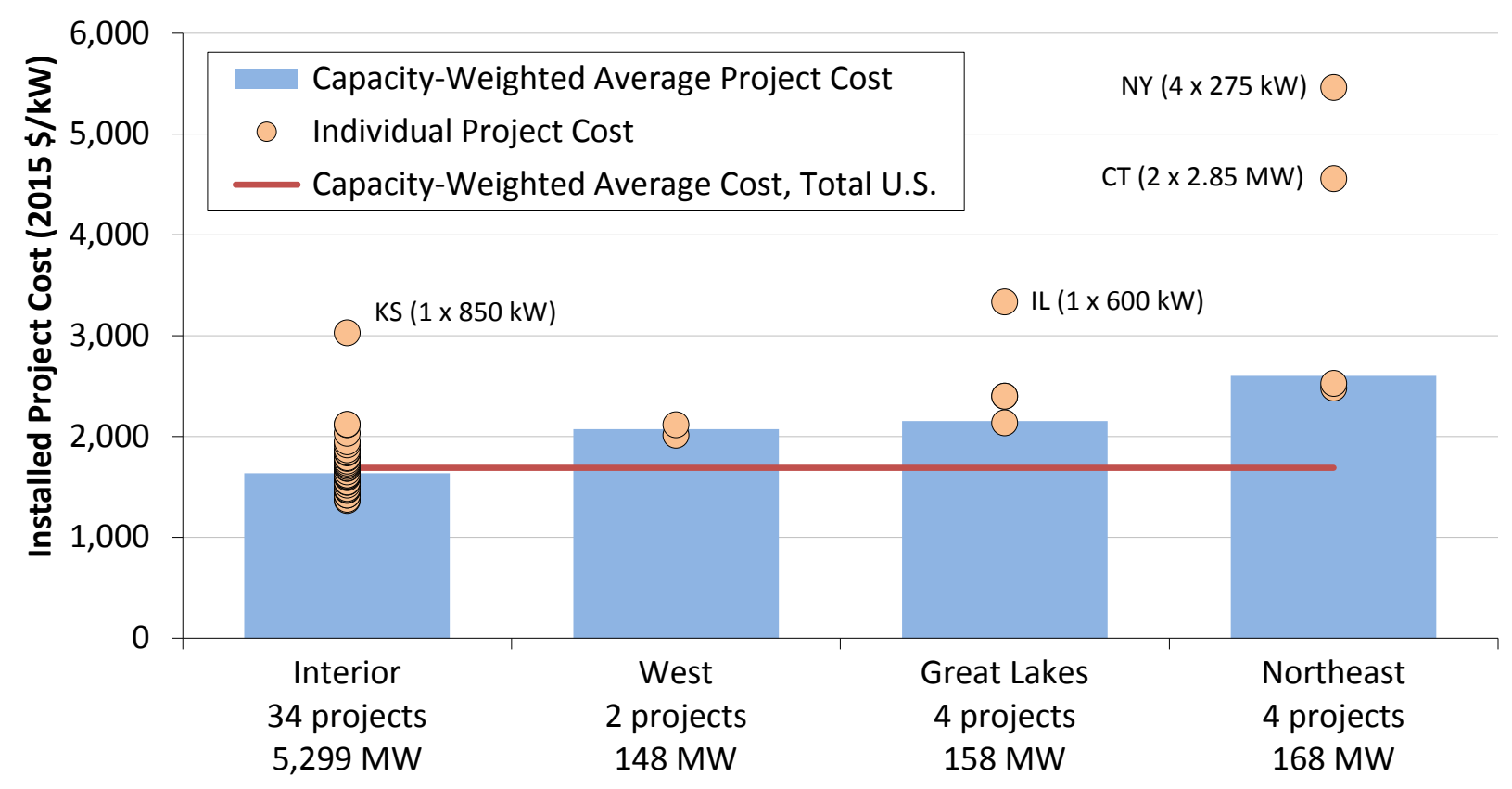

Source: Berkeley Lab

Figure 43. Installed wind power project costs by region: 2015 projects

Finally, Figure 44 shows two histograms that present the distribution of installed project costs among 2015-vintage projects, in terms of both capacity and number of projects. The four projects with costs above $\$ 3,000 / \mathrm{kW}$ are evident in the histogram of projects, but given their small size, they do not really show up in the capacity histogram; hence it is truncated at $\$ 2,500 / \mathrm{kW}$. More generally, it is clear that most of the projects - and all of the low-cost projects - are located in the Interior region, where the distribution is centered on the $\$ 1,600-\$ 1,700 / \mathrm{kW}$ bin. Projects in other regions have higher costs.

\footnotetext{
${ }^{52}$ Graphical presentation of the data in this way should be viewed with some caution, as numerous other factors also influence project costs, and those are not controlled for in Figure 43.
} 

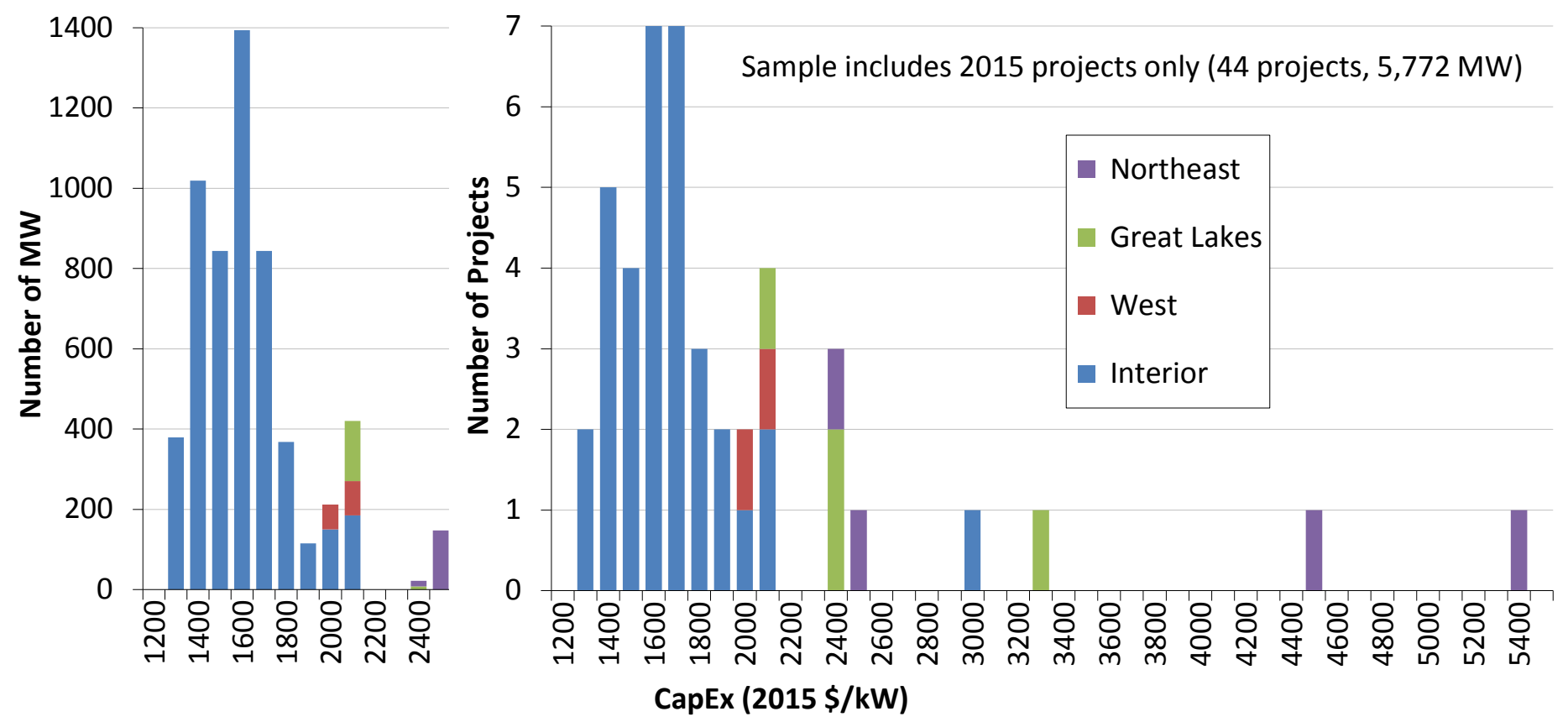

Note: The capacity histogram is truncated at $\$ 2,500 / \mathrm{kW}$ as a space-saving measure, given that the four projects that have higher costs are all very small and hence imperceptible on the capacity histogram.

Source: Berkeley Lab

Figure 44. Histogram of installed costs by MW and projects: 2015 projects

\section{Operations and maintenance costs varied by project age and commercial operations date}

Operations and maintenance costs are an important component of the overall cost of wind energy and can vary substantially among projects. Unfortunately, publicly available market data on actual project-level O\&M costs are not widely available. Even where data are available, care must be taken in extrapolating historical O\&M costs given the dramatic changes in wind turbine technology that have occurred over the last two decades (see Chapter 4).

Berkeley Lab has compiled limited O\&M cost data for 154 installed wind power projects in the United States, totaling 12,080 MW with commercial operation dates of 1982 through 2014.

These data cover facilities owned by both IPPs and utilities, although data since 2004 are exclusively from utility-owned projects. A full time series of O\&M cost data, by year, is available for only a small number of projects; in all other cases, O\&M data are available for just a subset of years of project operations. Although the data sources do not all clearly define what items are included in O\&M costs, in most cases the reported values include the costs of wages and materials associated with operating and maintaining the facility, as well as rent. ${ }^{53}$ Other ongoing expenses, including general and administrative expenses, taxes, property insurance,

\footnotetext{
${ }^{53}$ The vast majority of the recent data derive from FERC Form 1, which uses the Uniform System of Accounts to define what should be reported under "operating expenses"— namely, those operational costs associated with supervision and engineering, maintenance, rents, and training. Though not entirely clear, there does appear to be some leeway within the Uniform System of Accounts for project owners to capitalize certain replacement costs for turbines and turbine components and report them under "electric plant" accounts rather than maintenance accounts.
} 
depreciation, and workers' compensation insurance, are generally not included. As such, the following figures are not representative of total operating expenses for wind power projects; the last paragraphs in this section include data from other sources that demonstrate higher total operating expenses. Given the scarcity, limited content, and varying quality of the data, the results that follow should be taken as indicative of potential overall trends. Note finally that the available data are presented in $\$ / \mathrm{MWh}$ terms, as if O\&M represents a variable cost; in fact, O\&M costs are in part variable and in part fixed. Although not presented here, expressing O\&M costs in units of $\$ / \mathrm{kW}$-year yields qualitatively similar results to those presented in this section.

Figure 45 shows project-level O\&M costs by commercial operation date. ${ }^{54}$ Here, each project's O\&M costs are depicted in terms of its average annual O\&M costs from 2000 through 2015, based on however many years of data are available for that period. For example, for projects that reached commercial operation in 2014, only year 2015 data are available, and that is what is shown in the figure. ${ }^{55}$ Many other projects only have data for a subset of years during the 20002015 timeframe, either because they were installed after 2000 or because a full time series is not available, so each data point in the chart may represent a different averaging period within the overall 2000-2015 timeframe. The chart highlights the 71 projects, totaling 8,465 MW, for which 2015 O\&M cost data were available; those projects have either been updated or added to the chart since the previous edition of this report.

The data exhibit considerable spread, demonstrating that O\&M costs (and perhaps also how O\&M costs are reported by respondents) are far from uniform across projects. However, Figure 45 also suggests that projects installed within the past decade have, on average, incurred lower O\&M costs than those installed earlier. Specifically, capacity-weighted average 2000-2015 O\&M costs for the 24 projects in the sample constructed in the 1980s equal \$35/MWh, dropping to $\$ 24 / \mathrm{MWh}$ for the 37 projects installed in the 1990 s, to $\$ 10 / \mathrm{MWh}$ for the 65 projects installed in the $2000 \mathrm{~s}$, and to $\$ 9 / \mathrm{MWh}$ for the 28 projects installed since $2010 .{ }^{56}$ This drop in O\&M costs may be due to a combination of at least two factors: (1) O\&M costs generally increase as turbines age, component failures become more common, and manufacturer warranties expire; ${ }^{57}$

\footnotetext{
${ }^{54}$ For projects installed in multiple phases, the commercial operation date of the largest phase is used; for repowered projects, the date at which re-powering was completed is used.

${ }^{55}$ Projects installed in 2015 are not shown because only data from the first full year of project operations (and afterwards) are used, which in the case of projects installed in 2015 would be year 2016.

${ }^{56}$ If expressed instead in terms of $\$ / \mathrm{kW}$-year, capacity-weighted average $2000-2015$ O\&M costs were $\$ 68 / \mathrm{kW}$-year for projects in the sample constructed in the $1980 \mathrm{~s}$, dropping to $\$ 57 / \mathrm{kW}$-year for projects constructed in the $1990 \mathrm{~s}$, to $\$ 28 / \mathrm{kW}$-year for projects constructed in the 2000 s, and to $\$ 26 / \mathrm{kW}$-year for projects constructed since 2010 . Somewhat consistent with these observed O\&M costs, Bloomberg NEF (2016c) shows a general reduction in the cost of a sample of initial full-service O\&M contracts (pertaining to the first years of turbine life, and only about 4 GW of which are from North America) since 2008, reaching 21.6 Euro/kW-year in 2015 ( $\$ 24 / \mathrm{kW}$-year). An NREL analysis based on data from DNV KEMA and GL Garrad Hassan covering roughly $5 \mathrm{GW}$ of operating wind projects (with only about half that amount having been operable for longer than five years) also shows average levels of expenditure consistent with the Berkeley Lab dataset, at least when focusing on turbine and balance-of-plant O\&M costs for projects commissioned in the 2000s (Lantz 2013).

${ }^{57}$ Many of the projects installed more recently may still be within their turbine manufacturer warranty period, and/or may have capitalized O\&M service contracts within their turbine supply agreement. Projects choosing the Section 1603 cash grant over the PTC may have had a particular incentive to capitalize service contracts (29 projects totaling $44 \%$ of the sample capacity installed since 2000 were installed from 2009-2012-i.e., within the period of eligibility for the Section 1603 grant - though only five of these 29 projects actually elected the grant over the PTC). In either case, reported O\&M costs will be artificially low.
} 
and (2) projects installed more recently, with larger turbines and more sophisticated designs, may experience lower overall O\&M costs on a per-MWh basis.

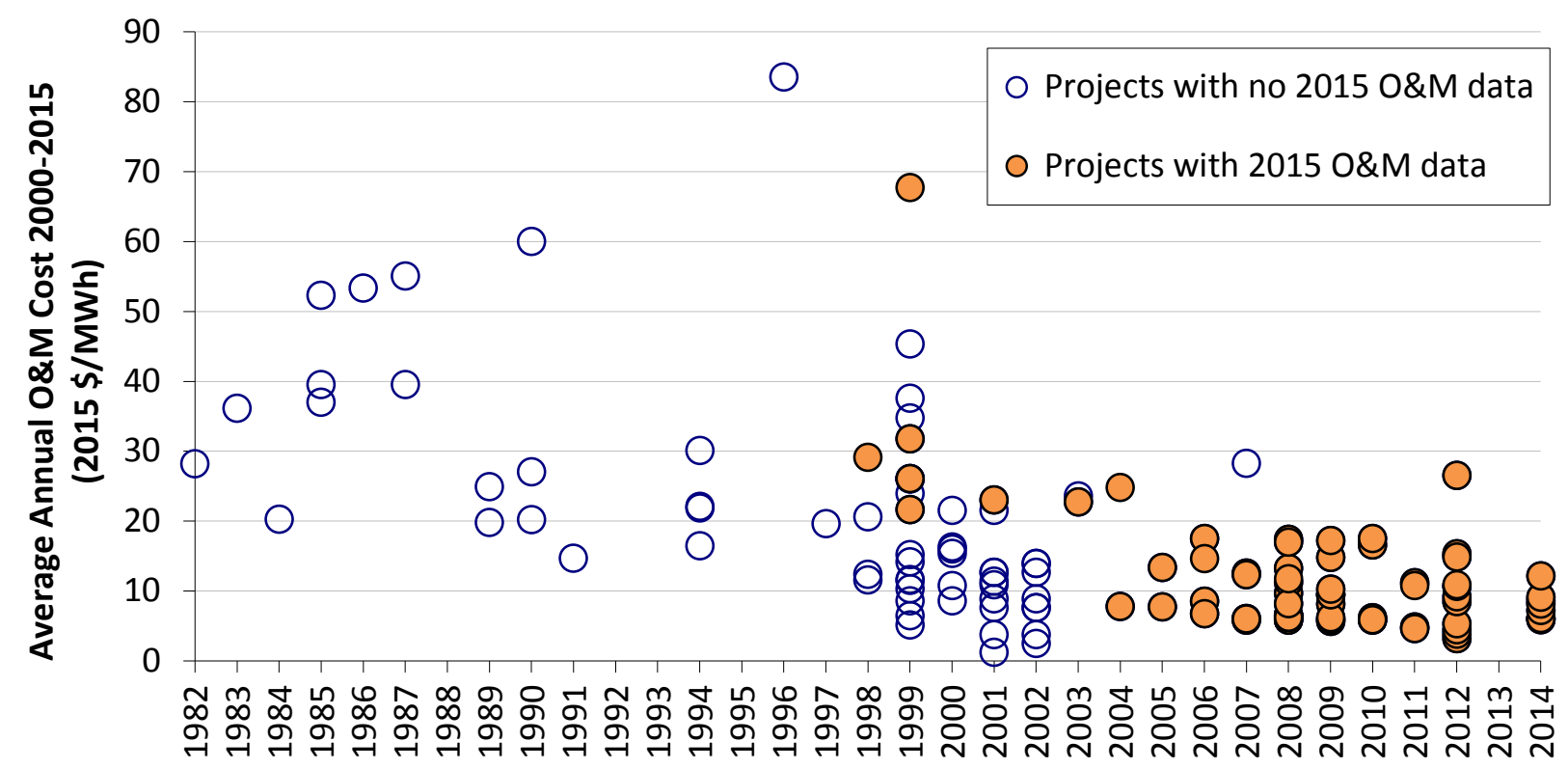

Commercial Operation Date

Source: Berkeley Lab; seven data points suppressed to protect confidentiality

Figure 45. Average O\&M costs for available data years from 2000-2015, by commercial operation date

Although limitations in the underlying data do not permit the influence of these two factors to be unambiguously distinguished, to help illustrate key trends, Figure 46 shows median annual O\&M costs over time, based on project age (i.e., the number of years since the commercial operation date) and segmented into three project-vintage groupings. Data for projects under $5 \mathrm{MW}$ in size are excluded, to help control for the confounding influence of economies of scale, which reportedly can be significant (Bloomberg NEF 2016c). Note that, at each project age increment and for each of the three project vintage groups, the number of projects used to compute median annual O\&M costs is limited and varies substantially.

With these limitations in mind, Figure 46 shows an upward trend in project-level O\&M costs as projects age, at least among the oldest projects in our sample - i.e., those built from 1998-2004 although the sample size after year 4 is rather limited for these earliest projects. This upward trend is consistent with Bloomberg NEF (2016c) data showing that O\&M contract renewals are more expensive than initial service agreements. In addition, the figure shows that projects installed more recently (from 2005-2008 and/or 2009-2014) have had, in general, lower O\&M costs than those installed in earlier years (from 1998-2004), at least for the first 10 years of operation. Parsing the "recent project" cohort into two sub-periods, however, reveals that this trend towards lower costs has not necessarily continued with the most recent projects in the sample; cost differences between the 2005-2008 and 2009-2014 project samples are small, with no consistent trend as projects age. 


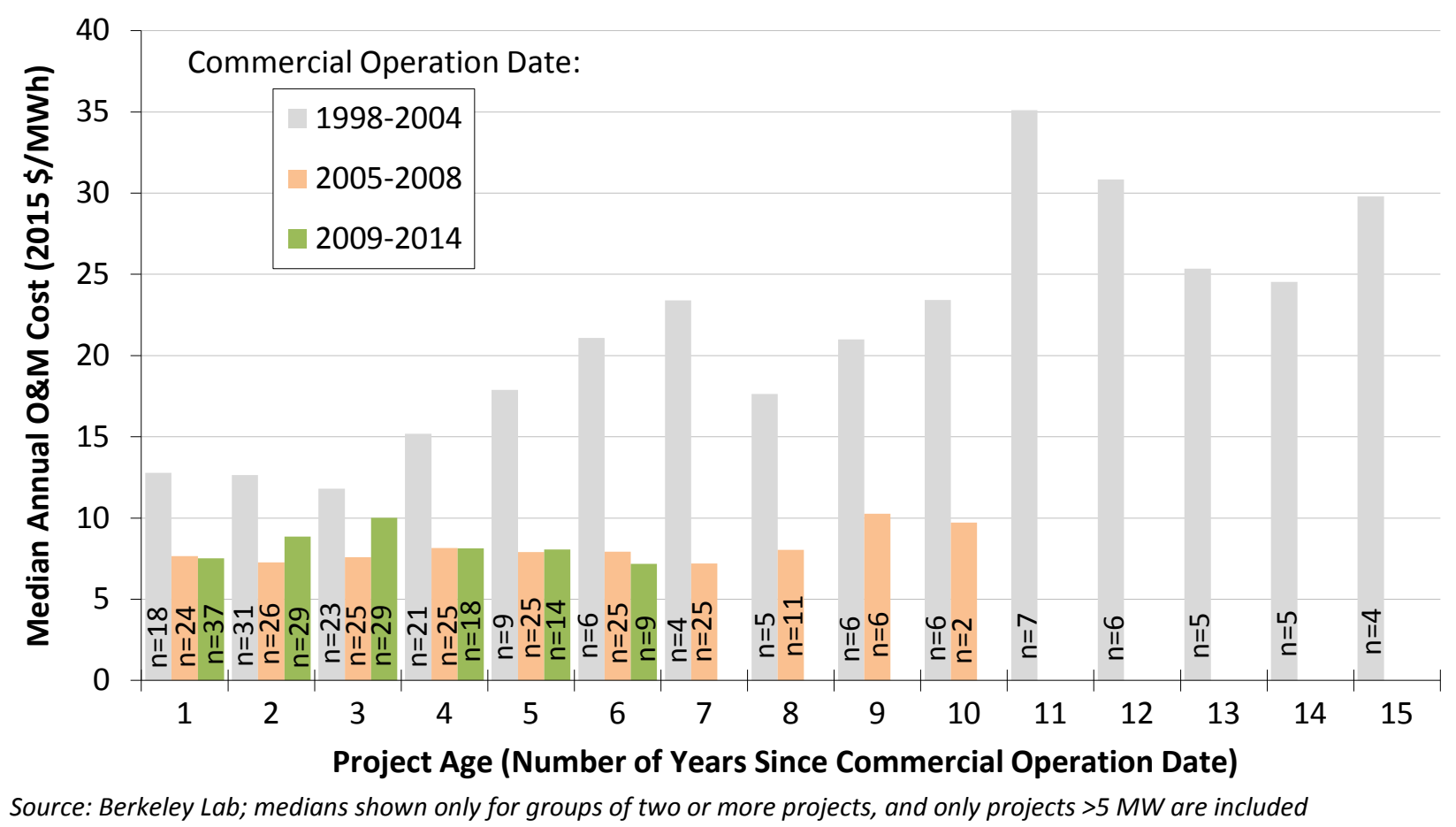

Figure 46. Median annual O\&M costs by project age and commercial operation date

As indicated previously, the data presented in Figures 45 and 46 include only a subset of total operating expenses. In comparison, the financial statements of EDP Renováveis (EDPR), a public company that owned more than $4 \mathrm{GW}$ of U.S. wind project assets at the end of 2015 (all of which has been installed since 2000), indicate markedly higher total operating costs. ${ }^{58}$ Specifically, EDPR (2016) reported total operating expenses of \$25.5/MWh for its U.S. wind project portfolio in $2015^{59}$ - i.e., more than twice the $\sim \$ 10 / \mathrm{MWh}$ average O\&M cost reported above for the 93 projects in the Berkeley Lab data sample installed since 2000.

This disparity in operating costs between EDPR and the Berkeley Lab data sample reflects, in large part, differences in the scope of expenses reported. For example, EDPR breaks out its total U.S. operating costs in 2015 (\$25.5/MWh) into three categories: supplies and services, which "includes O\&M costs" (\$13.5/MWh); personnel costs $(\$ 4.0 / \mathrm{MWh})$; and other operating costs, which "mainly includes operating taxes, leases, and rents" (\$7.9/MWh). Among these three categories, the $\$ 13.5 / \mathrm{MWh}$ for supplies and services is probably closest in scope to the Berkeley Lab data. Confirming these basic findings (i.e., that turbine and balance-of-plant O\&M costs make up only about half of total operating costs), NREL analysis based on data from DNV KEMA on plants commissioned before 2009 shows total operating expenditures of $\$ 40-\$ 60 / \mathrm{kW}$ year depending on project age, with turbine and balance-of-plant O\&M costs representing roughly half of those expenditures (Lantz 2013).

\footnotetext{
${ }^{58}$ Past editions of this report also reported O\&M costs for Infigen, but in October 2015 Infigen's U.S. wind assets were sold to a privately held company that does not file public financial statements.

${ }^{59}$ Though not entirely clear, EDPR's reported operating expenses may exclude any repair or replacement costs that have been capitalized rather than expensed.
} 


\section{Wind Power Price Trends}

Earlier sections documented trends in capacity factors, wind turbine prices, installed project costs, O\&M costs, and project financing - all of which are determinants of the wind power purchase agreement (PPA) prices presented in this chapter. In general, higher-cost and/or lowercapacity-factor projects will require higher PPA prices, while lower-cost and/or higher-capacityfactor projects can have lower PPA prices.

Berkeley Lab collects data on wind PPA prices from the sources listed in the Appendix, resulting in a dataset that currently consists of 387 PPAs totaling 34,558 MW from wind projects that have either been built (from 1998 to the present) or are planned for installation later in 2016 or 2017. All of these PPAs bundle together the sale of electricity, capacity, and renewable energy certificates (RECs), and most of them have a utility as the counterparty. ${ }^{60}$

Except where noted, PPA prices are expressed throughout this chapter on a levelized basis over the full term of each contract, and are reported in real 2015 dollars. ${ }^{61}$ Whenever individual PPA prices are averaged together (e.g., within a region or over time), the average is generationweighted. ${ }^{62}$ Whenever they are broken out by time, the date on (or year in) which the PPA was signed or executed is used, as that date provides the best indication (i.e., better than commercial operation date) of market conditions at the time. Finally, because the PPA prices in the Berkeley Lab sample are reduced by the receipt of state and federal incentives (e.g., the levelized PPA prices reported here would be at least $\$ 15 / \mathrm{MWh}$ higher without the PTC, ITC, or Treasury Grant $^{63}$ ) and are influenced by various local policies and market characteristics, they do not directly represent wind energy generation costs.

\footnotetext{
${ }^{60}$ Though we do have pricing details for some PPAs with corporate off-takers, in many cases such PPAs are synthetic or financial arrangements in which the project sponsor enters into a "contract for differences" with the corporate off-taker around an agreed-upon strike price. Because the strike price is not directly linked to the sale of electricity, it is rarely disclosed (at least through our traditional sources, like regulatory filings). Though only a minor omission at present, this distinction could limit our sample more severely in the future if the popularity of corporate offtake agreement continues to grow at its current pace.

${ }^{61}$ Having full-term price data (i.e., pricing data for the full duration of each PPA, rather than just historical PPA prices) enables us to present these PPA prices on a levelized basis (levelized over the full contract term), which provides a complete picture of wind power pricing (e.g., by capturing any escalation over the duration of the contract). Contract terms range from 5 to 34 years, with 20 years being by far the most common (at $58 \%$ of the sample; $89 \%$ of contracts in the sample are for terms ranging from 15 to 25 years). Prices are levelized using a $7 \%$ real discount rate.

${ }^{62}$ Generation weighting is based on the empirical project-level performance data analyzed earlier in this report and assumes that historical project performance (in terms of annual capacity factor as well as daily and/or seasonal production patterns where necessary) will hold into the future as well. In cases where there is not enough operational history to establish a "steady-state" pattern of performance, we used discretion in estimating appropriate weights (to be updated in the future as additional empirical data become available).

${ }^{63}$ The estimated levelized PPA price impact of $\sim \$ 15 / \mathrm{MWh}$ is less than the PTC's 2015 face value of \$23/MWh for several reasons. First, the PTC is a 10-year credit, whereas most PPAs are for longer terms (e.g., 20 years). Second, the PTC is a tax credit, and must be converted to pre-tax equivalent terms before being compared to PPA prices. Finally, the presence of the PTC constrains financing choices for many wind project owners and drives up the project's weighted average cost of capital. In other words, if not for the PTC, projects could be financed more cheaply; this difference in the weighted average cost of capital with and without the PTC erodes some of the PTC's value (for more information, see Bolinger (2014)).
} 
This chapter summarizes wind PPA prices in a number of different ways: by PPA execution date, by region, compared to wholesale power prices, and compared to future natural gas prices. In addition, REC prices are presented in a text box on page 67.

\section{Wind PPA prices remain very low}

Figure 47 plots contract-level levelized wind PPA prices by contract execution date, showing a clear downward trend in PPA prices since 2009 and 2010 - both overall and by region (see Figure 29 for regional definitions). ${ }^{64}$ This trend is particularly evident within the Interior region, which - as a result of its low average project costs and high average capacity factors shown earlier in this report-also tends to be the lowest-priced region over time. Prices generally have been higher in the rest of the United States. ${ }^{65}$

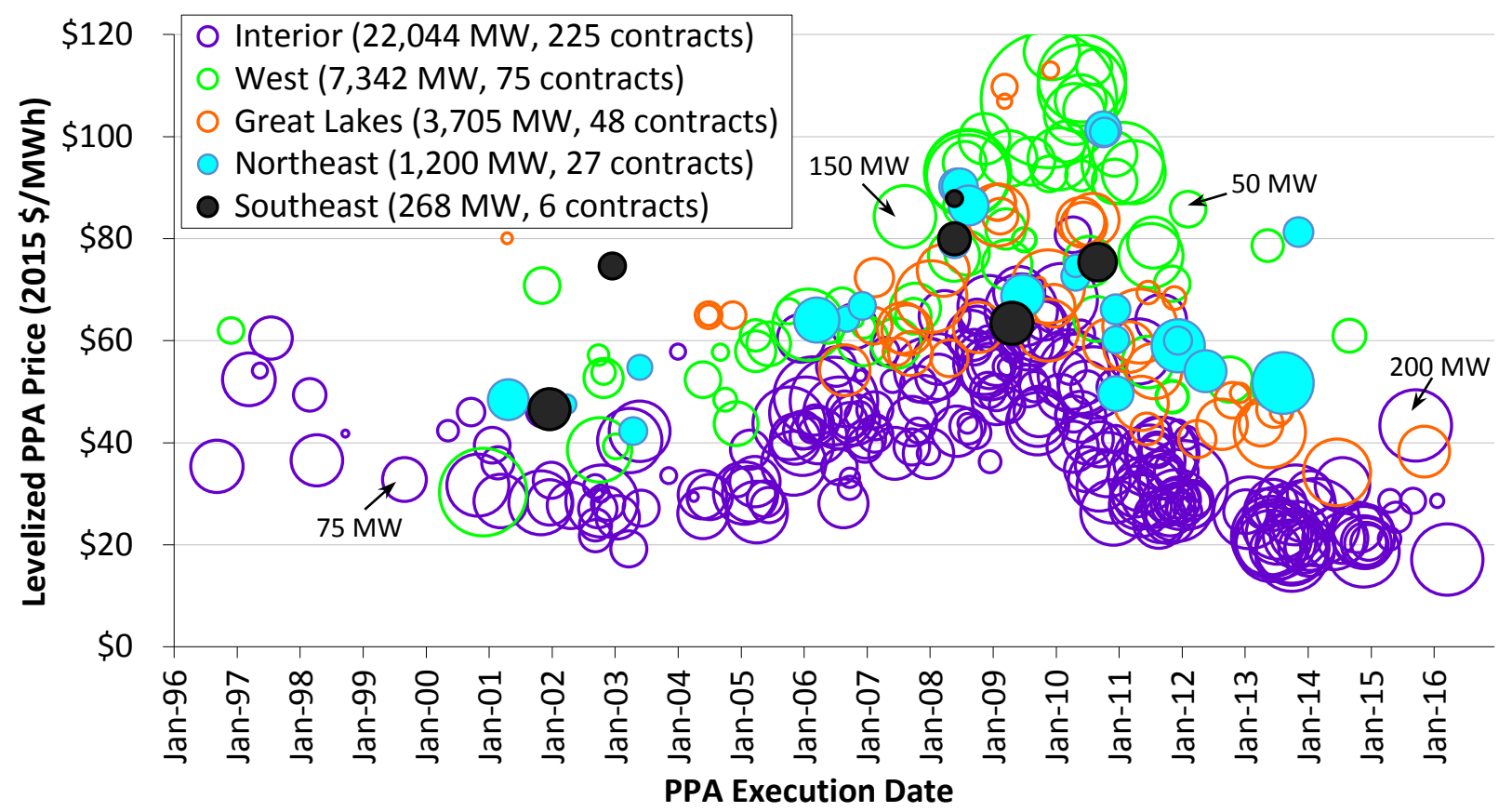

Note: Area of "bubble" is proportional to contract nameplate capacity

Source: Berkeley Lab

Figure 47. Levelized wind PPA prices by PPA execution date and region

Figure 48 provides a smoother look at the time trend nationwide (the blue columns) by averaging the individual levelized PPA prices shown in Figure 47 by year. After topping out at nearly \$70/MWh for PPAs executed in 2009, the national average levelized price of wind PPAs within the Berkeley Lab sample has dropped to around the \$20/MWh level— though this nationwide average is admittedly focused on a sample of projects that largely hail from the lowest-priced

\footnotetext{
${ }^{64}$ Roughly $99 \%$ of the contracts that are depicted in Figure 47 are from projects that are already online. For the most part, only the most recent contracts in the sample are from projects that are not yet online.

${ }^{65}$ Regional differences can affect not only project capacity factors (depending on the strength of the wind resource in a given region), but also development and installation costs (depending on a region's physical geography, population density, labor rates, or even regulatory processes). It is also possible that regions with higher wholesale electricity prices or with greater demand for renewable energy will, in general, yield higher wind energy contract prices due to market influences.
} 
Interior region of the country where most of the new capacity built in recent years is located. Focusing only on the Interior region, the PPA price decline has been more modest, from $\sim \$ 55 / \mathrm{MWh}$ among contracts executed in 2009 to $\sim \$ 20 / \mathrm{MWh}$ today. The temporary price spike among PPAs signed in 2015 is attributable to a small sample (just six projects totaling $401 \mathrm{MW}$ ) that is dominated by two higher-priced contracts totaling $300 \mathrm{MW}$, one of which is located in the Interior region but is selling into California (which perhaps explains the higher price).

The trend of rising PPA prices from 2003 to 2009 and then falling prices since then is directionally consistent with the turbine price and installed project cost trends shown earlier in Chapter 6. In addition, the turbine scaling described in Chapter 4 has, on average, boosted the capacity factors of more recent project vintages, as documented in Chapter 5. This combination of declining costs and improved performance (along with historically low interest rates, as shown earlier in Figure 17) has enabled wind PPA prices to fall to today's record-low levels.

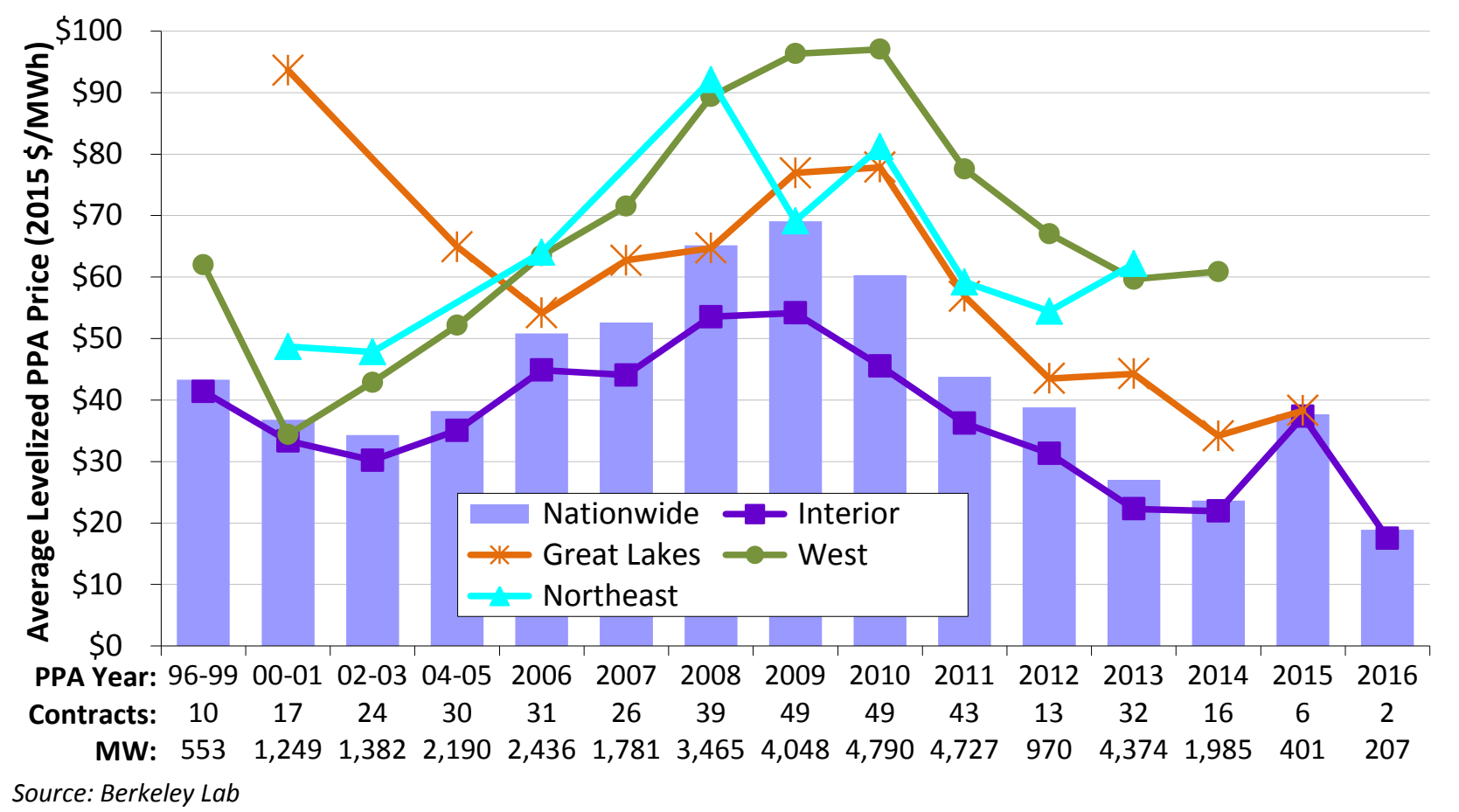

Figure 48. Generation-weighted average levelized wind PPA prices by PPA execution date and region

Figure 48 also shows trends in the generation-weighted average levelized PPA price over time among four of the five regions broken out in Figure 29 (the Southeast region is omitted from Figure 48 owing to its small sample size). Figures 47 and 48 both demonstrate that, based on our contract sample, PPA prices are generally low in the U.S. Interior, high in the West, and moderate in the Great Lakes and Northeast regions. As shown by the close agreement between the two, the large Interior region - where much of U.S. wind project development occursdominates the nationwide sample, particularly in recent years. 


\section{The relative economic competitiveness of wind power declined in 2015 with the drop in wholesale power prices}

The blue-shaded area of Figure 49 shows the range (minimum and maximum) of average annual wholesale electricity prices for a flat block of power ${ }^{66}$ going back to 2003 at 23 different pricing nodes located throughout the country (refer to the Appendix for the names and approximate locations of the 23 pricing nodes represented by the blue-shaded area). Similarly, the orangeshaded area shows the range of wholesale prices among only those nodes that are located within the Interior region. Our PPA price sample is increasingly dominated by projects in this region. Finally, the dark diamonds represent the generation-weighted average levelized wind PPA prices (with error bars denoting the $10^{\text {th }}$ and $90^{\text {th }}$ percentiles) in the years in which contracts were executed (consistent with the nationwide averages presented in Figure 48).

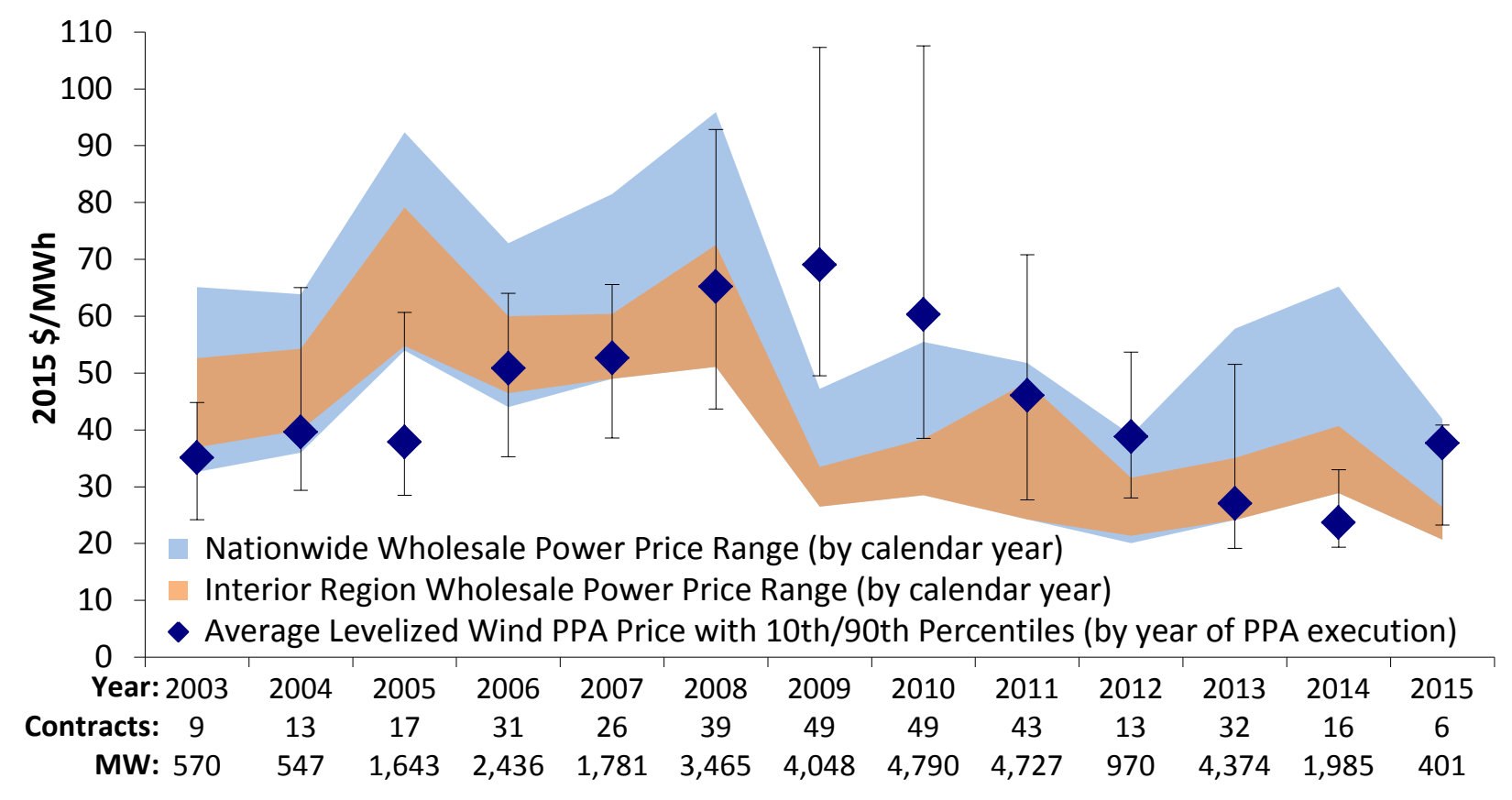

Source: Berkeley Lab, FERC, ABB, IntercontinentalExchange

Figure 49. Average levelized long-term wind PPA prices and yearly wholesale electricity prices over time

At least within the sample of projects reported here, average long-term wind PPA prices compared favorably to yearly wholesale electricity prices from 2003 through 2008. Starting in 2009 , however, the sharp drop in wholesale electricity prices (driven primarily by lower natural gas prices) squeezed average wind PPA prices out of the wholesale power price range on a

\footnotetext{
${ }^{66}$ A flat block of power is defined as a constant amount of electricity generated and sold over a specified period. Although wind power projects do not provide a flat block of power, as a common point of comparison a flat block is not an unreasonable starting point. In other words, the time variability of wind energy is often such that its wholesale market value is somewhat lower than, but not too dissimilar from, that of a flat block of (non-firm) power, at least at lower levels of wind penetration (Fripp and Wiser 2006). At higher levels of wind penetration, wind power can suppress local wholesale power prices during times of peak output and/or low demand, thereby eroding its value in the wholesale market relative to a flat block of power.
} 
nationwide basis. Wind PPA prices have since fallen, however, and in 2011 and 2012 reconnected with the upper end of the wholesale power price range. In 2013 and 2014, further PPA price declines, along with a bit of a rebound in wholesale prices, put wind back at the bottom of the range once again. Subsequently, the sharp drop in average wholesale electricity prices in 2015 has made it somewhat harder for wind to compete in the market. The spike in PPA prices among the small sample of 2015 projects mentioned above did not help, though focusing on the $10^{\text {th }}$ to $90^{\text {th }}$ percentile range rather than the weighted-average PPA price perhaps provides a more representative comparison in that year. Even so, the much narrower and lower range of wholesale power prices in the Interior region is arguably the more relevant comparison in recent years, as project development has been largely concentrated within that region.

The comparison between levelized wind PPA and wholesale power prices in Figures 49 is imperfect, in part because the levelized wind PPA prices represent a future stream of prices that has been locked in (and that often extends for 20 years or longer), whereas the wholesale power prices are pertinent to just the single year in question. Figure 50 attempts to remedy this temporal mismatch by presenting an alternative (yet still imperfect) way of looking at how wind stacks up relative to its competition.

Rather than levelizing the wind PPA prices, Figure 50 plots the future stream of wind PPA prices (the $10^{\text {th }}, 50^{\text {th }}$, and $90^{\text {th }}$ percentile prices are shown, along with a generation-weighted average) from PPAs executed in 2014, 2015, or 2016 against the EIA's latest projections of just the fuel costs of natural gas-fired generation. ${ }^{67}$ As shown, the median and generation-weighted average wind PPA prices from contracts executed in the past three years are consistently at or below the low end of the projected natural gas fuel cost range over the entire period, while the $90^{\text {th }}$ percentile wind PPA prices are initially above the high end of the fuel cost range, but fall below the reference case projection and into the lower portion of the fuel cost range from 2024-2040.

Figure 50 also hints at the long-term value that wind power can provide as a "hedge" against rising and/or uncertain natural gas prices. The wind PPA prices that are shown have been contractually locked in, whereas the fuel cost projections to which they are compared are highly uncertain. Actual fuel costs could ultimately be lower or much higher. Either way, as evidenced by the widening range of fuel cost projections over time, it becomes increasingly difficult to forecast fuel costs with any accuracy as the term of the forecast increases.

\footnotetext{
${ }^{67}$ The fuel cost projections come from the EIA's Annual Energy Outlook 2016 publication, and increase from around $\$ 3.89 / \mathrm{MMBtu}$ in 2017 to $\$ 5.36 / \mathrm{MMBtu}$ (both in 2015 dollars) in 2040 in the reference case. The upper and lower bounds of the fuel cost range reflect the low (and high, respectively) oil and gas resource and technology cases. All fuel prices are converted from \$/MMBtu into $\$ / \mathrm{MWh}$ using a flat heat rate of $7 \mathrm{MMBtu} / \mathrm{MWh}$, which is aggressive compared to the heat rates implied by the reference case modeling output (which start at roughly 7.9 MMBtu/MWh in 2017 and gradually decline to just above 7 MMBtu/MWh by 2040).
} 


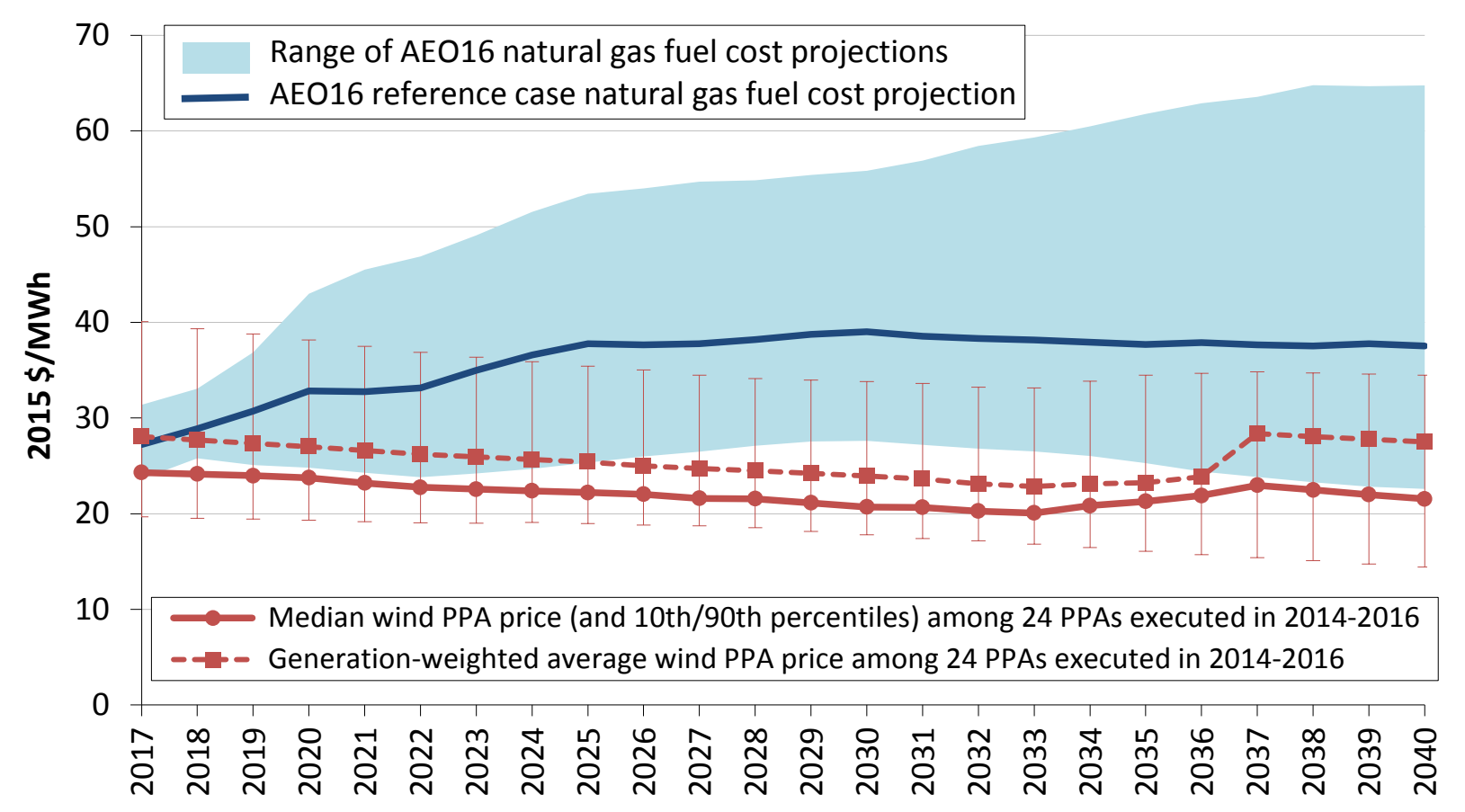

Source: Berkeley Lab, EIA

Figure 50. Wind PPA prices and a natural gas fuel cost projections by calendar year over time

Important Note: Notwithstanding the comparisons made in this section, neither the wind nor wholesale electricity prices (nor fuel cost projections) reflect the full social costs of power generation and delivery. Among the various shortcomings of comparing wind PPA and wholesale power prices in this manner are the following:

- Wind PPA prices are reduced by virtue of federal and, in some cases, state tax and financial incentives. Similarly, wholesale electricity prices (or fuel cost projections) are reduced by virtue of any financial incentives provided to fossil-fueled generation and its fuel production, as well as by not fully accounting for the environmental and social costs of fossil generation.

- Wind PPA prices do not fully reflect integration, resource adequacy, or transmission costs, while wholesale electricity prices (or fuel cost projections) also do not fully reflect transmission costs, and may not fully reflect capital and fixed (or variable) operating costs.

- Wind PPA prices - once established - are fixed and known, whereas wholesale electricity prices are short-term and therefore subject to change. As shown in Figure 50, EIA projects natural gas prices to rise from current levels, resulting in an increase in wholesale electricity prices.

- The location of the sampled wholesale electricity nodes and the assumption of a flat block of power are not perfectly consistent with the location and output profile of the sample of wind power projects. Especially at higher penetrations and in locations where wind generation profiles are poorly correlated with local load profiles, excessive wind generation during times of peak output and/or low load can push the wholesale market value of wind power well below that of a flat block of power.

In short, comparing levelized long-term wind PPA prices with either yearly wholesale electricity prices or forecasts of the fuel costs of natural gas-fired generation is not appropriate if one's goal 
is to account fully for the costs and benefits of wind energy relative to its competition. Nonetheless, these comparisons still provide some sense for the short-term competitive environment facing wind energy, and convey how that environment has shifted over time.

\section{REC Prices Remained Near "Alternative Compliance Payment" Levels in the Northeast, While Falling Modestly among Mid-Atlantic States}

The wind power sales prices presented in this report reflect only the bundled sale of both electricity and RECs; excluded are projects that sell RECs separately from electricity, thereby generating two sources of revenue. REC markets are somewhat fragmented in the United States but consist of two distinct segments: compliance markets, in which RECs are purchased to meet state RPS obligations, and green power markets, in which RECs are purchased on a voluntary basis.

The figures below present indicative data of spot-market REC prices in both compliance and voluntary markets. Data for compliance markets focus on "Class I" or "Tier I" RPS requirements, as these are the RPS compliance markets in which wind energy would typically participate. Clearly, spot REC prices have varied substantially, both across states and over time within individual states, though prices within regional power markets (New England and the Mid-Atlantic) are linked to varying degrees. In New England compliance markets (other than Maine), REC prices in 2015 remained relatively high; prices hovered around the $\$ 55 / \mathrm{MWh}$ alternative compliance payment $(A C P)$ rate in Connecticut and Rhode Island, reflecting an expectation of continued under-supply in the region. Among Mid-Atlantic states, REC pricing generally ranged from $\$ 15-20 / \mathrm{MWh}$, falling modestly over the course of the year. Prices for RECs offered in the national and western voluntary markets and for RPS compliance in Texas remained at roughly $\$ 1 / \mathrm{MWh}$ throughout the year, reflecting sustained over-supply.
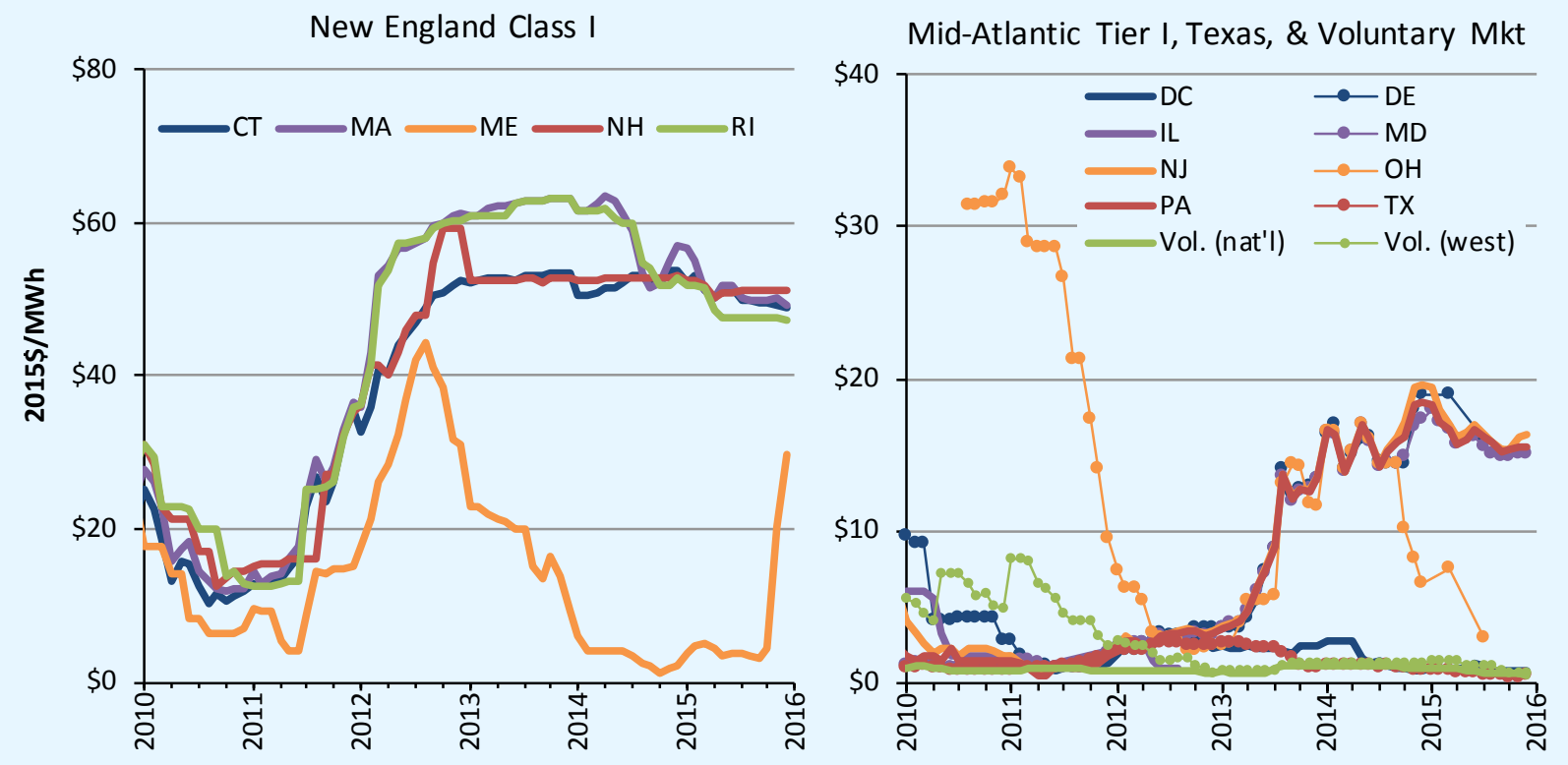

Notes: Plotted values are the monthly averages of daily closing prices for REC vintages from the current or nearest future year traded.

Source: Marex Spectron. 


\section{Policy and Market Drivers}

\section{A long-term extension and phase down of federal incentives for wind projects is leading to a resurgent domestic market}

Various policy drivers at both the federal and state levels, as well as federal investments in wind energy research and development (R\&D), have been important to the expansion of the wind power market in the United States. At the federal level, the most important policy incentives in recent years have been the PTC (or, if elected, the ITC) and accelerated tax depreciation.

Initially established in 1994, the PTC provides a 10-year, inflation-adjusted credit that stood at \$23/MWh in 2015 (Table 5). The historical importance of the PTC to the U.S. wind industry is illustrated by the pronounced lulls in wind additions in the 4 years $(2000,2002,2004,2013)$ during which the PTC lapsed as well as the increased development activity often seen during the year in which the PTC is otherwise scheduled to expire (see Figure 1).

In December 2015, Congress passed a long term, 5-year extension of the PTC (or, if elected, the ITC). To qualify, projects must begin construction before January 1, 2020. Moreover, in May 2016, the IRS issued favorable guidance allowing four years for project completion after the start of construction, without the burden of having to prove continuous construction. This new guidance lengthened the "safe harbor" completion period from the previous term of two years.

In extending the PTC, Congress also put the wind industry on a glide path to a lower PTC, with a progressive reduction in the value of the credit for projects starting construction after 2016. Specifically, the PTC will phase down in 20\%-per-year increments for projects starting construction in 2017 (80\% PTC value), 2018 (60\%), and 2019 (40\%).

In addition to the PTC, a second form of federal tax support for wind is accelerated tax depreciation, which historically has enabled wind project owners to depreciate the vast majority of their investments over a 5- to 6-year period for tax purposes. Even more attractive "bonus depreciation" schedules have been periodically available, since 2008.

The near-term availability of the PTC is leading a resurgence of the U.S. wind power market, with solid continued growth in capacity additions expected over the next five years. The PTC phase down, on the other hand, imposes longer-term risks. Potentially helping to partially fill that void are the prospective impacts of more-stringent EPA environmental regulations on fossil plant retirement, energy costs, and demand for clean energy - which may create new opportunities for wind in the longer term. Of note are the actions to address carbon emissions that have been initiated at the EPA through the Clean Power Plan, though those regulations remain in limbo as legal challenges are resolved. Finally, R\&D investments by the DOE continue, and could further reduce the cost of wind energy. 
Table 5. History of the Production Tax Credit Extensions

\begin{tabular}{|c|c|c|c|c|}
\hline Legislation & $\begin{array}{c}\text { Date } \\
\text { Enacted }\end{array}$ & $\begin{array}{c}\text { Start of } \\
\text { PTC Window }\end{array}$ & $\begin{array}{l}\text { End of } \\
\text { PTC Window }\end{array}$ & $\begin{array}{c}\text { Effective PTC } \\
\text { Planning Window } \\
\text { (considering lapses and } \\
\text { early extensions) }\end{array}$ \\
\hline Energy Policy Act of 1992 & 10/24/1992 & $1 / 1 / 1994$ & $6 / 30 / 1999$ & 80 months \\
\hline $\begin{array}{l}\text { Ticket to Work and Work } \\
\text { Incentives Improvement } \\
\text { Act of } 1999\end{array}$ & $\begin{array}{c}12 / 19 / 1999 \\
\text { (lapsed for }>5 \\
\text { months) }\end{array}$ & 7/1/1999 & $12 / 31 / 2001$ & 24 months \\
\hline $\begin{array}{l}\text { Job Creation and Worker } \\
\text { Assistance Act }\end{array}$ & $\begin{array}{c}3 / 9 / 2002 \\
\text { (lapsed for }>2 \\
\text { months) }\end{array}$ & $1 / 1 / 2002$ & $12 / 31 / 2003$ & 22 months \\
\hline $\begin{array}{l}\text { The Working Families Tax } \\
\text { Relief Act }\end{array}$ & $\begin{array}{c}10 / 4 / 2004 \\
\text { (lapsed for }>9 \\
\text { months) }\end{array}$ & $1 / 1 / 2004$ & $12 / 31 / 2005$ & 15 months \\
\hline Energy Policy Act of 2005 & $8 / 8 / 2005$ & $1 / 1 / 2006$ & $12 / 31 / 2007$ & 29 months \\
\hline $\begin{array}{l}\text { Tax Relief and Healthcare } \\
\text { Act of } 2006\end{array}$ & $12 / 20 / 2006$ & $1 / 1 / 2008$ & $12 / 31 / 2008$ & 24 months \\
\hline $\begin{array}{l}\text { Emergency Economic } \\
\text { Stabilization Act of } 2008\end{array}$ & $10 / 3 / 2008$ & $1 / 1 / 2009$ & $12 / 31 / 2009$ & 15 months \\
\hline $\begin{array}{l}\text { The American Recovery and } \\
\text { Reinvestment Act of } 2009\end{array}$ & $2 / 17 / 2009$ & $1 / 1 / 2010$ & $12 / 31 / 2012$ & 46 months \\
\hline $\begin{array}{l}\text { American Taxpayer Relief } \\
\text { Act of } 2012\end{array}$ & $\begin{array}{c}1 / 2 / 2013 \\
\text { (lapsed for } 1-2 \\
\text { days) }\end{array}$ & $1 / 1 / 2013$ & $\begin{array}{l}\text { Start construction } \\
\text { by } 12 / 31 / 2013\end{array}$ & $\begin{array}{l}12 \text { months (in which to start } \\
\text { construction) }\end{array}$ \\
\hline $\begin{array}{l}\text { Tax Increase Prevention Act } \\
\text { of } 2014\end{array}$ & $\begin{array}{l}12 / 19 / 2014 \\
\text { (lapsed for } \\
\text { >11 months) }\end{array}$ & $1 / 1 / 2014$ & $\begin{array}{l}\text { Start construction } \\
\text { by } 12 / 31 / 2014\end{array}$ & $\begin{array}{l}2 \text { weeks (in which to start } \\
\text { construction) }\end{array}$ \\
\hline \multirow{4}{*}{$\begin{array}{l}\text { Consolidated } \\
\text { Appropriations Act of } 2016\end{array}$} & \multirow{4}{*}{$\begin{array}{l}12 / 18 / 2015 \\
\text { (lapsed for } \\
>11 \text { months) }\end{array}$} & \multirow{4}{*}{$1 / 1 / 2015$} & $\begin{array}{l}\text { Start construction } \\
\text { by } 12 / 31 / 2016\end{array}$ & $\begin{array}{l}12 \text { months to start construction } \\
\text { and receive } 100 \% \text { PTC value }\end{array}$ \\
\hline & & & $\begin{array}{l}\text { Start construction } \\
\text { by } 12 / 31 / 2017\end{array}$ & $\begin{array}{l}24 \text { months to start construction } \\
\text { and receive } 80 \% \text { PTC value }\end{array}$ \\
\hline & & & $\begin{array}{l}\text { Start construction } \\
\text { by } 12 / 31 / 2018\end{array}$ & $\begin{array}{l}36 \text { months to start construction } \\
\text { and receive } 60 \% \text { PTC value }\end{array}$ \\
\hline & & & $\begin{array}{l}\text { Start construction } \\
\text { by } 12 / 31 / 2019\end{array}$ & $\begin{array}{l}48 \text { months to start construction } \\
\text { and receive } 40 \% \text { PTC value }\end{array}$ \\
\hline
\end{tabular}

Notes: Although the table pertains only to PTC eligibility, the American Recovery and Reinvestment Act of 2009 enabled wind projects to elect a $30 \%$ investment tax credit (ITC) in lieu of the PTC starting in 2009; though it is rarely used, this ITC option has been included in all subsequent PTC extensions (and will follow the same phase down schedule as the PTC, as noted in the table: from $30 \%$ to $24 \%$ to $18 \%$ to $12 \%$ ). Section 1603 of the same law enabled wind projects to elect a $30 \%$ cash grant in lieu of either the $30 \%$ ITC or the PTC; this option was only available to wind projects that were placed in service from $2009-2012$ (and that had started construction prior to the end of 2011), and was widely used during that period. Finally, beginning with the American Taxpayer Relief Act of 2012, which extended the PTC window through 2013, the traditional "placed in service" deadline was changed to a more-lenient "construction start" deadline, which has persisted in the two subsequent extensions. Related, the IRS initially issued safe harbor guidelines providing projects that meet the applicable construction start deadline up to two full years to be placed in service (without having to prove continuous effort) in order to qualify for the PTC. In May 2016, the IRS lengthened this safe harbor window to four full years.

Source: Berkeley Lab 


\section{State policies help direct the location and amount of wind power development, but current policies cannot support continued growth at recent levels}

As of July 2016, mandatory RPS programs existed in 29 states and Washington D.C. (Figure 51). ${ }^{68}$ Attempts to weaken RPS policies have been initiated in a number of states, and in limited cases - thus far only Ohio in 2014 and Kansas in 2015-have led to a freeze or repeal of RPS requirements. In contrast, other states - including, most recently, California, Hawaii, Oregon, Rhode Island, and Washington, DC - have increased and extended their RPS targets. Vermont has created a new RPS.

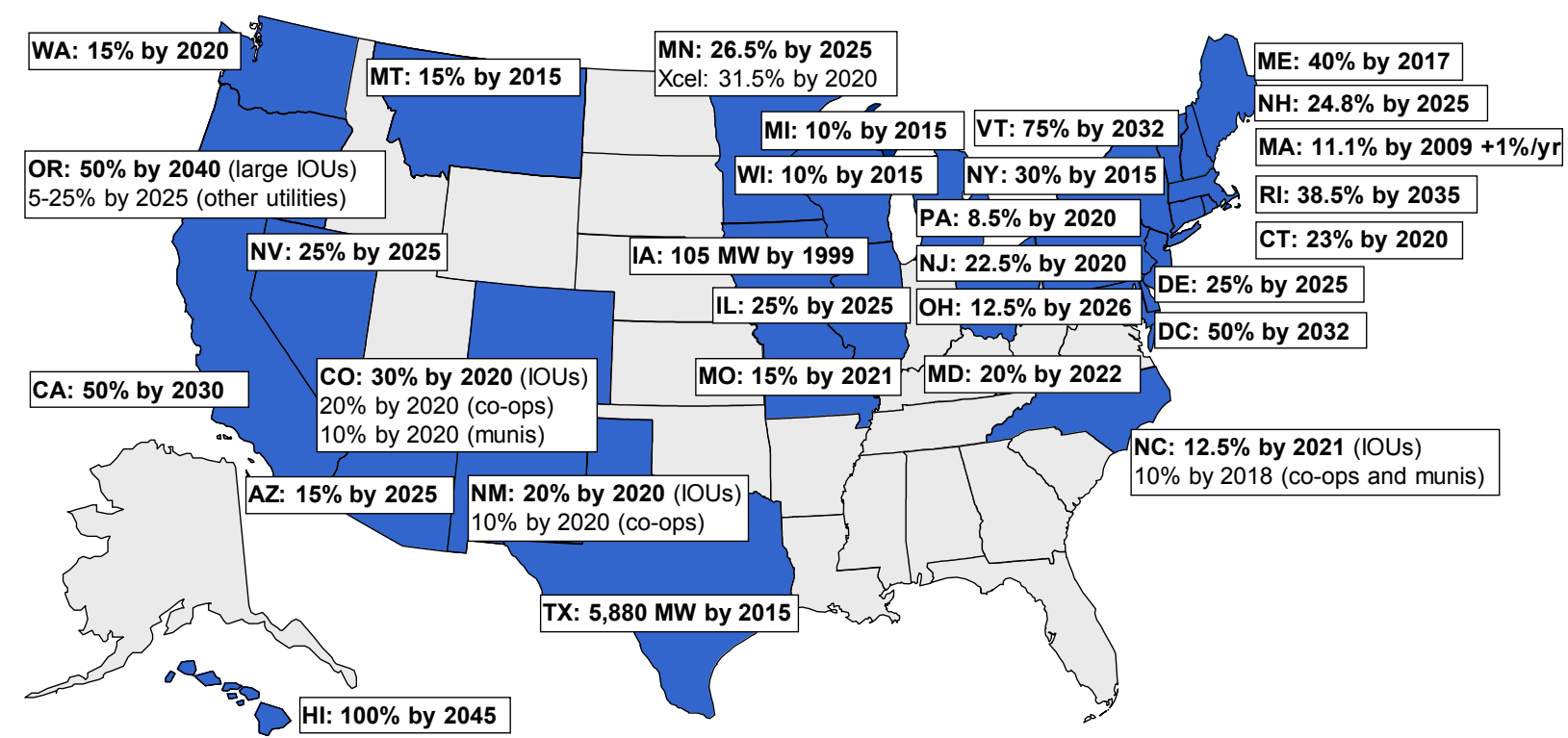

Notes: The figure does not include mandatory RPS policies established in U.S. territories or non-binding renewable energy goals adopted in U.S. states and territories. Note also that many states have multiple "tiers" within their RPS policies, though those details are not summarized in the figure.

Source: Berkeley Lab

Figure 51. State RPS policies as of July 2016

Of all wind power capacity built in the United States from 2000 through 2015 , roughly $51 \%$ is delivered to load serving entities (LSEs) with RPS obligations. In recent years, however, the role of state RPS programs in driving incremental wind power growth has diminished, at least on a national basis; just $24 \%$ of U.S. wind capacity additions in 2015 serve RPS requirements. Outside of the wind-rich Interior region, however, $88 \%$ of wind capacity additions in 2015 are serving RPS demand, and RPS requirements continue to serve as a strong driver for wind power growth.

In aggregate, existing state RPS policies will require 420 terawatt-hours of RPS-eligible forms of renewable electricity by 2030, at which point most state RPS requirements will have reached their maximum percentage targets. Based on the mix and capacity factors of resources currently used or contracted for RPS compliance, this equates to a total of roughly $130 \mathrm{GW}$ of RPS-

\footnotetext{
${ }^{68}$ Although not shown in Figure 51, mandatory RPS policies also exist in a number of U.S. territories, and nonbinding renewable energy goals exist in a number of U.S. states and territories.
} 
eligible renewable generation capacity needed to meet RPS demand in $2030 .{ }^{69}$ Given current renewable energy supplies available for RPS compliance, Berkeley Lab estimates that existing state RPS programs will require roughly $55 \mathrm{GW}$ of renewable capacity additions by 2030 , relative to the installed base at year-end $2015 .{ }^{70}$ This equates to an average annual build-rate of roughly $3.7 \mathrm{GW}$ per year, not all of which will be wind. This is below the average of $6.6 \mathrm{GW}$ of wind power capacity added in each year over the past decade, and even further below the average $9.5 \mathrm{GW}$ per year of total renewable generation capacity added during that time frame.

In addition to state RPS policies, utility resource planning requirements, principally in Western and Midwestern states, have spurred wind power additions in recent years. So has voluntary customer demand for "green" power (see box below for a discussion of burgeoning commercial interest in wind energy). State renewable energy funds provide support (both financial and technical) for wind power projects in some jurisdictions, as do a variety of state tax incentives. Finally, concerns about the possible impacts of global climate change continue to fuel interest in implementing and enforcing carbon reduction policies in some states and regions. The Northeast's Regional Greenhouse Gas Initiative (RGGI) cap-and-trade policy, for example, has been operational for a number of years, and California's greenhouse gas cap-and-trade program commenced operation in 2012, although carbon pricing seen to date has been too low to drive significant wind energy growth. How these dynamics will evolve as the EPA steps in to regulate power sector carbon emissions through the Clean Power Plan, and the role that RPS programs will play in achieving carbon emissions targets, both remain unclear.

\footnotetext{
${ }^{69}$ Berkeley Lab's projections of new renewable capacity required to meet each state's RPS requirements assume different combinations of renewable resource types for each RPS state. Those assumptions are based, in large part, on the actual mix of resources currently used or under contract for RPS compliance in each state or region. To the extent that RPS requirements are met with a larger proportion of high-capacity-factor resources than assumed in this analysis, or are met with biomass co-firing at existing thermal plants, the required new renewable capacity would be lower than the projected amount presented here.

${ }^{70}$ This estimate of required renewable electricity capacity additions is derived by comparing, on a region-by-region basis, the total amount of renewable capacity required for RPS demand in 2030 to the current installed base of renewable capacity deemed "available" for RPS compliance. Individual renewable generation facilities are deemed available for RPS compliance if they are currently under contract to LSEs with RPS obligations or if the energy is sold on a merchant basis into regional power markets with active RPS obligations. This analysis ignores several complexities that could result in either higher or lower incremental capacity needs, including: retirements of existing renewable capacity, constraints on intra-regional trade of renewable energy and RECs, and the possibility that resources currently serving renewable energy demand outside of RPS requirements (e.g., voluntary corporate procurement) might become available for RPS demand in the future.
} 


\section{System operators are implementing methods to accommodate increased penetrations of wind energy, but transmission and other barriers remain}

Wind energy output is variable and often the areas with the best wind speeds are distant from load centers. As a result, integration with the power system and provision of adequate transmission capacity are particularly important for wind energy. Concerns about, and solutions to, these issues have affected, and continue to impact, the pace of wind power deployment in the United States. Experience in operating power systems with wind energy is also increasing worldwide, leading to an emerging set of recently published best practices (e.g., Jones 2014, Milligan et al. 2015).

Figure 52 provides a selective listing of estimated wind integration costs at various levels of wind power capacity penetration from studies completed from 2003 through 2015 . With one exception, costs estimated by the studies reviewed are below $\$ 12 / \mathrm{MWh}$ - and often below $\$ 5 / \mathrm{MWh}$ - for wind power capacity penetrations up to and even exceeding $40 \%$ of the peak load of the system in which the power is delivered. Variations in estimated costs across studies are due, in part, to differences in methodologies, definitions of integration costs, power system and market characteristics, wind energy penetration levels, fuel price assumptions, wind output forecasting details, and the degree to which thermal power plant cycling costs are included. ${ }^{71}$

Two new integration cost studies were completed in 2015: one for Northern States Power (NSP) in Minnesota as part of the Xcel-Minnesota integrated resource plan (NSP 2015), and one for the California IOUs as part of the Long Term Procurement Planning process (SCE 2015). The NSP integration costs of $\$ 1.1-1.34 / \mathrm{MWh}$ in the most recent study are lower than the costs in previous studies in Minnesota due to the more-sophisticated operating practices currently employed by MISO than assumed in previous studies. The costs are primarily due to cycling coal and managing day-ahead forecast errors. The $\$ 3.10 / \mathrm{MWh}$ integration cost for wind in California is an estimate of the marginal integration cost to accommodate more wind than already planned to meet the 33\% RPS. Subsequent analysis by the authors, however, found that the estimates were unreliable largely due to methodological challenges in estimating integration costs (SCE 2016).

\footnotetext{
${ }^{71}$ Caveats on the interpretation and comparability of these costs discussed in previous versions of this report still apply here.
} 


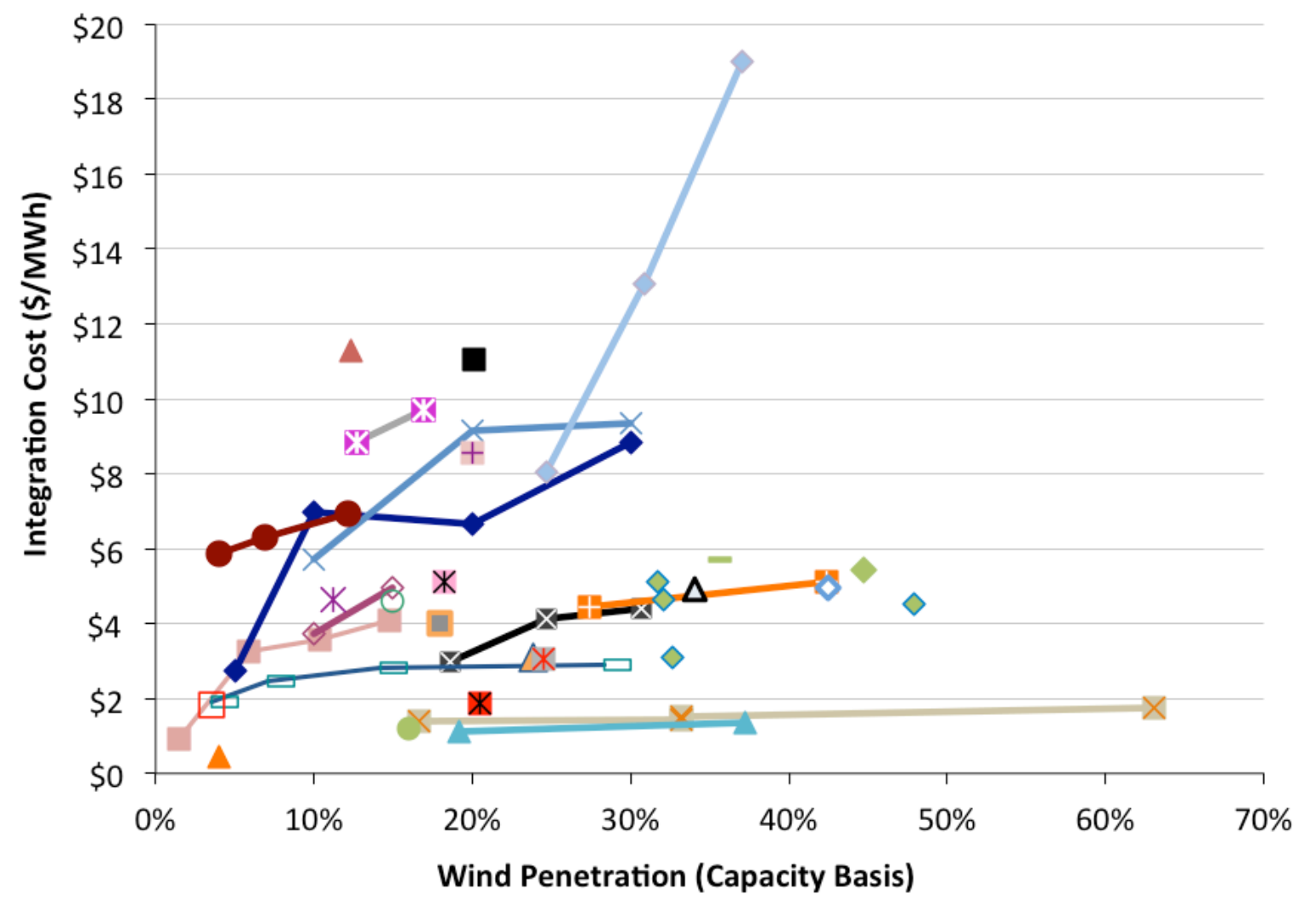

\begin{tabular}{|c|c|}
\hline-1 -APS (2007) & $\sim$ Avista (2007) \\
\hline - BPA (2009) [a] & BPA (2011) [a] \\
\hline$\diamond$ BPA (2013) & $\triangle$ CA RPS (2006) [b] \\
\hline$\triangle$ CAISO (2015) & ERCOT (2012) \\
\hline$\diamond$ EWITS $(2010)$ & $\leftarrow$ Idaho Power (2007) \\
\hline$\leadsto$ Idaho Power (2012) & $-\mathrm{X}-\mathrm{MN}-\mathrm{MISO}(2006)[\mathrm{c}]$ \\
\hline$-8-$ Nebraska $(2010)$ & A NorthWestern (2012) \\
\hline * Pacificorp (2005) & * Pacificorp (2007) \\
\hline$-\approx$-PacifiCorp (2010) & * PacifiCorp (2012) \\
\hline * PacifCorp (2014) & - Portland GE (2011) \\
\hline Portland GE (2013) & -Puget Sound Energy (2007) \\
\hline$\Delta$ SPP-SERC (2011) & -We Energies (2003) \\
\hline O Xcel-MNDOC (2004) & - Xcel-NSP (2015) \\
\hline$\curvearrowright$ Xcel-PSCo (2006) & + Xcel-PSCo (2008) \\
\hline \#-Xcel-PSCo (2011) [d] & $\square$ Xcel-UWIG (2003) \\
\hline
\end{tabular}

Notes: [a] Costs in \$/MWh assume 31\% capacity factor; [b] Costs represent 3-year average; [c] Highest over 3-year evaluation period; [d] Cost includes the coal cycling costs found in Xcel Energy (2011). Listed below the figure are the organizations for which each study was conducted, and the year in which the analysis was conducted or published.

Figure 52. Integration costs at various levels of wind power capacity penetration

In addition to studying wind integration costs, system operators and planners continue to make progress integrating wind into the power system. Strategies for reducing the challenges with wind integration include improved integration of wind into markets and improved coordination between balancing authorities: 
- A recent wind integration study by the Southwest Power Pool (SPP 2016a) examined a scenario with enough wind to a have $60 \%$ instantaneous wind penetration. Even with additional transmission investments, significant wind curtailment was required to re-dispatch generation around contingency constraints. The study found that curtailment of wind could be substantially reduced if a greater share of wind participated in the market as a dispatchable variable energy resource, and recommended acceleration of certain transmission upgrades.

- ISO-NE is implementing a program to provide dispatch signals to wind generators through a "Do Not Exceed" dispatch program. The signal represents the maximum generation that can be accepted by each wind plant without affecting reliability. Similar to SPP findings, using this signal to control wind will lower overall wind curtailments and increase utilization of the transmission system.

- MISO incorporated a ramp product into its market operations to better manage uncertainty and variability - from wind, in some cases - and to provide a clear price signal for the value of flexible generation.

- In part due to growing shares of wind energy, ERCOT has proposed revisions to its ancillary service markets to unbundle different products and fine-tune requirements to match system conditions and resource capabilities. An economic analysis indicates that the improvements in market design could create benefits on the order of $\$ 200$ million over the next ten years (Newell et al. 2015).

- In June 2015, SPP began providing balancing services to the Western Area Power Administration's Upper Great Plains Region (WAPA-UGP), Basin Electric Power Cooperative and Heartland Consumers Power District. In October, the three utilities transferred control of their transmission system to SPP. WAPA-UGP is the first federal power marketing administration to become a full member of a regional transmission organization (RTO).

- The western Energy Imbalance Market (EIM) now includes the CAISO, PacifiCorp, and NV Energy. The EIM allows for increased transfers between the participating balancing authorities and it increases diversity of resources. As of the first quarter of 2016, the EIM was averaging $\$ 6.3$ million per month in consumer benefits and was reducing renewables curtailment by an average of $38 \mathrm{GWh} /$ month (CAISO 2016). Work is underway to integrate Puget Sound Energy, Arizona Public Service, Portland General Electric, and Idaho Power into the EIM. In addition, PacifiCorp is exploring the prospect of becoming a full participating transmission owner within the CAISO, though the governance structure for a multi-state ISO is likely to be the key issue.

- A flexibility assessment of the Western Interconnection found that it is technically feasible to obtain $40 \%$ of energy from renewables, though with increasing curtailment. Increased regional coordination of balancing areas and measures that increase load during times when curtailment would occur, such as charging energy storage, can lower the amount of curtailment (E3 2015).

Recent studies of wind integration have sometimes focused on conditions that are likely to be the most challenging. For example, a recent GE transient stability ${ }^{72}$ study focused on spring light load, high wind periods in Wyoming when most of the region's synchronous generators will be

\footnotetext{
${ }^{72}$ Transient stability is the ability of a synchronous power system to return to a stable condition following a relatively large disturbance.
} 
offline (Miller et al. 2015). Maintaining stability after a major disturbance, like the loss of a large transmission line, will be challenging in some extreme hours under weak system conditions. Achieving acceptable performance is found to require combinations of traditional mitigation strategies, including the potential need for transmission system improvements, and nontraditional wind power plant controls. The changes to wind plant controls would alter the low voltage power logic in a wind plant to suppress active current during severe faults.

With growing shares of renewables and improvements to technology, wind is increasingly being asked to have the capability to supply grid services:

- FERC eliminated the exemption for asynchronous generators to provide reactive power for new interconnection requests in the pro forma Large Generator Interconnection Agreement (LGIA) and the Small Generator Interconnection Agreement (SGIA) (FERC 2016a). FERC cites the technological advances in inverters that make it inexpensive for new wind projects to be able to provide this function. FERC held a technical conference on compensation for reactive power supply in ISO markets in June 2016.

- FERC also released a Notice of Inquiry soliciting comments on whether the LGIA and SGIA should be revised to require all new generation resources to have frequency response capabilities as a precondition of interconnection (FERC 2016b). In addition, they asked whether existing resources should be required to have primary frequency response capabilities and arrangements for the provision and compensation of primary frequency response. FERC noted that ERCOT, ISO-NE, and PJM already require new generators, including wind in some cases, to have primary frequency response capabilities.

- NERC's Essential Reliability Services Task Force, noting a changing generation resource mix that includes more non-synchronous generation, recommends that all new resources have the capability to support voltage and frequency (NERC 2015).

It is also clear that transmission expansion helps to manage increasing wind energy:

- The recent wind integration study by SPP (SPP 2016a) confirmed the need for transmission projects already identified in the integrated transmission planning process and discovered additional transmission needs beyond the approved projects. Further, some of the approved transmission projects should be expedited so that the projects can be placed in-service sooner than originally scheduled. A separate study by SPP found that 348 transmission upgrades constructed between 2012 and 2014 will provide more than $\$ 16$ billion in benefits over a 40year period (SPP 2016b).

- The NSP wind integration study (EnerNex 2014) found that existing wind curtailment in the region is almost all due to transmission congestion. Wind curtailment is expected to be considerably lower after planned regional transmission solutions - identified through the Multi-Value Project Portfolio Analysis - are put in place. Separately, MISO found that its Multi-Value Project, a series of transmission projects encompassing eight states, will have a benefit-to-cost ratio varying from 2.6 to 3.9 and create net benefits of $\$ 13.1$ to $\$ 49.6$ billion.

Transmission additions, however, slowed in 2015 compared to previous years. About 1,500 miles of transmission lines came online in 2015, the lowest amount since FERC began publishing this data in 2009 (see Figure 53). As of March 2016, FERC (2016c) estimates that another 14,000 miles of new transmission lines (or line upgrades) are proposed to come online 
by March 2018, with about 5,500 miles of those having a high probability of completion. The Edison Electric Institute (EEI), meanwhile, projects that transmission investment will amount to \$22 billion in both 2016 and 2017 before falling to \$20 billion in 2018 (EEI 2015a). EEI states that 46 percent of the transmission projects it is tracking will, at least in part, support the integration of renewable energy (EEI 2015b).

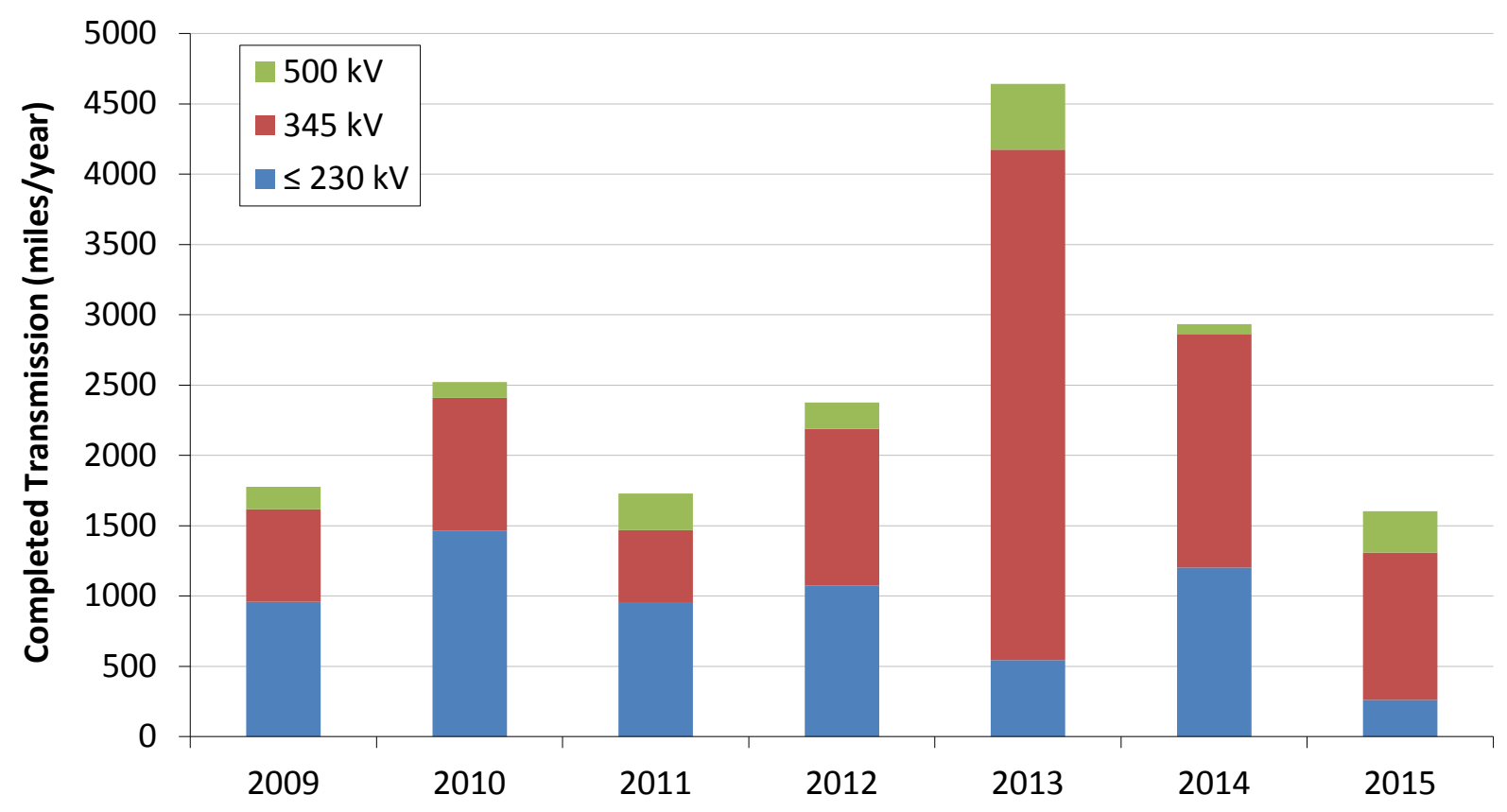

Source: FERC monthly infrastructure reports

Figure 53. Miles of transmission projects completed, by year and voltage

Three major transmission projects that will transport wind energy were completed in 2015, summarized in Table 6. Moreover, AWEA (2016a) has identified 15 additional near-term transmission projects that, if all were completed, could transmit $52.4 \mathrm{GW}$ of additional wind capacity, as depicted in Table 7.

Table 6. Transmission Projects Completed in 2015

\begin{tabular}{|l|c|c|c|}
\hline \multicolumn{1}{|c|}{ Transmission Project Name (State) } & $\begin{array}{c}\text { Voltage } \\
\text { (kilovolts) }\end{array}$ & $\begin{array}{c}\text { Estimated In- } \\
\text { service Date }\end{array}$ & $\begin{array}{c}\text { Estimated Potential } \\
\text { Wind Capacity, MW }\end{array}$ \\
\hline $\begin{array}{l}\text { Big Eddy - Knight and Central Ferry - Lower } \\
\text { Monumental (OR, WA) }\end{array}$ & 500 & 2015 & 4,200 \\
\hline $\begin{array}{l}\text { Maine Power Reliability Program } \\
\text { Most CapX Segments (MN, ND, SD, WI) }\end{array}$ & $\begin{array}{c}345,115 \\
\text { Mostly 345, } \\
\text { some 230 and } \\
165 \text { lines }\end{array}$ & 2015 & n/a \\
\hline Total Potential Wind Capacity & $2014-16$ & 2,000 \\
\hline Source: AWEA (2016a) & & 6,200 \\
\hline
\end{tabular}


Table 7. Planned Near-Term Transmission Projects and Potential Wind Capacity

\begin{tabular}{|c|c|c|c|}
\hline Transmission Project Name (State) & $\begin{array}{l}\text { Voltage } \\
\text { (kilovolts) }\end{array}$ & $\begin{array}{l}\text { Estimated In- } \\
\text { service Date }\end{array}$ & $\begin{array}{l}\text { Estimated Potential } \\
\text { Wind Capacity, MW }\end{array}$ \\
\hline Tehachapi Phases 2-3 (CA) & 500 & 2016 & 3,800 \\
\hline $\begin{array}{l}\text { MISO Multi-Value Projects (IA, IL, MI, MN, } \\
\text { MO, ND, SD, WI) }\end{array}$ & $\begin{array}{l}\text { 345, one } 765 \\
\text { line }\end{array}$ & $2015-2020$ & 14,000 \\
\hline Grand Prairie Gateway (IL) & 345 & 2017 & 1,000 \\
\hline $\begin{array}{l}\text { Nebraska City - Mullin Creek - Sibley (NE- } \\
\text { MO; SPP Priority Project) }\end{array}$ & 345 & 2017 & $\begin{array}{l}\text { (SPP Priority Project } \\
\text { Component) }\end{array}$ \\
\hline Southline Transmission Project (AZ, NM) & 345,230 & 2018 & 1,000 \\
\hline TransWest Express (WY) & $600 \mathrm{DC}$ & 2018 & 3,000 \\
\hline Power for the Plains (NM, OK, TX) & $115,230,345$ & $2016-2020$ & $\mathrm{n} / \mathrm{a}$ \\
\hline Clean Line Projects (AZ, IA, KS, NM, OK) & $600 \mathrm{DC}$ & $2018-2020$ & 16,000 \\
\hline Pawnee - Daniels Park (CO) & 345 & $2019-2020$ & 500 \\
\hline Gateway West (ID, WY) & 500 & $2019-2021$ & 3,000 \\
\hline Sunzia (AZ, NM) & 500 & 2020 & 3,000 \\
\hline Boardman-Hemingway (ID, OR) & 500 & 2020 & 1,000 \\
\hline Gateway South (WY, UT) & 500 & $2020-2022$ & 1,500 \\
\hline SPP 2012 ITP10 Projects (KS, MO, OK, TX) & 345 & $2018-2022$ & 3,500 \\
\hline Total Potential Wind Capacity & & & 52,400 \\
\hline
\end{tabular}

Source: AWEA (2016a)

FERC held a technical conference in June 2016 to review the implementation of Order 1000, which was intended to improve intra- and inter-regional transmission planning and cost allocation. Order 1000 requires public utility transmission providers to: participate in a regional transmission planning process; establish procedures to identify transmission needs driven by public policy requirements; and coordinate with neighboring planning regions to solve mutual transmission needs (FERC 2011). Recent literature has suggested that Order 1000 needs to be reexamined. A 2015 report found that most transmission investments are based on meeting reliability needs, and that the increased market efficiency and economic benefits of transmission are not evaluated comprehensively in transmission plans. That same study found that interregional transmission planning is still very much in its infancy and has not resulted in identifying viable inter-regional transmission projects (Pfeifenberger et al. 2015). Others note that Order 1000 has resulted in a wide variance of cost allocation methodologies because FERC left cost allocation to RTOs and individual transmission owners (Edelston 2015).

Transmission also figured prominently in two legal proceedings. The Seventh Circuit Court of Appeals upheld FERC's requirement in Order 1000 that transmission owners remove the rightof-first-refusal provisions for building new transmission from their transmission tariffs (U.S. Court of Appeals 2016). In April 2016, DOE announced it will use its authority under Section 1222 of the Energy Policy Act of 2005 (EPAct) to participate in the development of a planned Clean Line Energy Partners LLC transmission project, known as the Plains and Eastern project, that would stretch from western Oklahoma to eastern Arkansas (DOE 2016). If developed, the 
project could transmit up to 4,000 MW. This is the first time that the DOE is utilizing its authority under EPAct to participate in the development of a transmission project. 


\section{Future Outlook}

With the 5-year extension of the PTC signed in December 2015 and IRS guidance allowing a safe-harbor period of 4 years in which to complete construction, but with progressive reductions in the value of the credit for projects starting construction after 2016, annual wind power capacity additions are projected to continue at a rapid clip for several years, before declining. Near-term additions will also be driven by improvements in the cost and performance of wind power technologies, which continue to yield very low power sales prices. Growing corporate demand for wind energy and state-level policies play important roles as well, as might utility action to proactively get out ahead of possible future CPP compliance obligations.

Among the forecasts for the domestic market presented in Figure 54, expected capacity additions average more than 8,000 MW/year from 2016 to 2020, somewhat higher than the pace of growth witnessed since 2007. With AWEA (2016b) reporting that more than 15,000 MW of wind power were under construction or at an advanced stage of development at the end of the first quarter of 2016, the industry appears to be on track to meet these expectations at least in the early years.

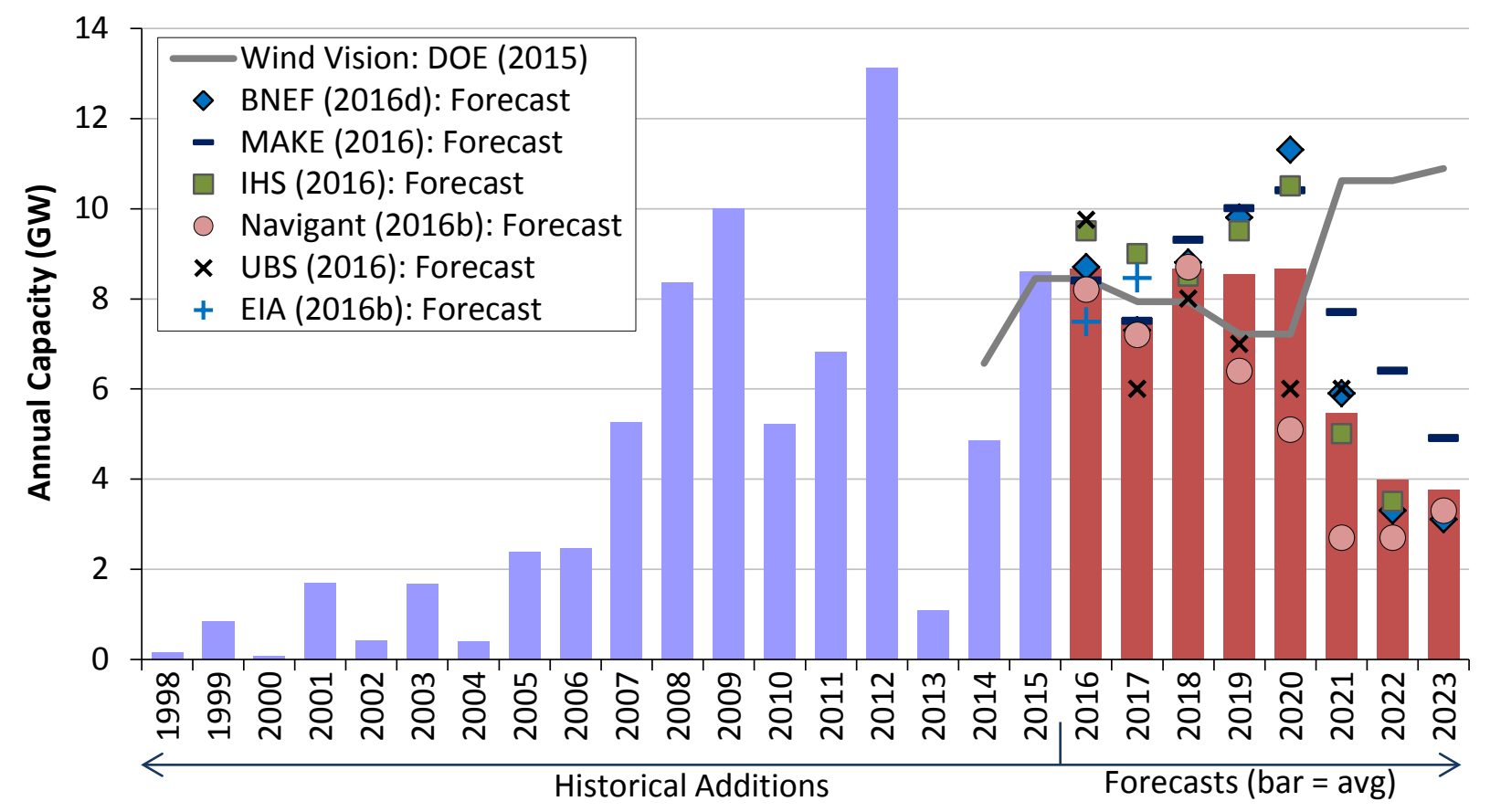

Source: AWEA (historical additions), individual forecasts, DOE 2015 (Wind Vision)

Figure 54. Wind additions: historical installations, projected growth, DOE Wind Vision report

Forecasts for 2021 to 2023 show a downturn in additions as the PTC progressively delivers less value to the sector. Expectations for continued low natural gas prices, modest electricity demand growth, and lower near-term renewable energy demand from state RPS policies also put a damper on growth expectations, as do inadequate transmission infrastructure and competition from solar energy in certain regions of the country. At the same time, declines in the price of wind energy over the last half decade have been substantial, helping to improve the economic position of wind even in the face of low natural gas prices. The potential for continued 
technological advancements and cost reductions enhance the prospects for longer-term growth, as does burgeoning corporate demand for wind energy and state RPS requirements. EPA's Clean Power Plan, depending on its ultimate fate, may also create new markets for wind. Moreover, new transmission in some regions is expected to open up high-quality wind resources to development. Given these diverse underlying potential trends, wind capacity additions, especially after 2020, remain deeply uncertain.

In 2015, the DOE published its Wind Vision report (DOE 2015), which analyzed a scenario in which wind energy reaches $10 \%, 20 \%$, and $35 \%$ of U.S. electric demand in 2020, 2030, and 2050, respectively. Plotted in Figure 54 are the annual gross wind additions from 2014 through 2023 analyzed by the DOE in order to ultimately reach those percentage targets. As shown, actual and projected wind additions from 2014 through 2020 are consistent with the pathway envisioned in the DOE report. Projected growth from 2021 through 2023, however, is well below the Wind Vision pathway. As discussed in DOE (2015), and as further suggested by these comparisons, achieving $10 \%, 20 \%$, and $35 \%$ wind energy on the timeframe analyzed by the DOE is likely to require efforts that go beyond business as usual expectations. 


\section{Appendix: Sources of Data Presented in this Report}

\section{Installation Trends}

Data on wind power additions in the United States (as well as certain details on the underlying wind power projects) largely come from AWEA (2016a). We thank AWEA for the use of their comprehensive wind project database. Annual wind power capital investment estimates derive from multiplying these wind power capacity data by weighted-average capital cost data, provided elsewhere in the report. Data on non-wind electric capacity additions come from ABB Ventyx's Velocity database, except that solar data come from GTM Research. Information on offshore wind power development activity in the United States was compiled by NREL.

Global cumulative (and 2015 annual) wind power capacity data come from Navigant (2016a) but are revised to include the U.S. wind power capacity used in the present report. Wind energy as a percentage of country-specific electricity consumption is based on year-end wind power capacity data and country-specific assumed capacity factors that come from Navigant (2016a), as revised based on a review of EIA country-specific wind power data. For the United States, the performance data presented in this report are used to estimate wind energy production. Countryspecific projected wind generation is then divided by country-specific electricity consumption. The latter is estimated based on actual past consumption as well as forecasts for future consumption based on recent growth trends (these data come from EIA).

The wind power project installation map was created by NREL, based in part on AWEA's database of projects. Wind energy as a percentage contribution to statewide electricity generation is based exclusively on wind generation data divided by in-state total electricity generation in 2015, using EIA data.

Data on wind power capacity in various interconnection queues come from a review of publicly available data provided by each ISO, RTO, or utility. Only projects that were active in the queue, but as yet built, at the end of 2015 are included. Suspended projects are not included in these listings. Data on projects that are in the nearer-term development pipeline comes from ABB (2016), AWEA (2016b), and EIA (2016c).

\section{Industry Trends}

Turbine manufacturer market share data are derived from the AWEA wind power project database, with some processing by Berkeley Lab.

Information on wind turbine and component manufacturing comes from NREL, AWEA, and Berkeley Lab, based on a review of press reports, personal communications, and other sources. Data on U.S. nacelle assembly capability come from Bloomberg NEF (2015a) and AWEA (2016a), while U.S. tower and blade manufacturing capability come from AWEA (2016a). The listings of manufacturing and supply-chain facilities are not intended to be exhaustive. OEM profitability data come from a Berkeley Lab review of turbine OEM annual reports (where necessary, focusing only on the wind energy portion of each company's business). 
Data on U.S. imports and exports of selected wind turbine equipment come primarily from the Department of Commerce, accessed through the U.S. International Trade Commission (USITC), and they can be obtained from the USITC's DataWeb (http://dataweb.usitc.gov/). The analysis of USITC trade data relies on the "customs value" of imports as opposed to the "landed value" and hence does not include costs relating to shipping or duties. The table below lists the specific trade codes used in the analysis presented in this report.

Harmonized Tariff Schedule (HTS) Codes and Categories Used in Wind Import Analysis

\begin{tabular}{|c|c|c|c|}
\hline HTS Code & Description & $\begin{array}{c}\text { Years } \\
\text { applicable }\end{array}$ & Notes \\
\hline 8502.31 .0000 & wind-powered generating sets & $2005-2015$ & $\begin{array}{l}\text { includes both utility-scale and } \\
\text { small wind turbines }\end{array}$ \\
\hline 7308.20 .0000 & towers and lattice masts & $2006-2010$ & $\begin{array}{l}\text { not exclusive to wind turbine } \\
\text { components }\end{array}$ \\
\hline 7308.20 .0020 & towers and lattice masts - tubular & 2011-2015 & virtually all for wind turbines \\
\hline 8501.64 .0020 & $\begin{array}{l}\text { AC generators (alternators) from } 750 \text { to } 10,000 \\
\text { kVA }\end{array}$ & $2006-2011$ & $\begin{array}{l}\text { not exclusive to wind turbine } \\
\text { components }\end{array}$ \\
\hline 8501.64 .0021 & $\begin{array}{l}\text { AC generators (alternators) from } 750 \text { to } 10,000 \\
\text { kVA for wind-powered Generating sets }\end{array}$ & 2012-2015 & $\begin{array}{l}\text { exclusive to wind turbine } \\
\text { components }\end{array}$ \\
\hline 8412.90 .9080 & other parts of engines and motors & $2006-2011$ & $\begin{array}{l}\text { not exclusive to wind turbine } \\
\text { components }\end{array}$ \\
\hline 8412.90 .9081 & wind turbine blades and hubs & 2012-2015 & $\begin{array}{l}\text { exclusive to wind turbine } \\
\text { components }\end{array}$ \\
\hline 8503.00 .9545 & $\begin{array}{l}\text { parts of generators (other than commutators, } \\
\text { stators, and rotors) }\end{array}$ & 2006-2011 & $\begin{array}{l}\text { not exclusive to wind turbine } \\
\text { components }\end{array}$ \\
\hline 8503.00 .9546 & $\begin{array}{l}\text { parts of generators for wind-powered } \\
\text { generating sets }\end{array}$ & 2012-2015 & $\begin{array}{l}\text { exclusive to wind turbine } \\
\text { components }\end{array}$ \\
\hline 8503.00 .9560 & $\begin{array}{l}\text { machinery parts suitable for various machinery } \\
\text { (including wind-powered generating sets) }\end{array}$ & 2014-2015 & $\begin{array}{l}\text { not exclusive to wind turbine } \\
\text { components; nacelles when } \\
\text { shipped without blades can be } \\
\text { included in this category }{ }^{73}\end{array}$ \\
\hline
\end{tabular}

As shown in the table, some trade codes are exclusive to wind, whereas others are not. As such, assumptions are made for the proportion of wind-related equipment in each of the non-windspecific HTS trade categories. These assumptions are based on: an analysis of recent trade data where separate, wind-specific trade categories exist; a review of the countries of origin for the imports; personal communications with USITC and AWEA staff; USITC trade cases; and import patterns in the larger HTS trade categories. The assumptions reflect the rapidly increasing imports of wind equipment from 2006 to 2008, the subsequent decline in imports from 2008 to 2010, and the slight increase from 2010 to 2012. To reflect uncertainty in these proportions, a $\pm 10 \%$ variation is applied to the larger trade categories that include wind turbine components for all HTS codes considered, except for nacelles shipped under 8503.00.9560. For nacelles, the variation applied is $\pm 50 \%$ of the total estimated wind import value under HTS code 8503.00.9560.

\footnotetext{
73 This was effective in 2014 as a result of Customs and Border Protection ruling number HQ H148455 (April 4, 2014). That ruling stated that nacelles alone do not constitute wind-powered generating sets, as they do not include blade assembly which are essential to wind-powered generating sets as defined in the HTS.
} 
Information on wind power financing trends was compiled by Berkeley Lab, based in part on data from AWEA and Chadbourne and Park LLP. Wind project ownership and power purchaser trends are based on a Berkeley Lab analysis of the AWEA project database.

\section{Wind Turbine Technology Trends}

Information on turbine hub heights, rotor diameters, specific power, and IEC Class was compiled by Berkeley Lab based on information provided by AWEA, turbine manufacturers, standard turbine specifications, Federal Aviation Administration data, web searches, and other sources. The data include only projects with turbines greater than or equal to $50 \mathrm{~kW}$ that began operation in 1998 through 2015. Some turbines - especially in 2015-have not been rated within a numerical IEC Class, but are instead designated as Class "S," for special. In such instances, they were not included in the reported average fleet-wide IEC class over time. Estimates of the quality of the wind resource in which turbines are located were generated as discussed below.

\section{Performance, Cost, and Pricing Trends}

Wind project performance data were compiled overwhelmingly from two main sources: FERC's Electronic Quarterly Reports and EIA Form 923. Additional data come from FERC Form 1 filings and, in several instances, other sources. Where discrepancies exist among the data sources, those discrepancies are handled based on judgment of Berkeley Lab staff. Data on curtailment are from ERCOT (for Texas), MISO (for the Midwest), PJM, NYISO, SPP (for the Great Plains states), ISO-New England, and BPA (for the Northwest).

The following procedure was used to estimate the quality of the wind resource in which wind projects are located. First, the location of individual wind turbines and the year in which those turbines were installed were identified using Federal Aviation Administration (FAA) Digital Obstacle (i.e., obstruction) files (accessed via ABB Ventyx' Intelligent Map) and FAA Obstruction Evaluation files combined with Berkeley Lab and AWEA data on individual wind projects. Second, NREL used 200-meter resolution data from AWS Truepower-specifically, gross capacity factor estimates - to estimate the quality of the wind resource for each of those turbine locations. These gross capacity factors are derived from average mapped 80-meter wind speed estimates, wind speed distribution estimates, and site elevation data, all of which are run through a standard wind turbine power curve (common to all sites). To create an index of wind resource quality, the resultant average wind resource quality (i.e., gross capacity factor) estimate for turbines installed in the 1998-1999 period is used as the benchmark, with an index value of $100 \%$ assigned in that period. Comparative percentage changes in average wind resource quality for turbines installed after 1998-1999 are calculated based on that 1998-1999 benchmark year. When segmenting wind resource quality into categories, the following AWS Truepower gross capacity factors are used: the "lower" category includes all projects or turbines with an estimated gross capacity factor of less than $40 \%$; the "medium" category corresponds to $\geq 40 \%-45 \%$; the "higher" category corresponds to $\geq 45 \%-50 \%$; and the "highest" category corresponds to $\geq 50 \%$. Not all turbines could be mapped by Berkeley Lab for this purpose; the final sample included 41,149 turbines of the 41,999 installed from 1998 through 2014 in the continental United States over that period, or $98 \%$.

Wind turbine transaction prices were compiled by Berkeley Lab. Sources of transaction price data vary, but most derive from press releases, press reports, and Securities and Exchange 
Commission and other regulatory filings. In part because wind turbine transactions vary in the turbines and services offered, a good deal of intra-year variability in the cost data is apparent. Additional data come from Vestas corporate reports and Bloomberg NEF.

Berkeley Lab used a variety of public and some private sources of data to compile capital cost data for a large number of U.S. wind projects. Data sources range from pre-installation corporate press releases to verified post-construction cost data. Specific sources of data include EIA Form 412, FERC Form 1, various Securities and Exchange Commission filings, filings with state public utilities commissions, Windpower Monthly magazine, AWEA's Wind Energy Weekly, the DOE and Electric Power Research Institute Turbine Verification Program, Project Finance magazine, various analytic case studies, and general web searches for news stories, presentations, or information from project developers. For 2009-2012 projects, data from the Section 1603 Treasury Grant program were used extensively. Some data points are suppressed in the figures to protect data confidentiality. Because the data sources are not equally credible, little emphasis should be placed on individual project-level data; instead, the trends in those underlying data offer insight. Only wind power cost data from the contiguous lower-48 states are included.

Wind project O\&M costs come primarily from two sources: EIA Form 412 data from 2001-2003 for private power projects and projects owned by POUs, and FERC Form 1 data for IOU-owned projects. Some data points are suppressed in the figures to protect data confidentiality.

Wind PPA price data are based on multiple sources, including prices reported in FERC's Electronic Quarterly Reports, FERC Form 1, avoided-cost data filed by utilities, pre-offering research conducted by bond rating agencies, and a Berkeley Lab collection of PPAs. Wholesale electricity price data were compiled by Berkeley Lab from the Intercontinental Exchange (ICE) as well as ABB Ventyx's Velocity database (which itself derives wholesale price data from the ICE and the various ISOs). Earlier years' wholesale electricity price data come from FERC (2007, 2005). Pricing hubs included in the analysis, and within each region, are identified in the map below. To compare the price of wind to the cost of future natural gas-fired generation, the reference case fuel cost projection from the EIA's Annual Energy Outlook 2016 is converted from \$/MMBtu into \$/MWh using a heat rate of $7 \mathrm{MMBtu} / \mathrm{MWh}$. REC price data were compiled by Berkeley Lab based on information provided by Marex Spectron. 


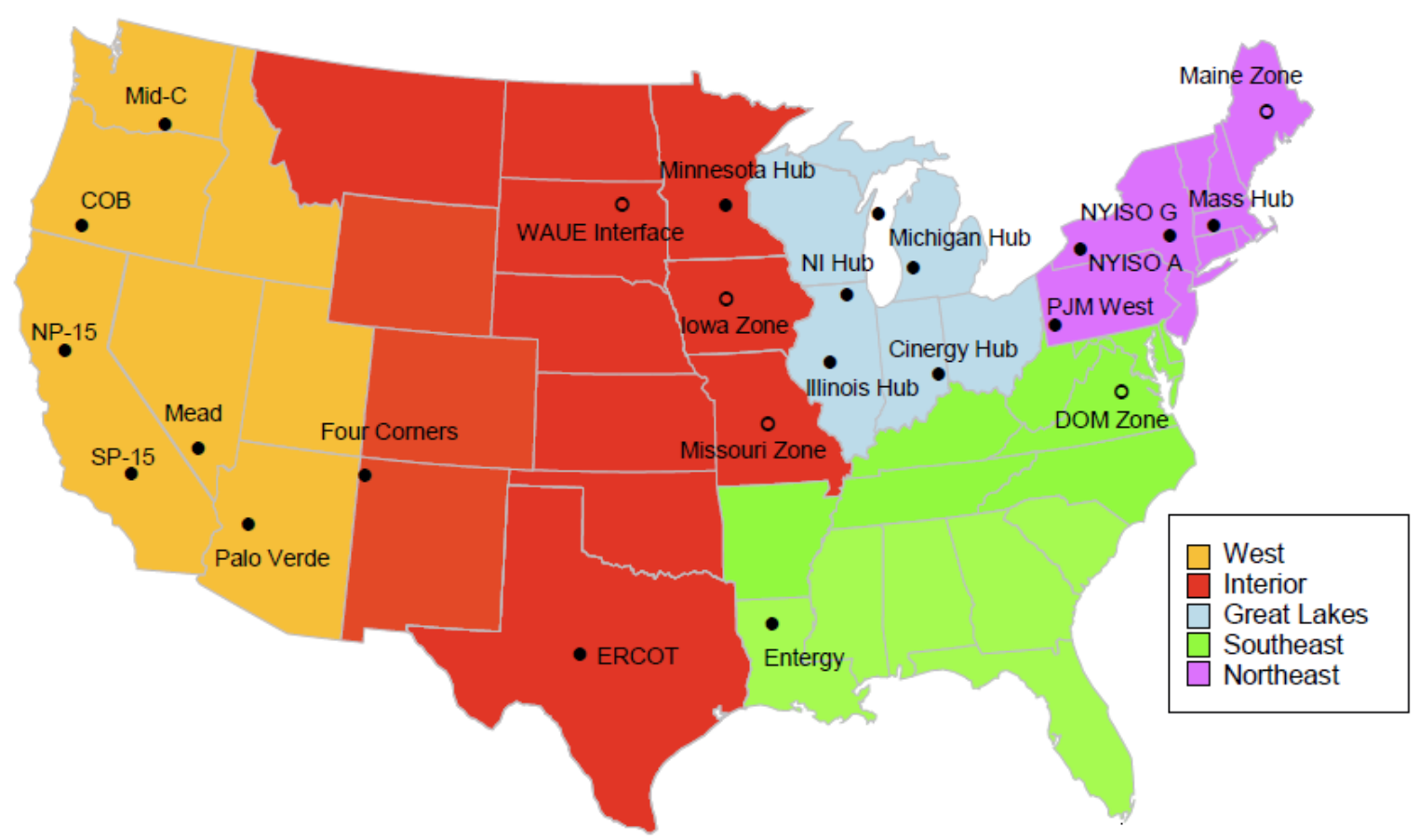

Note: The pricing nodes represented by an open, rather than closed, bullet do not have complete pricing history back through 2003.

Figure 55. Map of regions and wholesale electricity price hubs used in analysis

\section{Policy and Market Drivers}

The wind energy policy and grid integration sections were written by staff at Berkeley Lab and Exeter Associates, based on publicly available information.

\section{Future Outlook}

This chapter was written by staff at Berkeley Lab, based largely on publicly available information. 


\section{References}

ABB. 2016. Velocity Suite Data Product. Accessed June 2016.

American Wind Energy Association (AWEA). 2016a. U.S. Wind Industry Annual Market

Report: Year Ending 2015. Washington, D.C.: American Wind Energy Association.

American Wind Energy Association (AWEA). 2016b. AWEA U.S. Wind Industry First Quarter

2016 Market Report. Washington, D.C.: American Wind Energy Association.

AWS Truepower. 2016. 2015 Wind Trends Bulletin: wind speed performance.

Bloomberg New Energy Finance (Bloomberg NEF). 2015. Yes, US clean energy, there is a Santa Claus. Published December 18, 2015.

Bloomberg New Energy Finance (Bloomberg NEF). 2015a. H1 2015 North America Wind Market Outlook. Published April 9, 2015.

Bloomberg New Energy Finance (Bloomberg NEF). 2016a. Wind Turbine Price Index: H1 2016. Published April 2016.

Bloomberg New Energy Finance (Bloomberg NEF). 2016b. Q1 2016 Global Wind Market Outlook. Published February 18, 2016.

Bloomberg New Energy Finance (Bloomberg NEF). 2016c. H1 2016 O\&M Index Report. Published May 2016.

Bloomberg New Energy Finance (Bloomberg NEF). 2016d. US Wind to 2030: Mapping the Post-PTC Landscape. Presentation to WINDPOWER 2016. May 24, 2016.

Bloomberg New Energy Finance (Bloomberg NEF). 2016e. H1 2016 Tax Equity Market Outlook. Published May 31, 2016.

Bolinger, M. 2014. An Analysis of the Costs, Benefits, and Implications of Different Approaches to Capturing the Value of Renewable Energy Tax Incentives. LBNL-6350E. Berkeley, California: Lawrence Berkeley National Laboratory.

Bolinger, M. and R. Wiser. 2011. Understanding Trends in Wind Turbine Prices Over the Past Decade. LBNL-5119E. Berkeley, California: Lawrence Berkeley National Laboratory.

California ISO (CAISO). 2016. Benefits for Participating in EIM: Q1 2016 Report. Folsom, California: California Independent System Operator.

Chadbourne \& Parke LLP. 2016a. "New Trends in Financing Wind Farms." Project Finance Newswire. Published June 2016.

Chadbourne \& Parke LLP. 2016b. "Cost of Capital: 2016 Outlook." Project Finance Newswire. Published February 2016.

Department of Energy (DOE). 2016. Record of Decision in re Application of Clean Line Energy Partners LLC, No. 6450-01-P. Washington, D.C.: U.S. Department of Energy.

Department of Energy (DOE). 2015. Wind Vision: A New Era for Wind Power in the United States. DOE/GO-102015-4557. Washington, D.C.: U.S. Department of Energy.

Edelston, B. FERC Order 1000: A Solution Looking for a Problem? Presentation to the Harvard Electricity Policy Group. December 10, 2015.

Edison Electric Institute (EEI). 2015a. Actual and Planned Transmission Investment by InvestorOwned Utilities (2009-2018). Washington, D.C.: Edison Electric Institute. 
Edison Electric Institute (EEI). 2015b. Transmission Projects: At A Glance. Published March 2015. Washington, D.C.: Edison Electric Institute.

EDP Renováveis (EDPR). 2016. EDP Renováveis, 2015 Results. Published February 24, 2016.

Energy and Environmental Economics, Inc. (E3). 2015. Western Interconnection Flexibility Assessment. San Francisco, CA: Energy and Environmental Economics, Inc.

Energy Information Administration (EIA). 2016a. Annual Energy Outlook 2016. Washington D.C.: Energy Information Administration.

Energy Information Administration (EIA). 2016b. Short-Term Energy Outlook. Published July 12. Washington D.C.: Energy Information Administration.

Energy Information Administration (EIA). 2016c. Electric Power Monthly, with Data for April 2016 Washington D.C.: Energy Information Administration.

EnerNex Corp. 2014. NSP Wind Integration Study. Prepared for Northern States Power.

Federal Energy Regulatory Commission (FERC). 2016a. Reactive Power Requirements for NonSynchronous Generation. 155 FERC \ 61,277. Docket No. RM16-1; June 16, 2016. Washington D.C.: Federal Energy Regulatory Commission.

Federal Energy Regulatory Commission (FERC). 2016b. Essential Reliability Services and the Evolving Bulk-Power System-Primary Frequency Response. 154 FERC 9 61,117. Docket No. RM16-6; February 18, 2016. Washington D.C.: Federal Energy Regulatory Commission.

Federal Energy Regulatory Commission (FERC). 2016c. Energy Infrastructure Update for March 2016 (and previous editions). Washington, D.C.: Federal Energy Regulatory Commission.

Federal Energy Regulatory Commission (FERC). 2011. Transmission Planning and Cost Allocation by Transmission Owning and Operating Public Utilities. 136 FERC $961,051$. Docket No. RM10-23; Order No.1000. July 21, 2011. Washington D.C.: Federal Energy Regulatory Commission.

Federal Energy Regulatory Commission (FERC). 2007. 2006 State of the Markets Report. Washington, D.C.: Federal Energy Regulatory Commission.

Federal Energy Regulatory Commission (FERC). 2005. 2004 State of the Markets Report. Washington, D.C.: Federal Energy Regulatory Commission.

Federal Reserve Board. 2016. Selected Interest Rates (Daily) - H.15. http://www.federalreserve.gov/releases/h15/data.htm (accessed on June 6, 2016).

Fripp, M. and R. Wiser. 2006. Analyzing the Effects of Temporal Wind Patterns on the Value of Wind-Generated Electricity at Different Sites in California and the Northwest. LBNL60152. Berkeley, California: Lawrence Berkeley National Laboratory.

Hopper, A. Cape Wind Lease Suspension Order. U.S. Department of the Interior. Bureau of Ocean Energy Management. Published July 24, 2015.

IHS Energy. 2016. The US Wind Market Outlook: Capturing the Wind Fall of PTC Extension and a Transition to a Post-PTC World. Presentation to WINDPOWER 2016. May 24, 2016.

Jones, L. E. 2014. Renewable Energy Integration: Practical Management of Variability, Uncertainty, and Flexibility in Power Grids. Academic Press. 
Lantz, E. 2013. Operations Expenditures: Historical Trends and Continuing Challenges. Presentation to WINDPOWER 2013. May 7, 2013.

MAKE. 2016. Public Policy and Turbine Technology Drive Robust United States Market Outlook Through 2025. Presentation to WINDPOWER 2016. May 24, 2016.

Midcontinent Independent System Operator (MISO). 2014. MTEP14 MVP Triennial Review. Carmel, Indiana: Midcontinent Independent System Operator.

Miller, N.W., B. Leonardi, and R. D'Aquila. 2015. Western Wind and Solar Integration Study Phase 3A: Low Levels of Synchronous Generation. NREL/TP-5D00-64822. Golden, Colorado: National Renewable Energy Laboratory.

Milligan, M., B. Kirby, T. Acker, M. Alstrom, B. Frew, M. Goggin, W. Lasher, M. Marquis, and D. Osborn. 2015. Review and Status of Wind Integration and Transmission in the United States: Key Issues and Lessons Learned. NREL/TP - 5D00 - 61911. Golden, Colorado: National Renewable Energy Laboratory.

Moné, C., T. Stehly and B. Maples. 2015. 2014 Cost of Wind Energy Review. Golden, Colorado: National Renewable Energy Laboratory. Musial, W., D. Elliott, J. Fields, Z. Parker, G. Scott and C. Draxl. 2013a. Assessment of Offshore Wind Energy Leasing Areas for the BOEM Maryland Wind Energy Area. Golden, Colorado: National Renewable Energy Laboratory.

Musial, W., D. Elliott, J. Fields, Z. Parker, G. Scott and C. Draxl. 2013b. Assessment of Offshore Wind Energy Leasing Areas for the BOEM New Jersey Wind Energy Area. Golden, Colorado: National Renewable Energy Laboratory.

Navigant. 2016a. World Wind Energy Market Update 2016. Navigant Research.

Navigant. 2016b. U.S. Wind Market Outlook - Pathways to Competitiveness. Presentation to WINDPOWER 2016. May 24, 2016.

Newell, S.A., R. Carroll, P. Ruiz, and W. Gorman. 2015. Cost-Benefit Analysis of ERCOT's Future Ancillary Services (FAS) Proposal. Austin, TX: Electricity Reliability Council of Texas (ERCOT).

North American Electric Reliability Corporation (NERC). 2015. Essential Reliability Services Task Force Measures Framework Report. Atlanta, GA: North American Electric Reliability Corporation.

Northern States Power (NSP). 2015. 2015 Resource Plan: Appendix E - Renewable Energy. Xcel Energy.

Orrell, A. and N. Foster. 2016. 2015 Distributed Wind Market Report. Richland, Washington: Pacific Northwest National Laboratory.

Pfeifenberger, J., J. Chang, and A. Sheilendranath. 2015. Toward More Effective Transmission Planning: Addressing the Costs and Risks of an Insufficiently Flexible Electricity Grid. Washington, D.C.: WIRES.

Southern California Edison (SCE). 2016. Southern California Edison Company's Renewable Integration Cost Adder Report. R16-02-007. San Francisco, California: California Public Utilities Commission. 
Southern California Edison (SCE). 2015. Report of Southern California Edison Company on Renewable Integration Cost Study for 33\% Renewables Portfolio Standard. R13-12-010. San Francisco, CA: California Public Utilities Commission.

Southwest Power Pool (SPP). 2016a. 2016 Wind Integration Study.

Southwest Power Pool (SPP). 2016b. The Value of Transmission. Published January 26, 2016.

Smith, A., T. Stehly and W. Musial. 2015. 2014-2015 Offshore Wind Technologies Market Report. Golden, Colorado: National Renewable Energy Laboratory.

UBS. 2016. The Future of Distributed \& Renewable Resources. Moody's Solar and Distributed Generation Conference.

U.S. Court of Appeals, $7^{\text {th }}$ Circuit. 2016. MISO Transmission Owners, et al., v. Federal Energy Regulatory Commission, et al. Justia Dockets and Filings. 
WIND ENERGY WEBSITES

U.S. DEPARTMENT OF ENERGY WIND PROGRAM

energy.gov/eere/wind

\section{LAWRENCE BERKELEY NATIONAL} LABORATORY

emp.lbl.gov/research-areas/renewableenergy

\section{NATIONAL RENEWABLE ENERGY \\ LABORATORY \\ nrel.gov/wind}

SANDIA NATIONAL LABORATORIES sandia.gov/wind

PACIFIC NORTHWEST NATIONAL LABORATORY

energyenvironment.pnnl.gov/eere/

LAWRENCE LIVERMORE NATIONAL LABORATORY

missions.Ilnl.gov/energy/technologies/ wind-forecasting

OAK RIDGE NATIONAL LABORATORY ornl.gov/science-area/clean-energy
ARGONNE NATIONAL LABORATORY anl.gov/energy/renewable-energy

IDAHO NATIONAL LABORATORY inl.gov

SAVANNAH RIVER NATIONAL LABORATORY

srnl.doe.gov/energy-secure.htm

AMERICAN WIND ENERGY ASSOCIATION awea.org

DATABASE OF STATE INCENTIVES FOR RENEWABLES \& EFFICIENCY dsireusa.org

INTERNATIONAL ENERGY AGENCY WIND AGREEMENT

ieawind.org

NATIONAL WIND COORDINATING COLLABORATIVE

nationalwind.org

UTILITY VARIABLE-GENERATION INTEGRATION GROUP uvig.org/newsroom/

\section{FOR MORE INFORMATION ON THIS REPORT, CONTACT:}

Ryan Wiser, Lawrence Berkeley National Laboratory 510-486-5474; RHWiser@lbl.gov

Mark Bolinger, Lawrence Berkeley National Laboratory 603-795-4937; MABolinger@lbl.gov

\section{On the Cover}

Portland General Electric Tucannon Wind Farm

Photo by Josh Bauer/NREL 38025

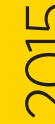

\section{WIND \\ TECHNOLOGIES}

\section{MARKET REPORT}

For more information, visit:

energy.gov/eere/wind

DOE/GO-10216-4885 • August 2016

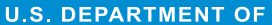 \\ EMTERCY}

Energy Efficiency \&

Renewable Energy 